\title{
VoL 7, No 2 (2017)
}

\section{TABLE OF CONTENTS}

\section{Articles}

Unfolding Practices: A Sociomaterial View of Interprofessional Collaboration in Health Care

e1699

Annika Lindh Falk, Nick Hopwood, Madeleine Abrandt Dahlgren

Occupational Control on Drift-National and Local Intervention in Clinical Work at Emergency

$\mathrm{e} 1765$

Departments

Eva Bejerot, Maria Gustavsson, Hans Hasselbladh, Tina Forsberg Kankkunen, Kerstin Ekberg

Are Teachers Increasingly Leaving the Profession?

e1723

Mari Lande With

Differentiation as a Consequence of Choice and Decentralization Reforms-Conditions for

$\mathrm{e} 1855$

Teachers' Competence Development

Karolina Parding, Anna Berg-Jansson, Therese Sehlstedt, Susan McGrath-Champ, Scott Fitzgerald

Veterinarians and Public Health: Food Control in the Professionalization of Veterinarians

e1806

Kari Tove Elvbakken 


\section{\& PROFESSIONS \\ PROFESSIONALISM}

ISSN: 1893-1049

Volume 7, No 2 (2017)

http://doi.org/10.7577/pp.1699

\section{Annika Lindh Falk, Nick Hopwood, and Madeleine Abrandt Dahlgren}

Annika Lindh Falk, Department of Medical and Health Sciences Linköping University, Sweden

Nick Hopwood, University of Technology Sydney, Australia and University of Stellenbosch, South Africa

Madeleine Abrandt Department of Medical and Health Sciences, Linköping University, Sweden

\section{Contact:}

Annika Lindh Falk, Department of Medical and Health Sciences Linköping University, Sweden annika.lindh.falk@ $\underline{\text { liu.se }}$

\section{Unfolding Practices: A Sociomaterial View of Interprofessional Collaboration in \\ Health Care}

\begin{abstract}
Knowledge sharing is an essential part of interprofessional practice and will be even more important in the future in regard to the opportunities and challenges in practices for delivering safe and effective healthcare. The aim of this ethnographic study was to explore how professional knowledge can be shared in an interprofessional team at a spinal cord injury rehabilitation unit. A sociomaterial perspective on practice was used to analyse the data, and by theorizing upon this, we captured different aspects of interprofessional collaboration in health care. The findings illuminate how knowledge emerges and is shared between professionals, and how it passes along as chain of actions between professionals, in various ways. The findings offer a novel perspective on how interprofessional collaboration as a practice, involving ongoing learning, unfolds. This reveals the mechanisms by which different forms of expertise are mobilized between professions as health care work.
\end{abstract}

Keywords: Ethnography, interprofessional collaboration, practice theory, professional knowledge, sociomaterial, team work

This paper presents findings from an ethnographic study at a spinal cord injury rehabilitation unit. The study has a specific focus on the crucial role of knowledge work in interprofessional practice. What it means to be a health care professional, and the qualities of health care professionalism are changing. One important aspect of this relates to interprofessional collaboration. Contemporary professionals are generally not expected to work in isolated silos, but with others. In health care, professionals need to be comfortable and skilled in working together as well. For many years, interprofessional collaboration has been emphasized as crucial and a strong force in ensuring sustainable, high-quality health care practice that responds to complex patient needs in contemporary health services (Batalden \& Davidoff, 2007; Howarth, Holland, \& Grant, 2006; McPherson, Headrick, \& Moss, 2001; Reeves, Tassone, Parker, Wagner, \& Simmons, 2012; Wilcock, Janes, \& Chambers, 2009). The term collaboration conveys the idea of sharing and implies collective action oriented towards a common goal (D'Amour \& Oandasan, 2005). According to Barr, Koppel, Reeves, Hammick, and Freeth (2005), interprofessional collaboration can be explained as an ongoing work, often between people from diverse professional backgrounds who work together at the same workplace, to solve problems and provide services.

Our specific interest concerns collaborative professional knowledge in health
Received: 11 May 2016 
care. Previous empirical studies in health care regarding interprofessional collaboration and the knowledge contribution in a team have used different approaches to describing a variety of factors that are necessary for professionals to work effectively together. Sargeant, Loney, and Murphy (2008) found in a focus group study, different aspects regarding working effectively in a team. These aspects were, understanding and respecting team members' roles, and the "know-how" of team members to share and communicate with the other members of the team. These findings have the focus on the cognitive and affective competencies as factors in successful teamwork. Kvarnström (2008) has highlighted the importance of both organisational and individuals' values and support to the team as factors for successful interprofessional collaboration and knowledge contribution. McDonald et al. (2009) found in their study that the competency to have knowledge about the professional roles of others was an important factor in achieving successful interprofessional collaboration. Engeström (1999) and Edwards (2012) have over the years, researched about professional and interprofessional work and learning using cultural-historical activity theory. Engeström has formulated an "expansive" view of learning which is useful for understanding the uptake of knowledge creation in organisations (Engeström, 2001).

The idea that we embrace in this study about interprofessional collaboration is that the valuable knowledge that professionals bring to bear can be even more developed and shared in order to provide appropriate care and avoid isolated and fragmented approaches to health care work. That is in line with Fenwick and Nerland's (2014) argument that differences in the ways that individual professionals construe and use professional knowledge are of interest when looking at interprofessional collaboration.

So, there are several attempts to define and deepen the view of interprofessional collaboration and knowledge contribution in health care and to specify what interprofessional collaboration should involve, using different approaches. Based on the literature review, there seems though still a lack of empirical data describing how interprofessional collaboration actually works in health care practice with a special interest in collaborative professional knowledge.

We have used an ethnographic research approach to get close to and observe the practice as it unfolds at a spinal cord injury rehabilitation unit. In this research project, we are interested in how knowledge can be shared among professionals when they collaborate in health care. Thus we respond to the need for the exploration of interprofessional collaboration in terms of collaborative professional knowledge and professional learning. We draw on some of the aspects of sociomaterial perspective on practice and learning that have not previously been taken up, to illuminate the question of how knowledge sharing can take place in and through an interprofessional practice.

\section{Theoretical approach}

Sociomaterial perspectives have been taken up in a range of contexts to explore links between practice, knowledge and learning. The perspectives tend to examine the whole system by tracing interactions among human as well as non-human parts of the system. A range of conceptions and methodologies can be described as sociomaterial, with slightly different foci, some more sociocultural and some more material-focused (see examples in Edwards, Daniels, Gallagher, Leadbetter, \& Warmington, 2009; Engeström, 2001; Lave \& Wenger, 1991; Schatzki, 2002). One common viewpoint is that material as well as social forces are mutually involved in everyday activities. More concretely, sociomaterial researchers are interested in both interactions between people (the social) as well as the objects that are significant in these interactions (the material). Different sociomaterial perspectives are used to foreground key aspects of professional learning. These perspectives are also relevant 
to the present study because they emphasize relationships and focus on practice as it unfolds. Professional knowledge and knowledge strategies are complex and are changing in the area of professional practice and work because of shifts in arrangements and responsibilities between professionals (Fenwick, Nerland, \& Jensen, 2012). To dig in a little bit deeper into one of the sociomaterial perspectives, Kemmis (2009) has argued that a practice is embodied and situated, referring to what a particular person does at a particular time and place. A practice is constituted of what individuals do, in physical and material space ("doings"), what people think and say in and about practice in words and discourses ("sayings") and finally the relation between people - people and people-objects ("relatings") that hang together in a distinctive project. The project of practice is what people say when they tell someone what they are doing while they are engaged in the practice. The project of practice includes the intention that motivates the practice, the actions (sayings, doings and relatings) undertaken in the conduct of the practice, and the ends the actor aims to achieve through the practice. Conceived this way, a practice requires people to engage in multiple activities spread over time or space, and the social and material dimensions cannot be separated. The material dimension refers to tools, technologies, bodies and objects.

Schatzki (2002) has stated that practices are organised by practical understandings (how to perform a specific action, bodily "doings" and "sayings"), rules (principles and regulations that guide actions), teleoaffective structures (which include what motivates people to act towards possible ends and goals in practice) and general understandings (common orientation among people or groups). The idea of practice being governed by what it makes sense for people to do, both on an individual level but also on a broader level with others. Schatzki (2002) also describes practices as temporally unfolding and spatially distributed. In this study, practical understanding refers to specific professional knowledge in the team, while the laws and regulations that direct and guide the health care practice are conceived of as rules. Teleoaffective structures point us to agreements about treatment, attitudes and ethical issues decided at the ward by the professionals, and finally, general understanding refers to the knowledge about the traditions and the nature of one's specific profession and professional role. Maintaining practice requires activity and skills and a shared understanding of the embodied knowledge.

Sociomaterial approaches are also associated with novel ways of approaching questions about knowledge. Some treat knowledge as knowing - a verb - highlighting performative aspects, and avoiding any uncoupling between doing and knowing (Gherardi, 2009). In this paper, we refer to knowledge but retain a key sociomaterial notion that knowledge is not a stable entity residing in individual practitioners' heads, but rather something that is emergent, a property of relationships between professionals, patients and the objects of practice. Learning between professionals is not seen as separate from practices, but part of knowing-in-practice (Rooney et al., 2012). Interprofessional collaboration challenges the boundaries of the expertise between professions, but also gives possibilities to share the knowledge while working with others who bring other forms of knowledge, traditions and roles into the practice. A study conducted by Edwards et al. (2009), investigated how multi-professional units developed new practices to serve young people. The findings provided evidence of how the boundary work between the professionals from different units offered significant spaces for learning. By studying what health care professionals actually do, we can learn more about practices of interprofessional collaboration and the knowledge and learning associated with those practices.

The aim of this study was to investigate how knowledge can be shared and emerges between different professionals in a health care practice. In order to offer a novel understanding of interprofessional collaboration, we use aspects of the sociomaterial perspective that have not previously been widely taken up when following healthcare practices as they unfold. 


\section{The empirical study}

The research that informs this paper is drawn from an ethnographic research project conducted during 2012 at a spinal cord injury rehabilitation unit at a university hospital in Sweden. The site was chosen based on the first authors' prior knowledge of existing interprofessional collaboration in health care. The project's ethnographic design suited the aim of exploring in-depth how knowledge can emerge and be shared in interprofessional collaboration in health care practice (Hammersley \& Atkinson, 2007; Savage, 2000). Schatzki (2012) has argued that ethnography is essential as a research method for acquiring knowledge about how practices and arrangements hang together and about the contexts in which activities and knowledge sharing can take place. According to O'Reilly, (2009) and Srivastava and Hopwood, (2009), taking up ethnography as an iterative-inductive research methodology means that the design evolves through the study process, responding to events and circumstances as they come up.

To facilitate in-depth investigation of interprofessional collaboration, the first author followed two different patients at the ward and a group of professionals built up around these patients. Each group constellation consisted of 1-2 physicians, 4-5 nurses, 4-5 nursing assistants, one occupational therapist, one physiotherapist and one rehabilitation assistant (10-12 people in total). The number of staff participants reflected the organic practice of working with the different patients during their rehabilitation process, rather than being specified in advance. This design enabled observations of many informal interactions, such as how the course of events developed and what was said. Such observation is important to take into account in an ethnographic study (Polit \& Beck, 2012).

The site had a nurse station located in the centre of the ward. There were also two separate offices for round meetings and team meetings located in the ward. Rooms for occupational therapy, physiotherapy and music therapy, and a dining room for patients were located on the same floor at the unit.

Several information sessions were used to introduce the study to the different professionals at the ward, after which they gave written informed consent to participate in the study. Further verbal consent was requested before observation started. No team member declined to participate. Patients were initially asked to participate by one of the head nurses. They were also given an information sheet describing the purpose of the study and were asked for their oral and written consent.

Data was collected by the first author by participant observations, informal conversations and by reading medical record documentation for the two involved patients. The participant observations and conversations involved direct and sustained contact with the different professionals as they went about their everyday practice, observing what happened and listening to what was said in different activities, a naturalistic approach in line with Lincoln and Guba (1985). The data collection was conducted during three periods from January to November 2012. Each period was about two months. To obtain a rich understanding of interprofessional collaboration, observations took place at different times of day and covered a range of activities reflecting work shifts and staff rotation schedules. However, night shifts were excluded. Most observations involved shadowing health care professionals when working in patients' rooms or in shared workspaces to observe both scheduled and more unforeseen activities between the team members. Conversations with participants during shadowing were supplemented to clarify and complement the observations. The observer also sat in the patient's room to catch up on what happened when different professionals entered the room for different reasons, with particular work to do. Observations of scheduled activities included in total of 12 interprofessional rounds (20 hours), six team meetings including the patients and relatives (10 hours), nine record reviews handover, when nurses and nursing assistants reported to each other and read the medical record together ( 10 hours), and five allied health meetings while planning the work with nursing assistants ( 7 hours). The reading through the 
medical records was carried out mainly after the observation periods to trace any connection between the observed work activities in the medical record. The study had a longitudinal approach to the collection of data over one year, which allowed the study to generate a detailed description of professional practice at the unit. It also helped the clinical staff and patients to become accustomed to the observer's presence over time.

The observer had experience as a health care professional but also as an academic teacher specialising in interprofessional education. Therefore, it was very important to take into account the impact of the "pre-knowing" of the researcher as well as the relationship between the researcher and the participants. The observer was dressed in white garments like the other professionals.

Field notes and informal conversations were jotted down in notebooks and transcribed into electronic documents directly after the observation sessions by the observer (in total 85 pages). Observer reflection notes were also written at this time. The collection of data and the analysis were carried out almost simultaneously, and the analysis was inspired by Srivastava and Hopwood's (2009) iterative framework, according to which the researchers are urged to ask themselves what the data is telling them and what they wanted to know.

In the earlier stage of the data collection phase, observations were more general, offering orientation to a wide range of professional activities, and informing subsequent observation of a more focused and targeted nature. First, the analysis included re-reading all data visit-by-visit, identifying several activities and locations derived from the site itself (such as rounds, handovers and caring activities, and different spaces such as the round room, patients' ward room and the nurse station). In the next phase, during the second and third observation periods, collaboration was identified in which some kind of knowledge work happened, between professionals and professionals or between professionals and the patient were identified. In the further analysis of these different collaborative activities, the focus was on how these projects were connected and how the connections could facilitate knowledge sharing. Interprofessional collaboration sometimes arose through activities where collaboration between professionals was planned beforehand, and at other times it arose in more spontaneous or responsive ways. Initial actions in particular sequences had specific implications or consequences for subsequent actions undertaken by other health professionals. To explain these patterns we have used the terms of commonality and orchestration (Schatzki, 2002). Commonality refers to something shared, which means activities and practices are structured by the same understandings, rules, intentions and purposes, i.e. they are common activities. Orchestration refers to instances where there are differences in understandings and rules but where one practice depends on or is affected by another in some way.

In accordance with Polit and Beck (2012), emerging analytical ideas were frequently discussed with the other authors. This strengthened the transparency of the process and outcomes and helped to establish the validity of the key ideas.

\section{Findings and discussion}

In the following section, we will present and discuss our findings and give examples of how different professionals' projects hang together during the daily practice and how knowledge could be shared. The findings show two different patterns of how knowledge was shared among professionals in their daily work practice as it unfolded. Using a sociomaterial lens when we look at practice and learning we can understand how knowledge sharing take place and hangs together in different ways we refer to as commonality and orchestration, enabling interprofessional collaboration. 
Table 1

Conceptual summary of the two different types of knowledge sharing through interprofessional collaboration using Schatzki's concept of Orchestration and Commonality

\begin{tabular}{|c|c|c|c|}
\hline Type & $\begin{array}{l}\text { Origin of } \\
\text { knowledge }\end{array}$ & $\begin{array}{l}\text { How knowledge } \\
\text { moves }\end{array}$ & Clinical consequence \\
\hline $\begin{array}{l}\text { A: Interprofes- } \\
\text { sional collabora- } \\
\text { tion through Or- } \\
\text { chestration }\end{array}$ & $\begin{array}{l}\text { From interac- } \\
\text { tion between } \\
\text { one profes- } \\
\text { sional and the } \\
\text { patient }\end{array}$ & $\begin{array}{l}\text { Chain of interac- } \\
\text { tions in which } \\
\text { knowledge be- } \\
\text { comes a common } \\
\text { resource; interac- } \\
\text { tions can be pro- } \\
\text { fessional-profes- } \\
\text { sional or profes- } \\
\text { sional - patient }\end{array}$ & $\begin{array}{l}\text { Profession-specific } \\
\text { projects continue, } \\
\text { now shaped by } \\
\text { knowledge of particu- } \\
\text { lar significance to one } \\
\text { professional; individ- } \\
\text { ual professional ac- } \\
\text { tions adjusted in light } \\
\text { of other professionals' } \\
\text { knowledge }\end{array}$ \\
\hline $\begin{array}{l}\text { B: Interprofes- } \\
\text { sional collabora- } \\
\text { tion through } \\
\text { Commonality }\end{array}$ & $\begin{array}{l}\text { From interac- } \\
\text { tion between } \\
\text { one or more } \\
\text { profes- } \\
\text { sional(s) (and } \\
\text { patient) }\end{array}$ & $\begin{array}{l}\text { Different pieces of } \\
\text { knowledge re- } \\
\text { source joint dis- } \\
\text { cussion (with or } \\
\text { without the pa- } \\
\text { tient) resulting in } \\
\text { shared stance and } \\
\text { new joint project }\end{array}$ & $\begin{array}{l}\text { Professional actions } \\
\text { now have new ele- } \\
\text { ment that contributes } \\
\text { to joint project of } \\
\text { shared significance, } \\
\text { no longer associated } \\
\text { with one particular } \\
\text { profession }\end{array}$ \\
\hline
\end{tabular}

The two different types of knowledge sharing are described in a conceptual summary in Table 1 using Schatzki's (2002) concept of orchestration and commonality, mentioned earlier. In Table 2, we will visualize some concrete examples of patterns by specifying the focus of the specific situation, and the origin of knowledge, and finally, we will show the movement of knowledge through orchestration and/or commonality. This table also present the clinical significance of knowledge. 
Table 1. Template with examples of patterns of how different professional practices hang together and how knowledge was shared in different projects of a practice (A-Orchestration, B-Communality, using Schatzki's concept, 2002)

\begin{tabular}{|c|c|c|c|c|}
\hline Type & $\begin{array}{l}\text { Knowledge focus in certain } \\
\text { projects }\end{array}$ & Origin of knowledge & How knowledge moves & $\begin{array}{l}\text { Clinical/care consequence or significance of } \\
\text { knowledge }\end{array}$ \\
\hline A1 & $\begin{array}{l}\text { Correction of the patient's } \\
\text { arm position while the pa- } \\
\text { tient was lying in the bed }\end{array}$ & $\begin{array}{l}\text { Interaction between a physi- } \\
\text { otherapist and a patient in a } \\
\text { bed in a ward room }\end{array}$ & $\begin{array}{l}\text { The knowledge moves from the physiother- } \\
\text { apist to the nurse and nursing assistant com- } \\
\text { ing into the room, and from the physiothera- } \\
\text { pist to the patient and relatives. }\end{array}$ & $\begin{array}{l}\text { The professional knowledge from the physiothera- } \\
\text { pist becomes a common resource for all involved. } \\
\text { All profession-specific projects continue, shaped } \\
\text { by knowledge of particular significance to one pro- } \\
\text { fessional and adjusted in light of other profession- } \\
\text { als' knowledge }\end{array}$ \\
\hline $\mathrm{A} 2$ & $\begin{array}{l}\text { Working with a solution for } \\
\text { how to position an alarm } \\
\text { button on patient's wheel- } \\
\text { chair for best safety and } \\
\text { independency for the patient }\end{array}$ & $\begin{array}{l}\text { Interaction between an occu- } \\
\text { pational therapist, patient } \\
\text { and the materiality of a } \\
\text { wheelchair }\end{array}$ & $\begin{array}{l}\text { The knowledge moves from the occupa- } \\
\text { tional therapist to a nursing assistant coming } \\
\text { into the room, and from the occupational } \\
\text { therapist to the patient. }\end{array}$ & $\begin{array}{l}\text { The professional knowledge from the occupational } \\
\text { therapist becomes a common resource for all in- } \\
\text { volved. All profession-specific projects continue, } \\
\text { shaped by knowledge of particular significance to } \\
\text { one professional and adjusted in light of other pro- } \\
\text { fessionals' knowledge. }\end{array}$ \\
\hline A3 & $\begin{array}{l}\text { A nurse is sitting in the nurse } \\
\text { station, searching for infor- } \\
\text { mation about a certain pa- } \\
\text { tient, preparing for the } \\
\text { round session }\end{array}$ & $\begin{array}{l}\text { Interaction between the } \\
\text { nurse, the nursing assistants } \\
\text { and later on the medical doc- } \\
\text { tor and others during the } \\
\text { round }\end{array}$ & $\begin{array}{l}\text { The knowledge moves from the nursing as- } \\
\text { sistants who has collected information about } \\
\text { a certain patient, further to the nurse and } \\
\text { then via the nurse to the medical doctor and } \\
\text { others }\end{array}$ & $\begin{array}{l}\text { The knowledge from the nursing assistants become } \\
\text { a common resource via the nurse into the round } \\
\text { where all the professionals more or less are influ- } \\
\text { enced and adjusted their actions in the future }\end{array}$ \\
\hline B1 & $\begin{array}{l}\text { Decision making for in- } \\
\text { creased patient and family } \\
\text { involvement }\end{array}$ & $\begin{array}{l}\text { Interaction between two or } \\
\text { more professionals in a ward } \\
\text { round room }\end{array}$ & $\begin{array}{l}\text { Different pieces of knowledge resource a } \\
\text { joint discussion (no patient) and resulting in } \\
\text { a shared stance and new joint projects. }\end{array}$ & $\begin{array}{l}\text { Professional actions now have a new element that } \\
\text { contributes to a joint project of shared significance, } \\
\text { no longer associated with one particular profession }\end{array}$ \\
\hline B2 & $\begin{array}{l}\text { Setting goals with the pa- } \\
\text { tient }\end{array}$ & $\begin{array}{l}\text { Interaction between two or } \\
\text { more professionals and the } \\
\text { patient in a room for team } \\
\text { meetings }\end{array}$ & $\begin{array}{l}\text { Different pieces of knowledge from differ- } \\
\text { ent professionals and the patient's own } \\
\text { knowledge and experience resulting in a } \\
\text { common decision and new joint projects. }\end{array}$ & $\begin{array}{l}\text { The professionals and the patient share the new } \\
\text { joint projects. }\end{array}$ \\
\hline
\end{tabular}


We will now illustrate these patterns with two different vignettes, using examples from each type of, A and B, from the table 2, to elaborate on and show evidence of the dynamic and fluid relationship between the different professionals.

The first vignette, gives an example of an activity (see Table 1, type A1), initiated by one professional as a planned action but which then became a shared activity performed with a nurse and a nurse assistant when they entered the space of action. The physiotherapist was working on contracture prevention by stretching the soft tissues of one of the patients in order to increase joint mobility. The physiotherapist observed that the patient's arm was positioned awkwardly as the patient was lying in bed.

The patient is lying in bed. The physiotherapist explains to the patient that the arm position will bring imbalance in muscle strength in the arms and lead to negative consequences for the arm function in the future. As the physiotherapist is continuing working with the patient, a nurse and a nursing assistant come into the room. The physiotherapist immediately explains to the nurse and nursing assistants about the arm position and the importance of the right position: "We'll try to help each other so that the arm is placed in the correct position," the physiotherapist says. The nurse and nursing assistant listen and observe the physiotherapist in action while positioning the arm using a specific pillow. "It's hard to write this practical information down on the whiteboard here so can you please try to inform our colleagues?" The nurse makes some notes in a notebook to remind herself to report that later. Then the physiotherapist turns to the patient's partner and asks her/him to notice the position as well. "You can also ask the staff to check your arm while helping you in bed," she says to the patient. When the physiotherapist leaves the room, the nurse and nursing assistant begin their routine care activities. It is clear that they are paying specific attention to the patient's arm position. They also ask the patient to check if the arm position was the same as when the physiotherapist did the positioning. The patient confirms that. A note from the occupational therapist a few days later in the medical record was related to the activity the physiotherapist had carried out. An adjustment had been made. No other notes in the medical record regarding the position in bed were then found. (Field notes)

This is an example of how an activity started up in an orchestrated way. The activity, performed by one professional with profession-specific practical understandings about what to do, connected to and influenced how other professionals in the team applied and then adjusted their work in relation to their profession-specific knowledge. The physiotherapist had an intention and a purpose going into the patient's room and starting up the activity as a specific project together with the patient. The profession-specific knowledge regarding contracture prevention is mostly carried by the physiotherapist, but it is common among the different professionals to share the total responsibility for the patient in general. Therefore, it was important to share this knowledge with others to ensure safety, consistency and quality of care. The physiotherapist took the opportunity to inform about the prevention strategy when the nurse and a nursing assistant came into the room. The physiotherapist's sayings and doings were connected to and affected the way the nurse and nursing assistant performed the specific activity (how to position the patient's arm in the bed) later on. The nurse and the nursing assistant had applied and adjusted their work activities as a new commonality, a new shared understanding and common intention between all of them about the specific situation. Thereby, the nurse and nursing assistant expanded their repertoire of actions by adjusting their professional doings. The vignette shows how material objects become involved in the emerging knowledge and knowledge sharing. The patient's body, the whiteboard, the pillow and medical record can be understood as relational to the knowledge sharing and social relations between the professionals. Their relations prefigure certain actions that can be efficiently carried out and are likely to succeed. Furthermore, the chain of action was later connected to the occupational therapist as well, who made an 
adjustment regarding the arm position and used the medical record to spread awareness of the new contribution. Future actions of individual professionals would be based on shared knowledge of the patient's situation.

The second vignette is an example of type B (see Table 1), from a round meeting at the ward, and illustrates an activity where two or more professions worked together without the patient present. All professionals participated, except nursing assistants. The purpose of the rounds was to discuss the patients' needs regarding medical treatment and rehabilitation. The arrangement of the room, with a table in the middle surrounded by the staff, and the digital record as a common tool for sharing knowledge, enabled the team to share their knowledge and experiences in a collaborative activity.

The functional round itself is an example of where commonality exists-a practice which is structured by shared rules, structures and understandings of how the round practice should be performed, in a common space.

One physician (a) and a physiotherapist are sitting together and reading the digital medical record about a certain patient, considering the notes from yesterday when an occupational therapist and physiotherapist visited the patient's home. Another physician (b) starts to read as well, sitting next to physician (a). He says: "Well, from the physiotherapist's comment in the record, it seems that the patient has to move from the house. It is very difficult to find solutions regarding how to adjust the house to address the patient's challenges with walking and managing the daily tasks. The patient's relative is old," the physician (a) says. They continue to talk about the patient's future and whether the plans are reasonable. The nurse enters the room and sits down with the physician (b) and the physiotherapist. She looks at her own notebook to find any additional information. The physiotherapist continues to talk about the patient and tells physician (b) that the patient said that she had been told that there was 50 percent chance of walking again, and the patient seems to have fixated on that. Physician (b) says: "I really tried to be clear about this to the patient when I talked to her the other day. We have to be more distinct and show a clear plan for the future."

Now everybody in the room turns to the physiotherapist and the physicians, and the physiotherapist starts reporting about the home visit to everyone in the room. The physiotherapist tells them briefly about the house, how the house was furnished, how the patient reacted when trying to move inside the kitchen and how the conversation with the patient and family went. The counsellor comments regarding the reaction from the patient and says that she had a different opinion when she talked to the patient after the home visit. The physiotherapist and the counsellor start to discuss this differences among the two of them, while the others in the group listen actively. The counsellor believes that the patient's daughter could be more involved in the discussion and physician (a) agrees on that and comments that the whole team has to talk to the daughter about how long the patient can stay in the rehabilitation unit. The counsellor asks "How do we continue?" The physiotherapist considers different factors regarding the patient's overall conditions and the possibility to get better function in the legs and then ends up with saying, "I really don't know. It is a tricky thing when the patient gets different messages from us." Physician (a) says: "We have to give our common and clear picture of the situation to the patient and relatives. We have a team meeting with the patient and relatives next week where we can talk about the plans. We have to be more concrete now, and the patients and family must decide." The physiotherapist suggests that the patient can have a day's furlough and asks the nurse whether there is any decision regarding transportation service the patient is entitled to. The nurse doesn't know but turns to the counsellor who says that they can arrange permission for one day. The physiotherapist asks physician (a) about the focus of the team meeting. "So we can have the same strategy, and 
how much can we push them in the decision process." Physician (a) hesitates a bit but then says, "We will probably have the discussion with the patient and relatives at the team meeting anyhow." (Field notes)

The above-described course of action started as a common activity where several professionals worked together with the patient present only via the medical record. The different professionals were well aware of the purposes, intentions and rules regarding the round meeting and brought in various aspects of profession-specific knowledge to the meeting in different orchestrated actions. While sitting around the table, discussing and listening to different arguments from each other in the group, joint decision-making about the purpose of future actions and treatment for the patient was accomplished. These decisions taken at the round then led to forms of the orchestration of future actions for each unique professional. The professionals had together shared their knowledge and established a common point of concern in order to define the direction of changes in each professional's understandings and how to meet the patient's and relative's concerns. The professionals were enabled to enact specific professional practice in individual, but coordinated ways, as newly established shared forms of knowledge.

\section{Discussion}

Our study has conceptualized empirical examples of the daily knowledge sharing in practice by studying what health care professionals actually do in practice. The professionals were constantly involved in different types of knowledge practices, by asking questions, exploring each other's knowledge or documenting their work, and that provided an opportunity to learn. Through constantly recurring sayings and doings and relatings between different professionals in the team, knowledge sharing took place and thereby a shared stance and new joint projects were established. Each professional was guided by the understandings gained from the new shared knowledge when planning and performing their future actions and professional projects with the patients. These actions indicate that the practical and material arrangements of the unit have an important impact on how sayings and doings and relatings unfold and how interprofessional activities emerge. The studies of both Hager, Lee and Reich (2012) and Fenwick and Nerland (2014) have stated that learning is an essential part of everyday practice. The ward rounds in the mornings, where almost all the professionals have the possibility to participate and share their professional ideas and standpoints, as well as the shared time and space in the patient's room, where it is also possible for different professionals to meet without any resistance, are successful activities where knowledge can be shared, and learning can happen.

Hubbard and Themessl-Huber (2005) emphasized that team collaboration is not just about transferring information between professionals, but also about how to create new ways of thinking, and seeing professionals as active problem-solvers. We want to add that it is also important to use the opportunity to share the knowledge in the daily practice between professionals while working so close to each other, which is possible in a hospital unit.

Researching boundary work in different interprofessional practices, Edwards has found three conceptual tools in terms of common knowledge, relational expertise and relational agency for describing the cross-practice collaboration (see, for example, Edwards et al., 2009; Edwards, 2012). Common knowledge based on shared experiences within a team can offer resources for joint decision-making. In this study, we want to emphasize that the different types of knowledge sharing that were observed represented important findings related to interprofessional collaboration as a practice for learning. These chains of actions brought professional projects of a practice into different kinds of relationship with one another; in some cases, through commonality, and in others through orchestration. These relationships provided the 
basis for interactions through which knowledge was shared between different professionals and used in practice. Thus, we can claim that learning between professionals as well as between professionals and patients is emergent as health care work unfolds. However, it is important to underline that the learning that occurs is not to learn how to do the work of others but to obtain insight and interact in the same spaces, with the same overall purposes of enabling collaboration and ensuring best practice for the patient. We can argue that the fluid movement between commonality and orchestration is a crucial feature of interprofessional collaboration and knowledge sharing. This view offers a novel perspective on how interprofessional collaboration as a practice involving ongoing learning, unfolds. It reveals the mechanisms by which different forms of professional knowledge are mobilized in this kind of work.

Crooker, Trede, and Higgs (2012) have stated that it is a challenge to achieve sufficient depth of understanding of complex collaborative practice. However, qualitative approaches such as ethnography are helpful when empirically studying the professional practices in health care and for developing a greater understanding of the complex nature of interprofessional practice (Reeves, Goldman, \& Zwarenstein, 2009). Several research studies regarding interprofessional collaboration, such as Croker Trede and Higgs (2012) and Kraft, Blomberg and Hedman (2012), have gathered interview data which add important reports of insights into professionals' views of their work, but still the data is perception-based. While first-hand perspectives and accounts of practice are important, observational approaches have a different value, particularly through their ability to trace what people do and how they relate to each other in practice. In this study, use of the ethnographic approach helped us to understand how knowledge can emerge and be shared in interprofessional practice by different professionals. By using a sociomaterial, practice-based approach we were able to trace these processes empirically, with a high degree of sensitivity to context that incorporated a material dimension, and yet always remained close to the actual performance of health care work.

However, it is important to note that this study was limited by the collection of data from only one site, and by considering only one particular kind of unit and two different teams. Savage (2000) has stated that ethnography is not used for developing generalized conclusions but rather for studying a specific group of people regarding a specific topic, and for drawing conclusions only about what was studied. Ethnographic findings come from certain individuals and situations and from a particular place and time (Hammersley \& Atkinson, 2007). Nonetheless, the wider relevance of this study comes not from an empirical generalization about the concrete content of what was depicted, but from the theoretical arguments about what knowledge is constructed and shared, and how this happens in the accomplishment of interprofessional collaboration.

\section{Conclusions}

Our aim of this article has been to show how knowledge can emerge and be shared between professionals in healthcare practice. Understood as a social practice, interprofessional collaboration is a specific kind of human activity in which characteristic actions and activities (doings) are understandable in terms of relevant ideas and discourses (sayings), and in which the people and objects involved, have certain relationships (relatings). By using a sociomaterial lens on practice and learning, our study has provided an additional perspective about interprofessional collaboration in health care practice. We have shown how knowledge emerged and was shared between professionals which brought professionals into different kinds of relationship with one another involving ongoing learning. The knowledge practices hung together through different chains of actions which prevented isolated and fragmented working approaches. Questions about how knowledge emerges and can be shared 
among professionals in the daily work with patients will be crucial in the future to respond to the opportunities and challenges in health care practices for delivering safe and effective healthcare. Our study provides insights to be considered by researchers interested in interprofessional collaboration and learning that can occur and unfolds in health care practices. Working together with others who bring other forms of knowledge and understanding to the practice adds the valuable insight that learning from and about each other has to be an integral part of interprofessional practice. Learning from and about each other included to obtain insight in others profession-specific knowledge in a specific situation and then adjusted and use in once own work repertoire and produce a new shared knowledge while interact in the same spaces with the patients. By using an ethnographic approach to studying what health care professionals do in practice, and staying close to the practices, we have learned more about the complex nature of interprofessional practice and about the knowledge and learning associated with such practices.

\section{References}

Barr, H., Koppel, I., Reeves, S., Hammick, M., \& Freeth, D. (2005). Effective interprofessional education: Argument, assumption \& evidence. Oxford: Blackwell Publishing. https://doi.org/10.1002/9780470776445

Batalden, P. B., \& Davidoff, F. (2007). What is "quality improvement" and how can it transform health care? Quality and Safe in Health Care, 16, 2-3. https://doi.org/10.1136/qshc.2006.022046

Croker, A., Trede, F., \& Higgs, J. (2012). Collaboration: What is it like?: Phenomenological interpretation of the experience of collaborating within rehabilitation teams. Journal of Interprofessional Care, 26(1), 13-20. https://doi.org/10.3109/13561820.2011.623802

D'Amour, D., \& Oandasan, I. (2005). Interprofessionality as the field of interprofessional practice and interprofessional education: An emerging concept. Journal of Interprofessional Care, 19(1), 8-20. https://doi.org/10.1080/13561820500081604

Edwards, A., Daniels, H., Gallagher, T., Leadbetter, J., \& Warmington, P. (2009). Improving inter-professional collaborations: Multi-agency working for children's wellbeing. London: Routledge.

Edwards, A. (2012). The role of common knowledge in achieving collaboration across practices. Learning, Culture and Social Interaction, 1(1), 22-32. https://doi.org/10.1016/j.lcsi.2012.03.003

Engeström, Y. (1999). Innovative learning in work teams. In Y. Engeström, R. Miettinen \& R.-J. Punamäki (Eds.), Perspectives on activity theory (pp. 377 406). Cambridge: Cambridge University Press. https://doi.org/10.1017/CBO9780511812774.025

Engeström, Y. (2001). Expansive learning at work: Toward an activity theoretical reconceptualization. Journal of Education and Work, 14(1), 133-156. https://doi.org/10.1080/13639080020028747

Fenwick, T., Nerland, M., \& Jensen, K. (2012). Sociomaterial approaches to conceptualising professional learning and practice. Journal of Education and Work, 25(1), 1-13. https://doi.org/10.1080/13639080.2012.644901

Fenwick, T., \& Nerland, M. (2014). Reconceptualising professional learning. sociomaterial knowledges, practices and responsibilities. New York, NY: Routledge.

Gherardi, S. (2009). Knowing and learning in practice-based studies: an introduction. The Learning Organisation, 16(5), 352-359. https://doi.org/10.1108/09696470910974144 
Hager, P., Lee, A., \& Reich, A. (2012). Practice, learning and change: Practicetheory perspectives on professional learning. Dortrecht: Springer.

Hammersley, M., \& Atkinson, P. (2007). Ethnography: Principles in practice (3rd ed). New York, NY: Routledge.

Howarth, M., Holland, K., \& Grant, M. J. (2006). Education needs for integrated care: A literature review. Journal of Advanced Nursing, 56(2), 144-156. https://doi.org/10.1111/j.1365-2648.2006.03992.x

Hubbard, G., \& Themessl-Huber, M. (2005). Professional perceptions of joint working in primary care and social care services for older people in Scotland. Journal of Interprofessional Care, 19(4), 371-385. https://doi.org/10.1080/13561820500165167

Kemmis, S. (2009). Understanding professional practice: A synoptic framework. In B. Green (Ed.), Understanding and researching professional practice (pp. 1939). Rotterdam: Sense Publishers.

Kraft, M., Blomberg, K., \& Hedman, A-M. (2012). The health care professionals' perspectives of collaboration in rehabilitation: An interview study. International Journal of Older People Nursing, 9(3), 209-216. https://doi.org/10.1111/opn.12020

Kvarnström, S. (2008). Difficulties in collaboration: A critical incident study of interprofessional healthcare teamwork. Journal of Interprofessional Care, 22(2), 191-203. https://doi.org/10.1080/13561820701760600

Lave, J., \& Wenger, E. (1991). Situated learning: Legitimate peripheral participation. Cambridge: Cambridge University Press. https://doi.org/10.1017/CBO9780511815355

Lincoln, Y. S., \& Guba, E. G. (1985). Naturalistic inquiry. Thousand Oaks, CA: SAGE.

McDonald, M. B., Bally, J. M., Ferguson, L. M., Lee Murray, B, Fowler-Kerry, S. E., \& Anunson, J. M. S. (2009). Knowledge of the professional role of others: A key interprofessional competency. Nurse Education in Practice, 10(4), 238-242. https://doi.org/10.1016/j.nepr.2009.11.012

McPherson, K., Headrick, L., \& Moss, F. (2001).Working and learning together: Good quality care depends on it, but how can we achieve it? Quality in Health Care, 10(2), 46-52. https://doi.org/10.1136/qhc.0100046

O'Reilly, K. (2009). Key concepts in ethnography. Thousand Oaks, CA: SAGE. https://doi.org/10.4135/9781446268308

Polit, D. F., \& Beck, C. T. (2012). Nursing research: Generating and assessing evidence for nursing practice. New York, NY: Lippincott Williams \& Wilkins.

Reeves, S., Goldman, J., \& Zwarenstein, M. (2009). An emerging framework for understanding the nature of interprofessional interventions. Journal of Interprofessional Care, 23(5), 539-542. https://doi.org/10.1080/13561820903078215

Reeves, S., Tassone, M., Parker, K., Wagner, S., \& Simmons, B. (2012). Interprofessional education: An overview of key developments in the past three decades. Work, 41(3), 233-245.

Rooney, D., Boud, D., Reich, A., Fitzgerald, T., Willey, K., \& Gardner, A. (2012). Using practice theory to investigate professional engineers' workplace learning. Proceedings from Frontiers in Education Conference, FIE. https://doi.org/10.1109/FIE.2012.6462392

Sargeant, J., Loney, E., \& Murphy, G. (2008). Effective interprofessional teams: "Contact is not enough" to build a team. Journal of Continuing Education in the Health Professions, 28(4), 228-234. 
Savage, J. (2000). Ethnography and health. British Medical Journal, 321, 14001402. https://doi.org/10.1136/bmj.321.7273.1400

Schatzki, T. (2002). The site of the social: A philosophical account of the constitution of social life and change. University Park, PA: The Pennsylvania State University Press.

Schatzki, T. (2012). A primer on practices. In J. Higgs, R. Barnett, S. Billett, M. Hutchings \& F. Trede (Eds.), Practice-based education: Perspectives and strategies (pp.13-26). Rotterdam: Sense Publishers. https://doi.org/10.1007/97894-6209-128-3_2

Srivastava, P., \& Hopwood, N. (2009). A practical iterative framework for qualitative data analysis. International Journal of Qualitative Methods, 8, 7684.

Wilcock, P. M., Janes, G., \& Chambers, A. (2009). Health care improvement and continuing interprofessional education: Continuing interprofessional development to improve patient outcomes. Journal of Continuing Education Health Profession, 29(2), 84-90. https://doi.org/10.1002/chp.20016 


\section{\& PROFESSIONS \\ PROFESSIONALISM}

ISSN: 1893-1049

Volume 7, No 2 (2017), e1765

http://doi.org/10.7577/pp.1765

\section{Eva Bejerot, Maria Gustavsson, Hans Hasselbladh, Tina Forsberg Kankkunen and Kerstin Ekberg}

\section{Occupational Control on Drift- National and Local Intervention in Clinical Work at Emergency Departments}

Eva Bejerot, Örebro University, Sweden

Maria Gustavssont, Linköping University, Sweden

Hans Hasselbladh, Örebro University, Sweden

Tina Forsberg

Kankkunen,

Stockholm

University,

Sweden

Kerstin Ekberg,

Linköping

University,

Sweden

Contact:

Eva Bejerot,

Örebro University,

Sweden

eva.bejerot@oru.se

Page 1

\begin{abstract}
In Swedish emergency departments, various initiatives have been introduced in order to reduce long waiting times for patients: lean methods, targets for waiting times related to revenues, interprofessional teams, and different forms of triage systems. This study focuses on the physicians' views on dilemmas related to these interventions. The study is based on the interviews with 14 physicians in four emergency departments. The interviews have been analysed thematically and presented in the form of brief narratives. The study follows changes from clinical practice to national policy level. The changes appear to be ineffective or counterproductive - waiting times are rather getting longer, but the measures have a number of other effects. Decisions are taken at a central level and are carried out by means of rules, incentives, and projects and end in the medical profession being displaced from the central position they have held in the working processes of health care.
\end{abstract}

Keywords: Discretion, emergency care, New Public Management, physicians, teamwork, work environment

According to the Swedish Work Environment Authority (2012), there is a chronic overcrowding at the emergency departments (ED) in Sweden, creating problems for the working environment in 54 out of 60 emergency hospitals. The hospitals in big cities face the most troublesome situation resulting in long waiting times (NBHW, 2014). When media sounded the alarm in 2010 , politicians promised changes to reduce waiting times and increase patient safety. Among other things, new targets have been set and new working methods brought in to increase flow and patient safety. But the changes did not produce the expected results. Waiting times have become longer and increasingly often a "stand-by" situation has been declared; that is, an extraordinary situation in which the hospital resources are reallocated from planned care to the ED.

This is the background to the present study, which focuses on the attempts to alleviate the crisis-like situation. The swift and decisive measures, of which some are designed at the national level and others at the local level, have had a considerable impact on the EDs. The effects, we argue, are an interesting example of how seemingly non-controversial "improvements" may undermine occupational control of clinical work, while at the same time not solving the espoused problem. We see interventions to rationalize EDs as a part of larger and more persistent pattern, where professions are increasingly under the pressure of new forms of management, which
Received:

7 Aug 2016

Accepted: $14 \mathrm{Feb} 2017$ 
is particularly the case for physicians (Aasland, 2015; Numerato, Salvatore, \& Fattore, 2012). The EDs are in many ways a crossroad for the interests, conflicts, and unavoidable problems that follow suit with that development.

The purpose of this study is to analyse how a set of decisive measures intended to improve patient flow at EDs affect the traditional form of occupational control of clinical work. The study highlights how physicians in EDs perceive and cope with this development. The development at three EDs are compared and put in a wider context by linking the local contexts studied to the interventions designed at the national level. The concluding sections of the paper discuss the results in the perspective of the conceptual apparatus introduced in the theoretical section, constitutive and contingent elements of professionalism (Freidson, 2001) and the socio-cultural and task-related sphere of professions.

\section{Conceptualizing professional control}

Professions display a considerable variation and heterogeneity over time and different contexts in terms of their manifest traits, such as working conditions, terms of employment, status, and regulation of practice. The variegated manifestations of professions can be understood in a systematic way suggested by Freidson (2001), which firstly denotes a number of constitutive elements of professions. The constitutive trait of professions are: work is intimately connected to a recognized body of knowledge based on theories and concepts, the professional labour of division and labour market are occupationally governed, and university education is partly under occupational control. The mentioned elements are not unexpectedly those that we associate with the medical, law, or accounting profession. But the invariable traits of professions are always situated in the midst of societal and historical particularities and idiosyncrasies, the contingent variables. Government organization and policy, dominant ideologies, and the substantial content of bodies of knowledge are typical examples of conditions that can and do vary considerably among contexts and over time. Freidson (2001) suggests and exemplifies in his seminal book that the distinction between constituting elements and contingent variables can be used as an analytical model. How and to what extent do changes in the contingencies of professions affect the conditions for reproducing the constitutive traits of a profession? For instance, do new dominant ideologies in the western societies impose obstacles to the traditional occupational control of labour of division, labour markets, and education for professions? In research on professions in working life, the most pertinent question is of course occupational control of division of labour and the work process at large - themes explored in numerous publications in the last decades. The development of occupational control of labour markets and education, on the other hand, has received considerable less attention as these elements of professionalism have seen modest or little changes in most countries.

In the wake of New Public Management (NPM), numerous studies have been devoted to the effects of new forms of management and governance (Brock \& Saks, 2016, Clarke \& Newman, 1997; Numerato, 2011; Pollitt \& Dan, 2013). With respect to the medical profession, the vast majority of measures in the last decades associated with NPM have been aimed at one of the constitutive elements of medical professionalism - occupational control of the labour process (Numerato et al., 2012). Admittedly, a complex and vexed issue, there is no consensus in this extensive branch of studies of professions in working life. However, if the previous distinction between constitutive and contingent elements of professions is recalled, the complexity is somewhat narrowed down. Hardly any recent research on professions employed in the public sectors of the industrialized world denies that the contingent elements of many professions have changed in recent years. Governments apply new methods to govern public services, guided by new policies, often intended to have an effect on professional groups. Albeit difficult to establish, dominant ideologies 
have probably also seen some change in the recent decades. In that respect, many researchers agree in that there have been considerable changes in the context of public sector professions (Kurunmäki, 1999; Levay \& Waks, 2009; Pollitt \& Dan, 2013), but there are different conclusions whether the manifest reforms also have changed more profound aspects of professions, such as their status, identity, and professional practice (Evetts, 2009; Kastberg \& Siverbo, 2016; Kurunmäki, 2004).

The conclusion that occupational control of division of labour in professional work is challenged find support in some extant research (e.g., Evetts, 2009; Jespersen \& Wrede, 2009), while others hold that the medical profession often succeed in mitigating or short-circuiting the attempts to impose new forms of control on their work (e.g., Hanning \& Spangberg, 2000; Levay \& Waks, 2009; Waring \& Currie, 2009). The most comprehensive recent account of extant research by Numerato et al. (2012) point out that the effects of managementization pertain to two different spheres of professional work - the socio-cultural and the task-related spheres, and the effects are conceptualized as five different forms of responding to challenges to professional control: submission to managerial hierarchy, co-optation of management, negotiated managerialism, strategic adaptation, and resistance. Again, it should be noted that according to Freidson's (2001) definition of professionalism, the socio-cultural sphere is by definition a part of the contingent elements, while occupational control of the task-related sphere is at the core of professional practice and a constituting element of professionalism. The research on effects on the taskrelated sphere summarized by Numerato el al. (2012) cover a wide variety of measures even though most examples are related to guidelines and medical protocols intentionally designed to govern medical practice.

Most research on how the medical profession is governed tends to focus on the measures that are unequivocally designed to alter the position and influence of physicians in the health care system. Changes with respect to new legislation and rules, the fee system, accreditation or the influence of a national medical association are typically such empirical cases. But public sector reforms often unfold in a vortex of many different forms of interventions (Bejerot \& Hasselbladh, 2013). Singular forms of interventions seldom have an effect on their own. But local interventions in management, audit or regulating professional practice often find its support (financially, ideologically or by guiding attention) in interventions by law, rules and ordnances or political initiatives on the national level. Sometimes there are considerable time lags between the different forms of interventions that make up public sector reforms such as new legislation and local instances of management practices. We have studied a number of changes in the Swedish healthcare system where a national initiative have become closely linked to various local redesigns of EDs. Our empirical case offers a window into the complex level crossing between new priorities and incentives set at the national level, intended to redirect the priorities of clinical work at EDs. In this case, contingent elements at the national level of healthcare systempolicy and regulation - become directly linked to the task-related sphere. The ways these measures are designed and launched at the local level directly impinge on one of the constituting elements of professionalism - occupational control of the division of labour - that largely corresponds to the task-related sphere.

\section{Method and material}

In 2014, 14 physicians working full-time in EDs were interviewed (five women and nine men). Four interviews were conducted in each of three hospitals: two very large EDs $(100,000$ patients/year) in a big city and one mid-sized ED $(50,000$ patients/year) in a mid-sized city. Two interviews were also conducted in a small ED $(20,000$ patients/year) in a small city closely connected to the mid-sized hospital but somewhat out of the centre of things. Nine of the individuals were specialists and consultants, and five were resident physicians. Among the latter, four were being 
trained within the new specialism of emergency care, that is physicians that reside in the ED and are not brought in as "guest physicians" from other clinics. The choice of informants was made through so-called "snowball sampling" (Biernacki \& Waldorf, 1981). This method entails a risk of a distorted selection. However, this process did not start from a single network but had different inputs.

The interviews lasted between 45 and 90 minutes and were recorded and transcribed, and anonymity was secured at this point. All informants received written information in advance on the focus of the research project, anonymity, and their freedom to end the interview at any time. The interviews were held by two of the authors of this article. The regional ethics committee approved the study. As the aim was to understand physicians' work from their own perspective, flexibility was important during the interviews. Thus, questions were asked based on a semi-structured guide that included questions on how clinical work was organized, what changes had occurred, if their work had been affected by these changes, what work dilemmas they perceived and how they dealt with them. The interviewer asked follow-up questions until the informant's account was well understood. The interviews were aimed to capture informants' stories, and it was often noticeable that informants had a work story that they wanted to pass on. In line with analytical interviews (Kreiner \& Mouritsen, 2006), the informants were encouraged to analyse and discuss these stories during the interviews. It is these sections of the interviews that are used in the presentation.

The analysis began with reading and rereading the transcribed material. First, a coding was carried out, inspired by thematic inductive analysis (Braun \& Clarke, 2006). The main categories were interventions by governance and management, and challenges or dilemmas at work (i.e., lack of discretion, resource deficiencies, frames of control, staff situations, cooperation with nurses, support and collegial arenas, patients' needs). Second, the context around the interventions and their impact was analysed by organizing the interviewees and their stories per organization, comparing similarities and differences between the EDs. This step of the analysis resulted in new knowledge and questions to ask in relation to the material. Third, the interventions mentioned by the informants were tracked to documents on the national level, where national priorities and even particular approaches to organize patient flows were described, and then back to the interviews in order to better understand the informants' stories. The process of analysis was characterized by "zigzagging back and forth between theoretical ideas, data collection and analysis" (Layder, 1988, p. 77).

We have chosen to present the interviews in a way that aims to capture the complex interplay of levels. Longer quotations are presented from one interview per organization in order to capture how the informants describe the contexts and the flow of events and how they interpret and deal with these. The chosen interview per organization is seen as being representative of the specific ED; that is, the themes and meanings presented are found also in the other interviews in the specific ED. The quotations capture complex reasoning and the different ways measures are designed and launched in the EDs. The quotations have been lightly edited for the sake of readability. Clarifications inserted within the quotations are written in the brackets.

The documents about measures to shorten waiting times were found in the archives of the Swedish Association of Local Authorities and Regions (SALAR) and the National Board of Health and Welfare (NBHW). Search was also carried in two Swedish journals that are arenas for information and discussions among physicians working in hospital environments: Läkartidningen and Sjukhusläkaren. The search was limited in time from 2010, when the change process started, to 2014 when the interviews were made. Although the results section is introduced with a description of the national level, the research process was largely in reverse, in that the work began with the interviews with physicians who indicated what external measures were influencing clinical practice-statements that were subsequently corroborated by analyses of documents from the national level. 


\section{National interventions in the governance of emergency departments}

In the interviews, two areas of national interventions stand out as reshaping the previously existing occupational control of clinical work: the introduction of waiting time targets, and new methods to improve throughput and the flow of patients though the healthcare system. These measures are described as a background to the interviews that follow.

\section{The four-hour target}

During the 2010 campaign for the Swedish parliamentary elections, the Minister for Health and Social Affairs announced that he wished to introduce legislation on a maximum waiting time in EDs. There was a political consensus on this goal, but after the election neither legislation nor waiting time guarantees followed for EDs. 1 Instead, waiting-time targets became related to revenues from the government to county councils and EDs. The targets define the maximum time patients should have to wait to one hour before meeting a physician and four hours before they are ready to return home or be transferred to a ward (hereinafter abbreviated as the four-hour target). On the request of the Government of Sweden (2012), the NBHW specified indicators and a new quality register for waiting times, measuring performance in detail, automatically and continuously (compare Bejerot \& Hasselbladh, 2010). Out of 21 county councils, 18 established these targets; between 70 and 100 per cent of all patients were to be completely processed within four hours, a target that few county councils succeeded in achieving (NBHW, 2013). 2

\section{New methods in clinical work}

In order to render ED working methods more effective, SALAR (2013) initiated a national programme in 2012, financed by the government to stimulate county councils to find solutions to reduce waiting times, increase patient safety, and improve staff satisfaction. In 27 projects, lean methods were introduced with the ambition of rendering processes more effective and speeding up flows. Central elements in these projects were: changing how cooperation between physicians and nurses is organized through the implementation of team triage in which specialist physicians work together with nurses sorting patients by priority on ED intake (traditionally intake was staffed by nurses, except ambulance patients that bypassed the intake), staffing the entire ED flow with interdisciplinary teams (physician, nurse, assistant nurse), checklists of treatment directions, fast tracks for different groups of patients (e.g., hip fractures), and minor injuries units for patients who are not seriously ill (SALAR, 2013). These are also the central points of advice in a regional report on best practices of organizing EDs by McKinsey \& Company (SLL, 2013). SALAR (2013, p.

1 However, national legislation was introduced in planned specialist care and primary care. The pressure to reduce waiting times in those parts of health care directed more patients to emergency care, as older patients and those with long-term illnesses were less likely to have planned follow-up appointments that they needed. This is considered as one explanation for why waiting times at EDs has been difficult to reduce (NBHW, 2012, p. 80 ff.).

2 Apart from a few minor units specializing in planned care and one hospital, the regional councils run Swedish hospitals. The regions employ the staffs, including physicians. The hospitals are often, but not always, governed through some kind of purchaser-provider arrangement within the region. The regions, or county councils, are organized in a national union (SALAR) of paramount importance in policy-making and relations to the national government. The latter is responsible for legislation and audit in health care sector. With respect to our present case, this is a typical situation where national initiatives must be handled at the local level, regardless if the measures are mandatory or recommendations. 
7) reported brilliant results based on these projects, but this success seems to have been local or short-lived, as countrywide waiting times were not reduced.

All in all, expert groups and research do not support the effectiveness of targets in reducing waiting times, although altered working methods with team triage may contribute to a positive development in EDs (SBU, 2010, p. 25),3 and lean methods may simplify clinical work processes (Mazzocato et al., 2014). However, research gives stronger support for structural changes such as initiating units for minor injuries and fast tracking for certain patient categories (SBU, 2010). The point here is that although the measures undertaken in Sweden do not seem to have unequivocal support, they are being widely introduced nevertheless.

\section{Submission to change}

The initiatives from the national level often display an amalgamation of different types of measures based on politics, management, evaluation and rationalization of professional practice (Bejerot \& Hasselbladh, 2013). The interventions aimed at EDs display a pattern similar to other parts of Swedish healthcare: politicians legitimize and finance, the National Board of Health and Welfare (NBHW) investigates and measures, and the national union of county councils (SALAR) design programmes for change. This may explain why comprehensive changes of governance in Swedish healthcare are often regarded as diffuse - many actors in different positions point in the same direction (Bejerot \& Hasselbladh, 2010; Hasselbladh \& Bejerot, 2016). Additionally, the county councils have some independence, so non-mandatory changes may not be introduced everywhere or simultaneously.

Even though the interventions designed at the national level was likely to have some effect on the occupational control of clinical work, the medical profession at large does not seem to have been involved in formulating the new priorities nor engaged in evaluating or commenting upon their possible, or known, effects (cf. previous studies displaying the same pattern: Bejerot \& Hasselbladh, 2006; 2010; Hasselbladh \& Bejerot, 2007). The two main journals aimed to physicians in Sweden (Läkartidningen and Sjukhusläkaren) briefly mentions the four-hour target in 2011 and a couple of published studies on team triage are referred to, while the organization of the entire work process in interdisciplinary teams is not described at all. No texts were found on new methods such as targets, team triage, interdisciplinary teams, lean methods or central registers for follow-up. This may partly be explained by the historical fact that EDs have traditionally been staffed by physicians from hospital wards who work there intermittently and correspondingly no physicians regarded emergency care as their domain before emergency medicine was established as a specialism in 2015.

The totality of interventions designed at the national level made up an unusual configuration by both specifying distinctive targets - what to do - and particular methods - how to do it. In terms of our model, there were decisive changes in some of the contingencies of professionalism - mainly regulation and managerial doctrines - that were likely to directly affect one of the constituting traits of professionalism - occupational control of the labour of division of professional work.

3 A Swedish study showed a reduction in waiting times when physicians work in team triage on intake (Burström et al., 2012). In this study, however, Sweden's only privately owned ED is compared with two publicly run EDs. Many factors differentiate these hospitals, and the conclusion that it is the position of physicians in the triage that is the decisive factor is questionable. 


\section{Interviews with physicians}

In all the studied EDs, physicians describe a heavy workload, difficult personnel situation, and lack of hospital beds and examination rooms. The themes recur in almost every interview with the exception of the two informants from the small ED, which seems less stricken by staff turnover and conflicts. However, when reading the fourteen interviews organized by workplace, some other differences also become visible. Although almost all the interviews relate to the four-hour target and the effects it has on the possibilities to exercise discretion in clinical practice, the extent of organizational changes to meet this goal differs. That is, some EDs are forerunners in programmes introducing new working methods. Differences in the work conditions of ED physicians are thus associated with how pliant local management or managers on the county council level have been to the interventions formulated on the national level.

The following section is based on the narratives of three physicians, one from each of the two large- and the one mid-sized EDs. Here, the physicians describe what they regard as problematic conditions and dilemmas in their work, related to governance and organization. The three cases are ordered after the extent of organizational changes. In the first example there have been least changes, and in the third, mid-seized hospital, most.

\section{“There's no other reason than angling for votes"}

This ED in a large city hospital has in recent years introduced a project on lean methods focused on improving flows; a flow-team with a doctor and nurse allot the patients on the ward. Lean methods were introduced by the clinic manager who learned this at a previous workplace, a private hospital, and the physicians of the ED seem to have had some influence on the design. For example, the clocks that showed each team's ranking, were removed after their complaints. No other organizational change was reported on this ED. The following interview was conducted with an experienced male specialist and consultant (IP 3). The physician is critical of many of the introduced governance measures and explains what he sees as causes of increased waiting times.

The short waiting times we used to have been based to a great extent on these chest pains... That patient doesn't exist anymore but has been replaced by a multimorbid 90-95-year-old without focus. Tired but nothing to get hold of. Has not been to the toilet for two weeks. Doesn't eat without help.... It would still work [in the ED] if we had somewhere to put all those people waiting for a bed [on the ward], then the flow would not in itself be a problem. But we have nothing. It is full, physically full in emergency.

The informant draws attention to a new and particularly care-demanding category of patients, the very elderly and multimorbid. These patients do not receive care from Geriatrics, as its compensation system now favours less sick patients. Also, the fourhour rule is assessed as being completely arbitrary, implying a resource shift from very sick patients on the wards to healthier patients in the ED, the other increasing patient group in the emergency.

It's nothing we have decided, this waiting time; [the minister] decided it, promised it. There is no evidence at all that precisely four hours is good. You might say, why should you need to wait more than three hours, or why not five? So what we have done is taking physicians from the ward and brought them down to emergency to talk to the healthier patients. That's the sum total of the four-hour rule. 
Completely without evidence.... There's no other reason than angling for votes.

The physician expresses himself cynically about the politics and measures to cut waiting times. Measurement is regarded as an irritation, as it does not measure what he considers to be important. Below, several measurements and rewards are described as steering the work in the wrong direction.

Personally, I have always been horrified at the fact that we have such an incredible number of metrics, how long the patient takes up a bed, what drugs they take, but no one has ever asked whether we made a good diagnosis or treatment. This is never measured.... [We can] never say that this patient came in with a supposed heart failure but didn't have that, but rather chronic obstructive lung disease. Good, five points! That has never happened. But that patient went home, after an adequate medical treatment, but there was no medication review! Our budget will be cut next year! That's the type of focus there has been.

This informant expresses bitterness on medical quality not being considered. A focus on the four-hour target and remuneration put the emphasis on monitoring waiting times. In this ED, however, management has not attempted to introduce new working methods such as teamwork and team triage. Although the physicians largely commit themselves entirely to patient work, not even the parameters of their most immediate tasks are considered to be possible to influence. The interview shows how the physician's thoughts are permeated by an irritation towards the national systems that form the framework for the ED. The physician does not express annoyance with how lean is implemented, or discontent with the management. The problems are considered as being of political origin.

\section{"The whole system around it is like treacle"}

The next ED is placed in a large city hospital where structural changes have been implemented. The queue to the ED has been cut from two sides, on the one hand a minor injuries unit for patients that are considered relatively healthy, and on the other hand-an "observation department" at the ED where ill patients who have not received a place in a ward within four hours are placed. Several doctors mention that these structural changes are made for economic reasons only. This is an ED whose leadership also have introduced SALAR's change initiative concerning new working methods such as lean methods and team triage. The physician quoted is a male resident who is soon to become a specialist in emergency medicine (IP 7). Replying to a question on what new measures have influenced his work, he mentions the fourhour target as well as the attempts to streamline patient flows by introducing team triage and interdisciplinary teams. The physician describes how these measures have failed in practice.

This four-hour target has led to certain organizational changes. Among other things, we have created an observation department.... So those patients we can't deal with in the emergency department within four hours, they are admitted there. And it's an admission only in an administrative sense, but it's something that reduces the waiting times in the statistics.... And they've also introduced another system in which the physician assesses the patient as early as possible [team triage], and there are good reasons for doing this, but that's all. In that, there is no spare capacity in the system, they take a physician from one place and move them to another in the chain of care, so they are short in another place.... Formally we should be working in a [interdisciplinary] team. In practice, it doesn't work like that, but it's a more or less organized chaos I'd say, how we work. 
This informant has no illusions about the changes; they only improve statistics, move physicians between positions, and so forth. He regards teamwork and team triage as good in themselves, but impossible to use properly because there are not enough nurses. The informant also describes inefficiency, what he calls working in "treacle."

I can quite quickly get a feeling for what it is I want to do ... but the whole system around it is like treacle. You have to do dictation, and then there's a long note to make sure you've included absolutely everything, and then you have to make phone calls here and there, and papers have to be sent here and there, and you have to talk to so and so.... While you're doing that, some relative arrive wanting to know what has happened, and then a new nurse arrives who has to know what has happened, and the patient may be getting worse during this... There is no bed anywhere [in the hospital] and then I have to go back.

In this hospital, the ED physicians do not have "key rights," that is, they cannot demand beds on other wards for their sick patients, and there are constant negotiations with the wards to produce beds. Some slowness also depends on difficult personnel situations with high staff turnover.

The emergency department is in a Catch-22, I would say. It is a very tough working environment ... and then people will not stay there very long.... So there is never a critical mass of experienced staff that knows the workplace and the work.

This physician describes a lack of professional influence in his work and keeps quiet to avoid being regarded as negative. Management encourages dialogue but primarily wants proposals for improvements.

Maybe, at least I feel that many of the problems that exist are so well known and they are maybe not always worth bringing up. And then there is also something else, you don't want to be regarded as somebody who, you know, brings up problems and so on.... And we are encouraged to come up with suggestions for improvements and the like.... I think a lot of people, you know, they've just given up and are resigned in the face of these things [lack of influence]. And then we have our patients to look after and our profession, we want to develop, we want to become good physicians and we support each other in this.

In the description of the lack of influence on the part of the medical team, the informant addresses how the physicians are resigned to their lack of influence and no longer suggest improvements. Instead, it is the professional project of becoming a competent physician that keeps them going and striving to improve. He points to politics, rationalization, and pushing responsibility downwards - with the ED at the bottom.

In one and the same breath they [the politicians] reduce the number of beds in [the hospital] by so many hundred. And then, the concomitant of this is: "I am convinced that the quality of care can be maintained and that this will not affect the quality of care." And they can say that, but then they're only moving the responsibility down the hierarchy, because the people down there, with fewer resources, have to maintain some kind of quality of care.... And at the bottom of the hierarchy is emergency care. 
This interview contains nothing to indicate that the structural interventions or the improvement project with lean methods, team triage, and teamwork have contributed to solving the problems the informant faces in his work. Rather a lack of resources, political promises and management's improvement projects appear to be sources of irritation. Resistance occurs in the form of distancing oneself from the involvement that management craves (that physicians should come up with suggestions for improvement). The physicians are, according to the informant, resigned on issues concerning the clinic, and instead concentrate entirely on their work with patients; this is where they are needed, and this focus makes them in some sense less vulnerable, they are doing their jobs. Although there is a clear criticism of the local management in this interview, the focus of criticism in the overall context.

\section{"Then I am just an island, an island that goes around"}

A third hospital in a mid-sized city stands at the forefront of introducing the specialism of emergency medicine and interdisciplinary teams. This means that the physicians work solely at the ED, and implies a change of roles and forms of collaboration of doctors and nurses. The focus on lean methods, teamwork, and economics is particularly prominent in this ED. The circumstances thus deviate somewhat from the other hospitals in the study. A female resident in emergency medicine describes lean methods and the four-hour target and its impact on clinical work (IP 12).

And lean is very much implemented in our working methods, in that together we [physician and nurse] have to look at the patient as quickly as possible and prepare this joint plan. Then we can also quickly process the patient and this way finalize the case because it is also important that we have a medical evaluation within an hour and the patient should be processed by the emergency department within four hours. These are the targets that provide the funding for the department.... On the other hand, it feels as if, because lean is so very important and the times are very important, as that's what provides financial compensation for the emergency department.... It's as if the content has less importance.

Thus, the targets of short waiting times and lean methods seem to threaten the physician's discretion in executing the daily clinical work. Apart from the focus on treatment times, a standardization of clinical work has been introduced. Team triage implies that the patients are categorized by colour coding that describes their degree of acuteness in order to facilitate communication with the care staff.

So, [the system of categorization] has really made things easier for us, because we have a better joint team understanding of the acuteness and investigation needs of the case. Then, in practice we can only press a button when we get this "abdominal pain, yellow," and then a piece of paper comes out with what the patient should have.... There is some resistance among physicians against this type of PM because they think that it is within our competence to be able to assess what should be done with a patient.

Here, standardization is embedded in the team triage system in the form of decision support for inexperienced staff - at the same time as management wants to place experienced specialists in triage. The physicians protest among themselves but accept the development. Below, the informant describes the loneliness that follows from interdisciplinary teamwork. 
So, we're working in these teams, and between the teams there is not much contact. So, you can work a full shift in this corner and have no idea who has worked here.... You know your team, of course, but I think that you also have a need of community with your own profession and, when you don't meet the other physicians so much, you can feel a little lonely.

Because of irregular working hours, there is no time for the physicians' traditional morning meetings, and monthly meetings are often held when they are working with patients. Senior consultants are not present in EDs as role models and give no support to resident physicians being trained in the new emergency specialism. There is no community, and the physician becomes "an island."

You see, in other clinics the consultants are very important, but here, well, they are rather invisible; they are out on the daily rounds, but they should be helping to look into the future a little and being seen and showing the youngsters the ropes.... When we as a group can't have some form of community, it is very difficult to pursue any kind of development work, and so workmates are important of course, they are very important, but if we never meet, then I'm just an island, a line on a timetable, an island that goes around. But I want to feel I'm part of a community.

Although work methods in the interdisciplinary team with a nurse and an assistant nurse are regarded as positive, this organization leaves physicians feeling isolated from their colleagues. Nor is there uncomplicated cooperation within the team.

In that, I have the highest medical competence, I also have the ultimate responsibility, and, in this way, I also see myself as team leader. But this has never been expressed, and when we write our report - we always have a written reflection after each shift - then it is often the case that the nurse sits as a team leader. I have not taken up this matter. I consider I have the responsibility, that's the case, and then I think I also have the right to take the decisions... [ [nterviewer: But do the nurses see themselves as team leaders?] I think they do, I think perhaps they do. It's a really interesting question. It is in a way something that you don't dare to raise. I have not dared to lift that rock, quite simply.

During this period, the framework for the new specialism emergency medicine is being drawn up and teamwork is being introduced, but in a diffuse and sometimes confounding way. An individual physician does not dare raise the question of which professional group should lead the team, nor is there any support from consultants or arenas for collegiality. The loneliness of the work that this doctor describes, is also mentioned by physicians at the previous ED that had carried out major changes, but at this ED, the question is even more prominent.

\section{Discussion}

The government, NBHW and SALAR were the driving actors behind the interventions concerning waiting times and new working methods at EDs. Between 2010 and 2015 , these interventions have not led to shorter waiting times. The solutions seem to have increased the problems they were intended to solve. Nor does this study find any indication that EDs have achieved a stronger position in hospitals through the introduction of targets (cf. Timmons, Coffey, \& Vezyridis, 2014), or that they were able negotiate or adapt the new targets (cf. Kitchener, 2002). The interviewed physicians work intensively with patients and have no opportunities to influence the 
larger framework of change, the organization of clinical work, nor priorities or working methods. From this perspective, the ED physicians appear to have been outmanoeuvred, such that their previous ability to exercise occupational control of clinical work has been diminished. Aside from insisting on trying to maintain good-quality medical work, the only resistance is silence and withdrawal from development projects and similar arenas. In principle, resistance is a possible scenario - but this study shows no trace of it on behalf of the medical profession.

There is no escape from the four-hour target, which is closely connected to revenues, but the results show that there are differences between EDs, which indicate that the management at the ED or hospital level has some discretion and can choose how proactively they want to engage with the methods proposed from the national level. Also, several interviews revealed that the cooperation between physicians and nurses had become more complicated. Limitations of this study lie in this complexity and the limited number of interviews. Future research in this area should include interviews with politicians, managers, and nurses.

Extant research on the medical profession tend to regard external interventions to impose control on clinical work, indirectly through the socio-cultural sphere or directly through regulating the task-related sphere, as destined to become watered out and adapted to priorities and concerns of the medical professions. The result of this study differs, therefore, from previous research that tends to emphasize the possibility to resist changes imposed from outside the profession (cf. Hanning \& Spangberg, 2000; Kastberg \& Siverbo, 2016; Levay \& Waks, 2009; Waring \& Currie, 2009). There are no signs of manifest resistance from physicians in our study, but ample evidence of cognitive and emotional reluctance (Piderit, 2000) to the measures imposed from above. The categorization of responses to challenges of professional control by Numerato et al. (2012) does not really cover our results. The identified reactions, which are not merely individual idiosyncrasies, attest to resignation, withdrawal, and sadness. It is akin to "cynical distance," as coined by Fleming \& Spicer (2003), when employees distance themselves from various forms of cultural control in organizations by silence, denial, and cynicism. The changes we have studied are even more difficult to contradict than programmes of cultural control, sanctioned by top management. The changes are seen as meaningless, well-intended but disastrously designed or opportunistic attempts at quick fixes, any such meaning can be harboured among the physicians as long as they do what they are told to do. This might explain the apparent contrast between the actions, which largely follow the intentions of the reform, and the gloomy attitude to the reform expressed in the interviews. The reform as such impinges forcefully on professional control over the process of medical work but also nurtures attitudes that might reshape the sociocultural dimension of professionalism; such as professional knowledge development, identity and sense of belonging (Numerato et al, 2012). If the attacks on professional control from local management, and the government, are perceived as strong enough, working in solitude becomes as a final protective strategy.

\section{Conclusions}

The distinction between constitutive and contingent elements of professionalism suggested by Freidson (2001), and the more fine-grained distinctions suggested by Numerato el al (2012), invites to an inquiry on how professionalism is reshaped by the elements that might vary greatly between contexts and over time. It seems apparent that different aspects of professionalism can change, sometimes fairly independent from each other. Our case study illustrates how one aspect of professionalism - occupational control of the division of labour - can be decisively affected by contingent elements (regulation, organization, and ideology), while not affecting other constitutive aspects of professionalism at all. Notwithstanding that the Swedish medical profession in many ways have maintained their occupational control over 
the constitutional elements of professionalism outside clinical work, our study illustrates how occupational control of the division of labour can be seriously undermined as a consequence of seemingly small interventions from the national level; such as changes in funding, national objectives, and recommended methods in clinical work, mediated through politicians in county councils and local managers. Physicians can still, with restrictions, make decisions about individual patients, but more as subordinate experts, and as trend suggests, in a team led by a nurse. This is a poignant example of how the autonomy and discretion of a professional group can be eroded under the pretext of high and pressing aims ("the patients must receive care quickly"), without neither involvement nor resistance from the profession. These changes pertain almost solely to what Numerato et al (2012) define as the task-related dimension of professionalism. But if such changes are considerable and reproduced over time, it seems likely that they also would affect the socio-cultural dimension of professionalism. Hard-wired changes of the type we have studied can also be seen as a way of ingraining certain values and principles, in a less negotiable manner than by way of exercising cultural control. Values, beliefs, and identities are difficult to separate from the practices where they are enacted and made real, a theme worthy of further investigation.

\section{References}

Aasland, O. G. (2015). Healthy doctors-Sick medicine. Professions \& Professionalism, 5(1). http://dx.doi.org/10.7577/pp.989

Bejerot, E., \& Hasselbladh, H. (2006). Diskursiv stängning, enrollering och materialisering-En studie av TQM i ett landsting [Discursive closure, enrollment and materialization-A study of TQM in a county]. Nordiske Organisasjonsstudier, (8)2,7-38.

Bejerot, E., \& Hasselbladh, H. (2010). Professional autonomy and pastoral power: The transformation of quality registers in Swedish health care. Public Administration, 89(4),1604-1621. https://doi.org/10.1111/j.14679299.2011.01945.x

Bejerot, E. \& Hasselbladh, H. (2013). Forms of intervention in public sector organizations: Generic traits in public sector reforms. Organization Studies, 34(9), 1357-1380. https://doi.org/10.1177/0170840613477639

Biernacki, P., \& Waldorf, D. (1981). Snowball sampling. Problems and techniques of chain referral sampling. Sociological Methods and Research, 10(2), 41-163.

Braun, V., \& Clarke, V. (2006). Using thematic analysis in psychology. Qualitative Research in Psychology, 3(2), 77-101. https://doi.org/10.1191/1478088706qp063oa

Brock, D. M., \& Saks, M. (2016). Professions and organizations: A European perspective. European Management Journal, 34, 1-6. https://doi.org/10.1016/j.emj.2015.11.003

Burström, L., Nordberg, M., Örnung, G., Castrén, M., Wiklund, T., Engström, M. L., \& Enlund. M. (2012). Physician-led team triage based on lean principles may be superior for efficiency and quality? A comparison of three emergency departments with different triage models. Scandinavian Journal of Trauma and Emergency Medicine, 20(57). https://doi.org/10.1186/1757-7241-20-57

Clarke, J., \& Newman, J. (1997). The managerial state: Power, politics and ideology in the remaking of the social welfare. London: Sage.

Evetts, J. (2009). New professionalism and new public management: Changes, continuities and consequences. Comparative Sociology, 8, 247-266.

https://doi.org/10.1163/156913309X421655 
Fleming, P., \& Spicer, A. (2003). Working at a cynical distance: Implications for power, subjectivity and resistance. Organization, 10(1), 157-179. https://doi.org/10.1177/1350508403010001376

Freidson, E. (2001). Professionalism: The third logic. Chicago: University of Chicago Press.

Government of Sweden. (2012). Uppdrag att utveckla uppföljningen av hälso- och sjukvårdens tillgänglighet [Assignment to develop the monitoring of healthcare accessibility]. Stockholm: Government of Sweden.

Hanning, M., \& Spangberg, U. W. (2000). Maximum waiting time-a threat to clinical freedom? Implementation of a policy to reduce waiting times. Health Policy, 52(1), 15-32. https://doi.org/10.1016/S0168-8510(00)00060-9

Hasselbladh, H., \& Bejerot, E. (2007). Webs of knowledge and circuits of communication - Constructing rationalaized agency in Swedish health care. Organization, 14(2),175-200. https://doi.org/10.1177/1350508407074223

Hasselbladh, H., \& Bejerot, E. (2016). Performative policy: the case of Swedish healthcare reforms. Critical Policy Studies, 1-20. https://doi.org/10.1080/19460171.2016.1166973

Jespersen, P. K., \& Wrede, S. (2009). The changing autonomy of the Nordic medical professions. In J. Magnusson, K. Vrangbaeck \& B. R. Saltman (Eds.), Nordic health care systems: Recent reforms and current policy challenges (pp. 151-179). Maidenhead: Open University Press.

Kastberg, G., \& Siverbo, S. (2016). The role of management accounting and control in making professional organizations horizontal. Accounting, Auditing \& Accountability Journal, 29(3), 428-451. https://doi.org/10.1108/AAAJ-032014-1632

Kitchener, M. (2002). Mobilizing the logic of managerialism in professional fields: The case of academic health center mergers. Organization Studies, 23(3), 391420. https://doi.org/10.1177/0170840602233004

Kreiner, K., \& Mouritsen, J. (2006). The analytical interview: Relevance beyond reflexivity. In S. Tengblad, R. Solli \& B. Czarniawska (Eds.), The art of science (pp. 153-176). Copenhagen: Liber Copenhagen Business School Press.

Kurunmäki, L. (1999). Professional vs financial capital in the field of health care struggles for the redistribution of power and control. Accounting, Organizations \& Society, 24(2), 95-124. https://doi.org/10.1016/S0361-3682(98)00030-0

Kurunmäki, L. (2004). A hybrid profession - the acquisition of management accounting expertise by medical professionals. Accounting, Organizations \& Society, 29(3), 327-347. https://doi.org/10.1016/S0361-3682(02)00069-7

Layder, D. (1998). Sociological practice: Linking theory and social research. London: Sage. https://doi.org/10.4135/9781849209946

Levay, C., \& Waks, C. (2009). Professions and the pursuit of transparency in healthcare: Two cases of soft autonomy. Organization Studies, 30(5), 509-527. https://doi.org/10.1177/0170840609104396

Mazzocato, P., Thor, J., Bäckman, U., Brommels, M., Carlsson, J., Jonsson, F., Hagmar, M. \& Savage, C. (2014). Complexity complicates lean: Lessons from seven emergency services. Journal of Health Organization and Management, 28(2), 266-288. https://doi.org/10.1108/JHOM-03-2013-0060

National Board of Health and Welfare (NBHW). (2012). Väntetider vid sjukhusbundna akutmottagningar: Plan för utveckling av system för uppföljning [Waiting times for emergency departments: Plan for the development of systems for monitoring]. Stockholm: Socialstyrelsen. 
National Board of Health and Welfare (NBHW). (2013). Väntetider vid sjukhusbundna akutmottagningar [Waiting times for emergency departments]. Stockholm: Socialstyrelsen.

National Board of Health and Welfare (NBHW). (2014). Väntetider vid sjukhusbundna akutmottagningar [Waiting times for emergency departments]. Stockholm: Socialstyrelsen.

Numerato, D., Salvatore, D., \& Fattore, G. (2012). The impact of management on medical professionalism: A review. Sociology of Health \& Illness, 34(4), 626644. https://doi.org/10.1111/j.1467-9566.2011.01393.x

Piderit, S. K. (2000). Rethinking resistance and recognizing ambivalence: a multidimensional view of attitudes toward an organizational change. Academy of Management Review, 25(4), 783-794.

Pollitt, C., \& Dan, S. (2013). Searching for impacts in performance-oriented management reforms: A review of the European literature. Public Performance and Management Review, 37(1), 7-32. https://doi.org/10.2753/PMR1530$\underline{9576370101}$

Swedish Association of Local Authorities and Regions (SALAR). (2013). Akut förbättring: Ett nationellt projekt för bättre patientflöden på akutmottagningar [Acute improvement: A national project to improve patient flow in the emergency department]. Stockholm: SALAR.

Swedish Association of Local Authorities and Regions (SBU). (2010). Triage och flödesprocesser på akutmottagningen: En systematisk litteraturöversikt [Triage and flow processes in the emergency department: A systematic literature review]. Stockholm: SBU.

Stockholm County Council (SLL). (2013). Genomlysning av Stockholms fem stora akutmottagningar [Examination of Stockholm's five big emergency departments]. Stockholm: Hälso och sjukvårdsförvaltningen, Stockholms läns landsting.

Swedish Work Environment Authority. (2012). Nationell tillsyn av överbeläggningar inom akutsjukvården [National supervision of overcrowding in emergency care]. Stockholm: Arbetsmiljöverket.

Timmons, S., Coffey, F., \& Vezyridis, P. (2014). Implementing lean methods in the Emergency Department: The role of professions and professional status. Journal of Health Organization and Management, 28(2), 214-228. https://doi.org/10.1108/JHOM-10-2012-0203

Waring, J., \& Currie, G. (2009). Managing expert knowledge: Organizational challenges and managerial futures for the UK medical profession. Organization Studies, 30(7), 755-778. https://doi.org/10.1177/0170840609104819 


\title{
\& PROFESSIONS \\ PROFESSIONALISM
}

ISSN: 1893-1049

Volume 7, No 2 (2017)

http://doi.org/10.7577/pp.1723

\section{Mari Lande With}

\section{Are Teachers Increasingly Leaving the Profession?}

\begin{abstract}
Changes in teachers' work, often labelled intensification, have raised concerns that teachers are leaving the profession at an increasing rate. The present paper uses high-quality data from Norwegian administrative registers to examine the trends in attrition across three decades. These data allow for a comprehensive examination of changes in attrition, taking teachers' education, school level, and demographic characteristics into account. Results show that early career attrition has declined over time, whereas the incidence of early retirement increased.
\end{abstract}

Keywords: Teachers, PGCE, attrition, change, retention

In recent decades, changes in teachers' work have raised concerns that teachers are leaving the profession at an increasing rate. Low pay, decline in public respect, increased workload, and declining autonomy are all factors that have been identified as potential triggers of teacher turnover (Skaalvik \& Skaalvik, 2011; Smethem, 2007; Webb et al., 2004). Nevertheless, despite widespread concerns for teacher attrition, there is limited empirical evidence of an increasing trend.

Moreover, developments in the labour market during the past decades may have improved the scope for teacher retention. As increasing shares of the population hold higher education degrees, the transferability of teaching credentials to non-teaching positions may have declined. This paper examines the relative importance of such trends for changes in teacher attrition in Norway across more than three decades.

Mari Lande With, Centre for the Study of Professions, Oslo and Akershus University College of Applied

Sciences,

Norway

\section{Contact:}

Mari Lande With, Centre for the Study of Professions, Oslo and Akershus University College of Applied Sciences, Norway mari-lande.with@ hioa.no The study uses high-quality data from administrative registers, allowing a more thorough examination of trends than data used in previous research. The Norwegian case is interesting because of Norway's generally low levels of unemployment and its strong economy, which, as noted by the OECD (2005), often creates particular difficulties in recruiting and retaining teachers. Despite variations between countries, concerns about the impact of heavy workloads and low rewards on teacher retention are widespread (Ingersoll, Merrill, \& Stuckey, 2014; Lindqvist, Nordanger, \& Carlsson, 2014; OECD, 2005; Webb et al., 2004). The generalizability of findings will be further discussed in the concluding section of this paper.

\section{Background}

Internationally, several widely cited studies have reported high levels of teacher attrition, particularly in the first few years after graduation. For instance, in the United States, researchers have estimated that $40 \%$ to $50 \%$ of new teachers leave within the first five years (Ingersoll et al., 2014; Stinebrickner, 1998). In the United Kingdom, Purcell, Wilton, Davies, and Elias (2005) found that between 25\% and 35\% of qualified teachers were employed outside teaching after seven years.

Received: 31 May 2016 
Despite the quite extensive research into factors associated with teacher attrition, few studies have systematically examined attrition patterns over time, the most important reason being the lack of appropriate data available. One exception is a study by Grissmer and Kirby (1992), who examined attrition from teaching in Indiana between 1965 and 1987. According to their study, attrition decreased over time. The pattern was largely explained by demographic changes, such as the age composition of the teacher workforce and female labour market participation. Several less comprehensive studies of attrition show varying patterns. In the UK, Smithers and Robinson (2005) found an increase in annual attrition rates between the mid-1990s and 2001; however, the trend did not continue in subsequent years. Luekens, Lyter, and Fox (2004) and Ingersoll et al. (2014) found an increase in attrition among US teachers since the 1990s. In Norway, Arnesen (2002) found that attrition declined among early-career teachers in the 1990s.

A limitation of previous studies is that teachers returning to the profession are not accounted for, even though there is evidence that teachers who leave often return to teaching (Grissmer \& Kirby, 1992; Lindqvist et al., 2014). Furthermore, most of the studies cited above do not control for demographic changes in the teacher population. If, on the one hand, increasing attrition rates are caused by changes in the demographic composition of the teaching force-for instance, in terms of teachers' age or gender - such trends may be difficult to combat. If, on the other hand, attrition increases among teachers with similar experience, age, and other characteristics, this is of particular policy interest. Examining variations in attrition patterns across different teacher groups is also relevant for deciding how such trends should be explained. An important contribution of this paper is that both characteristics of teachers and changes across the teaching career are taken into account.

\section{Concepts and delimitation of the study}

Typically, research on attrition distinguishes between teachers moving from one teaching position to another and teachers leaving the profession altogether. This study is primarily concerned with teachers leaving the profession. Furthermore, the analyses distinguish between cohort attrition, which refers to the total proportion of graduation cohorts from teacher education who leave the profession, and annual attrition, which refers to the proportion of teachers who are employed in schools one year and who leave in the subsequent year. Because the mechanisms leading to teachers "being 'lured' away ... by the attractiveness of non-teaching jobs" and those causing teachers to leave employment altogether are likely to differ (Stinebrickner, 2002, pp. 211-212), a further distinction is made between attrition to non-school employment and attrition to non-employment.

The data analysed in this paper do not include teachers' motives for leaving. However, the tenure rates in teaching are generally high, and regulations concerning terminations are strict. This indicates that attrition from teaching is predominantly voluntary. Nonetheless, the possibility that lower demand has affected attrition is discussed in relation to the results.

\section{The Norwegian school system and teacher education}

Norwegian pupils spend ten years in compulsory education, starting at age 6. Compulsory schooling is divided between the primary level (grades 1-7) and the lower secondary level (grades 8-10). Moreover, enrolment in either three-year academic or four-year vocational upper secondary programs is nearly universal. A large majority of schools are public.

Various teacher education programs qualify for work in primary and secondary education. The two largest programs are the general teacher education (GTE), a four-year bachelor's level degree that qualifies individuals for teaching in primary 
and lower secondary education, and the postgraduate certificate in education (PGCE), currently a one-year course for graduates from higher education that qualifies for teaching fifth through 13th grade. With some additional training, both teacher groups may teach all grades. Whereas most teachers at the primary level have GTE, about $80 \%$ of teachers in academic upper secondary programs hold a PGCE (Caspersen, Aamodt, Vibe, \& Carlsten, 2014; Turmo \& Aamodt, 2009). Although teachers with GTE represent a majority at the lower secondary level, PGCE teachers also make up a substantial share of teachers at this level.

\section{Theoretical perspectives}

A basic assumption underlying research on teacher attrition is that individuals will remain in the profession if teaching represents the most attractive activity to pursue among available alternatives (Guarino, Santibanez, \& Daley, 2006). Studying to become a teacher can be seen as an investment in human capital (Becker, 1993). According to human capital theories, actors invest in education based on available information on rewards, costs, and risks associated with this education. Teacher education may also be a way of accumulating human capital that is of value in other careers (Grissmer \& Kirby, 1992). In this sense, attrition may be a planned course of action. This may vary among teachers, depending on how much they have invested in their teacher education (Harris \& Adams, 2007).

However, desire is not sufficient to produce a given outcome. In order for this preference to affect a persons' actions one must also have the opportunity to do as one wishes (Hedström, 2005). Accordingly, the levels of teacher attrition are dependent on the availability of work that is perceived as more rewarding outside the teaching profession, as well as the transferability of teachers' accumulated human capital to other types of employment (Harris \& Adams, 2007).

Although human capital theories often focus on economic incentives, the idea that individuals maximize available rewards can be extended to include other types of rewards (Becker, 1993). The literature on teacher motivation typically distinguishes between extrinsic and intrinsic rewards (Watt et al., 2012). Teachers motivated by intrinsic rewards are attracted by the inherent satisfaction of teaching. By contrast, extrinsic motivation is induced by rewards that are external to the teaching activity itself, such as pay and job security.

\section{Previous research on causes of teacher attrition}

In line with the predictions of the human capital theory, previous studies indicate that a fairly high proportion of PGCE graduates do not plan to stay in the profession, or see teaching as a fallback career (Kyriacou \& Kunc, 2007; Turmo \& Aamodt, 2009; Watt et al., 2012). Research also shows that attrition is higher among teachers with a PGCE than among teachers with more specialized teacher education (Guarino et al., 2006; Purcell et al., 2005). Furthermore, teachers with credentials that are more sought after in the labour market, such a master's degree or a degree in science, are more likely to leave (Borman \& Dowling, 2008; Chevalier, Dolton, \& McIntosh, 2007; Mastekaasa, 2011).

Although a fairly consistent finding is that higher teacher salaries correlate with lower attrition (Borman \& Dowling, 2008; Guarino et al., 2006; Schøne, 1999), research on motivation typically finds that teachers emphasize intrinsic and social aspects of work as motivation for both entering and remaining in the profession (Guarino et al., 2006; Roness \& Smith, 2009). Among the highest-rated motives are the enjoyment of working with youth and contributing to society. Workload, government initiatives, lack of administrative and colleague support, and discipline problems have been found to influence teachers' turnover intentions (Lindqvist et al., 2014; Skaalvik \& Skaalvik, 2011; Smethem, 2007; Webb et al., 2004). Such 
factors are also cited as important reasons for leaving among individuals who have left teaching (Purcell et al., 2005; Struyven \& Vanthournout, 2014).

\section{Attrition, age, and career stage}

Attrition from teaching is typically highest among recent graduates and teachers approaching retirement (Grissmer \& Kirby, 1992; Guarino et al., 2006). Whereas younger teachers more often leave for other types of employment, older teachers retire from the labour market altogether. Factors contributing to teacher attrition vary among teachers in different career stages. Previous research indicates that salary and availability of permanent employment opportunities are more important for younger teachers, whereas workload has a particularly negative impact on retention among experienced teachers (OECD, 2005; Van Droogenbroeck \& Spruyt, 2014). Moreover, experienced teachers are often more negative toward educational change (Hargreaves, 2005; Maskit, 2011; Mausethagen, 2013a). Distinguishing between early-, mid-, and late-career teachers, Hargreaves (2005) suggested that early-career teachers experience "change as part of life" (p. 972-973), whereas late-career teachers often experience decreasing energy and are tired of "successive changes passing through their school" (p. 975). Nevertheless, workload is also associated with attrition among early-career teachers. In this group, attrition is frequently attributed to insufficient preparation combined with high demands (Smethem, 2007).

\section{Changes in teachers' work}

During the past few decades, teachers in many countries have faced new demands and challenges (Ballet \& Kelchtermans, 2009; Webb et al., 2004). According to the "thesis of intensification," managerial ideologies and an increased focus on the outcomes of education have resulted in a restructuring of teachers work (Apple, 1986). Several studies have linked such changes to teacher discontent and motivation to leave teaching. In recent years, intensification has been linked to accountability policies and an increase in teachers' workload owing to curriculum planning, student assessment, and test preparation (Ballet \& Kelchtermans, 2009; Smethem, 2007; Webb et al., 2004).

In Norway, political control of the school sector has increased since the 1990s, as exemplified by the 1997 introduction of a national instructional curriculum (Imsen \& Volckmar, 2014). The PISA survey in 2000 showed Norwegian students performing at or below the average of other OECD countries and played a central role in legitimizing accountability policies (Hatch, 2013; Mausethagen, 2013a). A national quality assessment system was introduced in 2004, which included instruments to evaluate pupil performance and progress, enabling principals and school owners to hold teachers accountable for results (Hatch, 2013; Tveit, 2014). Although these policies have relatively limited consequences for teachers compared with policies in many other countries (Hatch, 2013), demands for documentation and systematic evaluation of pupils have increased teacher workload (Norwegian Ministry of Education and Research, 2009).

Prior to the 2004 reform, there was no grading or other summative evaluation of pupils' performance at the primary school level. Thus, these policies represented a larger shift in the routines of teachers in lower school levels. Skaalvik and Skaalvik (2011) found that increased time pressure experienced by Norwegian primary and lower secondary teachers contributed to emotional exhaustion and motivation to leave the profession. However, Mausethagen (2013a) found that many Norwegian teachers accept new accountability measures, although some elements are negotiated and resisted by teachers. Early-career teachers were found to be more accepting, whereas "veterans" more often see these policies as a threat to teacher autonomy. Although recent educational changes are often perceived as limiting teachers' autonomy, there are also signs that teaching has become more collaborative (Hargreaves, 1994; Mausethagen, 2013b). Policies that have increased demands for teachers' 
presence at schools outside teaching hours may contribute to more teacher collaboration. This may improve retention, particularly among early-career teachers, for whom support from administration and colleagues has been found to be particularly important (Pomaki, DeLongis, Frey, Short, \& Woehrle, 2010). In sum, these studies indicate that if policy changes have led to increased teacher attrition, this should be particularly traceable among teachers in lower school levels, which is where reforms have had the greatest impact, and particularly among late-career teachers, who are most resisting towards change.

Accountability policies are quite recent in the Norwegian context. Furthermore, several other developments may have affected attrition in the period covered in this study. For instance, from the 1970s to mid-1980s teacher earnings declined compared with earnings in many other occupations, particularly for teachers with qualifications at the master's level (Aanensen, 2010; Høgsnes, 2000). In addition, a number of scholars have described a decrease in the social esteem of teachers (Høgsnes, 2000; Rovde, 2004). The negative media attention in the aftermath of PISA was associated with a decline in the public perception of teaching (Fladmoe \& Leiulfsrud, 2013). According to Skaalvik and Skaalvik (2010), teachers experience low status and negative media attention as stressful.

\section{Opportunities for leaving the profession}

As outlined above, attrition depends on teachers having both the motivation and the opportunity to leave. In Norway, higher education expanded greatly between the 1960s and 1990s. Consequently, the competition for positions requiring such qualifications may have increased. Although unemployment levels have been generally low, Barone and Ortiz (2011) found the prevalence of overeducation is higher than in many other European countries. The transition from university to employment in Norway has become more difficult since the 1990s, particularly for social science and humanities graduates (Opheim, 2004; Støren, 2014). By contrast, graduates from teacher education are rarely unemployed or in non-relevant employment (Opheim, 2004). These patterns suggest that school employment may be increasingly attractive and that the transferability of teacher human capital to non-teaching employment may have declined. Throughout the period under study, teachers - and other public servants - have enjoyed a relatively high level of job-security and a predictable pay schedule based on length of service.

Whereas attrition to non-school employment is affected by labour market opportunities, attrition to non-employment is contingent on retirement regulations. In Norway, the ordinary retirement age is 67 years. Teachers are also eligible for early retirement pension. The eligibility age for early retirement was reduced in the 1990s; from 65 years to 63 years in 1997, and subsequently to 62 in 1998 (Snartland \& Øverbye, 2003). Individuals with physical or psychological illness may also qualify for a disability pension. Because benefits generally are lower than teacher earnings, retirement implies incurring a financial penalty.

\section{Data and analytical strategy}

The data analysed in this paper were derived from administrative registers supplied by Statistics Norway. The data include detailed records on education for all Norwegian residents since 1975 and information on the highest level of education completed before 1975. Data on income and employment, reported by employers and tax authorities, were available for the years 1992 to 2008. The teachers included in the analyses hold either GTE, or a PGCE combined with a bachelor's or master's degree in humanities, social science, or science (including mathematics). Individuals without formal teacher credentials, PGCE teachers with other professional degrees and 
other types of teacher education are excluded. The selected groups constitute about $60 \%$ of all teachers.

The analyses were carried out in three stages. First, changes in attrition were examined comparing cohorts who graduated from teacher education at different time points ("cohort analysis"). Separate analyses were conducted for GTE graduates, bachelor's level PGCE graduates, and master's level PGCE graduates, which represent teachers with different levels of investment and transferability of skills. The analyses included all teachers under 60 years old who graduated from the selected teacher education programs between 1975 and 2003. Owing to greater variations in early- and late-career stages, only data on employment activity between five and 20 years after graduation were used in these models $(N=57025)^{1}$.

The second and third stages addressed annual attrition to other types of employment ("employment-exit") and to non-employment ("retirement-exit"). Whereas the cohort analyses compared groups with different types of teacher education, the analyses of annual attrition compared teachers employed at different school levels, based on the assumption that working conditions have changed more in lower school levels. These analyses included all GTE and PGCE graduates with a degree in humanities, social science, or science from 1951 through 2007 who were employed in primary or secondary education at some point between 1992 and $2008(N=97415)$. Because data on education are less detailed before 1975, the PGCE category also included teachers who completed a degree in the cited disciplines before 1975, without a registered PGCE. This group constituted nearly $90 \%$ of the teachers with a degree in these fields who graduated before 1975. It was assumed that most of these teachers hold a PGCE but that this information was missing in the database. According to the Norwegian Ministry of Education (1999), university graduates without teaching credentials comprised only $3 \%$ to $5 \%$ of teachers in the 1990s. Further analyses indicated that these teachers differed little from other PGCE graduates in terms of attrition (not shown).

\section{Variables}

Three dependent variables were defined. In the cohort analyses, the dependent variable distinguished between individuals who were employed in the school sector and those who were not (non-teacher $=1$, teacher $=0) .{ }^{2}$ Here, school employment included all employment in primary and secondary schools as well as special education and other types of education but excluded higher education. ${ }^{3}$

In the employment-exit models, the dependent variable distinguished between teachers who were employed in the same school level as the previous year and those who had left. Thus, for individuals identified as primary or lower secondary teachers in a specific year, the variable had the value of 1 if the teacher left this school level for any other teaching or non-teaching position by the next year. Similarly, it had the value of 1 if a teacher left upper secondary education for any other position. Consequently, in these analyses, attrition included teachers leaving to teach at a different school level, in order to examine whether changing working conditions in lower levels of schooling increasingly drove teachers away from this type of employment. Further analyses showed that among primary/lower secondary teachers who left, $60 \%$ left teaching altogether, while $40 \%$ remained in some type of education em-

\footnotetext{
${ }^{1}$ However, all graduates from the selected graduation cohorts are included in the analyses so that individuals never entering teaching and those who leave before five years are included among the "leavers." ${ }^{2}$ Both other employment and non-employment are counted as attrition.

${ }^{3}$ The category also includes some types of educational administration because it was not possible to distinguish between administration and primary school employees in some of the years. However, administration comprised less than $2 \%$ of the teachers in the years in which the categories are distinguishable. Self-employed individuals are included in the non-teaching category.
} 
ployment. Among upper secondary teachers, approximately 50\% left teaching altogether.

In the retirement-exit analyses, the dependent variable identified attrition to nonemployment (all employment $=0$ ). Individuals with very low annual income $\left(<600002011\right.$ NOK) were defined as not employed. ${ }^{4}$

School level was also included as an independent variable, referring to the school of employment in the previous year. This variable had two categories: primary/lower secondary and upper secondary. ${ }^{5}$

In the cohort analysis, change over time was examined by comparing graduation cohorts (year of completion of teacher education), grouped in five-year intervals (except for the last interval, which includes graduates between 2000 and 2003). Moreover, two spline variables (5-10 years, 11-20 years) were included to model the relationship between time since graduation and attrition as two linear segments (because attrition increases more early in the career). To allow for variations across cohorts, further analyses with interactions between cohort and time since graduation were conducted, but as they yielded very similar results, the simpler models were preferred.

In the employment-exit and retirement-exit analyses, the change was examined comparing attrition in different periods (1992-1997, 1998-2002, and 2003-2007), referring to the year of employment.

In the employment-exit models, time since graduation was used as a proxy for teaching experience. Separate analyses were conducted for teachers in different career stages, corresponding to Hargreaves's (2005) categories of early-career ( $<=$ five years), mid-career (6-20 years), and late-career teachers ( $>20$ years).

Because exits from the labour market are closely related to age, the retirementexit analyses focused on age rather than experience. The relationship between age and attrition is highly nonlinear. Therefore, age was measured by an age group variable, distinguishing between teachers 40 years or younger, 41 to 50 years, 51 to 60 years, and with each age between 61 and 66 years constituting a separate category. Teachers aged 67 years (ordinary retirement age) or older were excluded from the analyses.

Control variables included dummies for centrality of place of residence (five categories); enrollment in further education; completion of a master's degree; gender ${ }^{6}$; age at graduation; dummies for children under 1, 4, and 8 years old; and interactions of children and gender, and for PGCE graduates, field of study. Table 1 shows descriptive statistics for teachers by type of education and time of graduation. In supplementary analyses, a more detailed subject of study variable and higher education grade-point average (GPA) were included for PGCE graduates (not shown) ${ }^{7}$.

\footnotetext{
${ }^{4}$ The dependent variables are based on industry, self-employment, and income. Industry is coded according to ISIC Rev. 2 between 1992 and 1995, NACE Rev.1 between 1996 and 2002 and NACE Rev.2 from 2003. Figure A1 in the appendix shows the proportion of graduates in each cohort in non-school employment according to each standard. Although the standards do not perfectly overlap, the differences between cohorts are not affected by the differences in codification.

${ }^{5}$ Because many schools comprise both primary and lower secondary levels, it is not possible to separate these levels.

${ }^{6}$ Separate analyses by gender have also been tested, and although attrition is clearly higher among men, patterns over time are similar.

${ }^{7}$ Information on academic performance was not available for GTE teachers, nor for all PGCE graduates. As this considerably reduced the numbers of teachers who could be included in the analyses, the models presented here do not include this variable.
} 
Table 1

Descriptive statistics for graduates for general teacher education (GTE) and postgraduate teacher education (PGCE), by graduation cohort

\begin{tabular}{|c|c|c|c|c|c|c|c|c|c|c|}
\hline & & $<1975$ & $\begin{array}{r}1975- \\
1979\end{array}$ & $\begin{array}{r}1980- \\
1984 \\
\end{array}$ & $\begin{array}{r}1985- \\
1989 \\
\end{array}$ & $\begin{array}{r}1990- \\
1994\end{array}$ & $\begin{array}{r}1995- \\
1999\end{array}$ & $\begin{array}{r}2000- \\
2003\end{array}$ & $\begin{array}{r}2004- \\
2007\end{array}$ & Total \\
\hline \multicolumn{11}{|c|}{ GTE graduates } \\
\hline \multirow{2}{*}{$\begin{array}{l}\text { Female } \\
\text { Age at } \\
\text { grad. }\end{array}$} & $\%$ & 63 & 60 & 67 & 73 & 75 & 68 & 72 & 75 & 68 \\
\hline & Mean & - & 26 & 27 & 27 & 28 & 27 & 28 & 30 & 27 \\
\hline $\mathrm{N}$ & & 20739 & 8273 & 7685 & 4605 & 6038 & 7668 & 7377 & 7637 & 70022 \\
\hline
\end{tabular}

PGCE graduates

\begin{tabular}{|c|c|c|c|c|c|c|c|c|c|c|}
\hline Female & $\%$ & 33 & 37 & 44 & 54 & 57 & 65 & 65 & 62 & 49 \\
\hline $\begin{array}{l}\text { Age at } \\
\text { grad. }\end{array}$ & Mean & - & 29 & 30 & 32 & 32 & 30 & 33 & 33 & 30 \\
\hline $\begin{array}{l}\text { Master's } \\
\text { degree } \\
\text { Field of } \\
\text { study }\end{array}$ & $\%$ & 39 & 35 & 35 & 24 & 24 & 27 & 30 & 35 & 32 \\
\hline $\begin{array}{l}\text { Humani- } \\
\text { ties } \\
\text { Social }\end{array}$ & $\%$ & 52 & 60 & 64 & 60 & 53 & 64 & 63 & 58 & 58 \\
\hline sci. & $\%$ & 18 & 12 & 12 & 21 & 25 & 22 & 22 & 25 & 19 \\
\hline Science & $\%$ & 30 & 28 & 24 & 19 & 22 & 14 & 14 & 16 & 23 \\
\hline Total & $\%$ & 100 & 100 & 100 & 100 & 100 & 100 & 100 & 100 & 100 \\
\hline $\begin{array}{l}\text { N Uni- } \\
\text { versity, } \\
\text { no PGCE }\end{array}$ & & 5746 & & & & & & & & 5746 \\
\hline N PGCE & & 760 & 3866 & 3425 & 1797 & 2904 & 2812 & 2602 & 3481 & 21647 \\
\hline $\mathrm{N}$ Total & & 6506 & 3866 & 3425 & 1797 & 2904 & 2812 & 2602 & 3481 & 27393 \\
\hline $\begin{array}{l}\mathrm{N} \text { all } \\
\text { teachers }\end{array}$ & & 27245 & 12139 & 11110 & 6402 & 8942 & 10480 & 9979 & 11118 & 97415 \\
\hline
\end{tabular}




\section{Method}

The data were analysed using Poisson regression (Zou, 2004). An important advantage of Poisson regression for dichotomous dependent variables is that it is more robust to issues associated with omitted covariates than logistic regression is (Gail, Wieand, \& Piantadosi, 1984). Because the data included repeated observations for the same individuals, dependence across individuals over time was taken into account using cluster-robust standard errors. Results are presented in figures as predicted probabilities.

\section{Results}

\section{Changes in cohort attrition}

Figures 1 through 3 show the probability that graduates are not employed in the school sector, by graduation cohort. In all groups, results were predicted for a female who is 29 years old at graduation, has no children, has no further education, resides in a central municipality; and for PGCE graduates, a humanities degree holder. Full models are reported in Table A1 in the appendix. The predicted probabilities were calculated at five, 10, and 20 years after graduation. Because labour market data were available only from 1992 through 2008, not all cohorts were observed at each time point. Nonetheless, it was possible to examine cohorts at comparable stages of their careers. The first three cohorts were observed 20 years after graduation, cohorts graduating in the 1980s and 1990s were observed 10 years after graduation, and teachers graduating between the late 1980s and 2003 were observed five years after graduation.

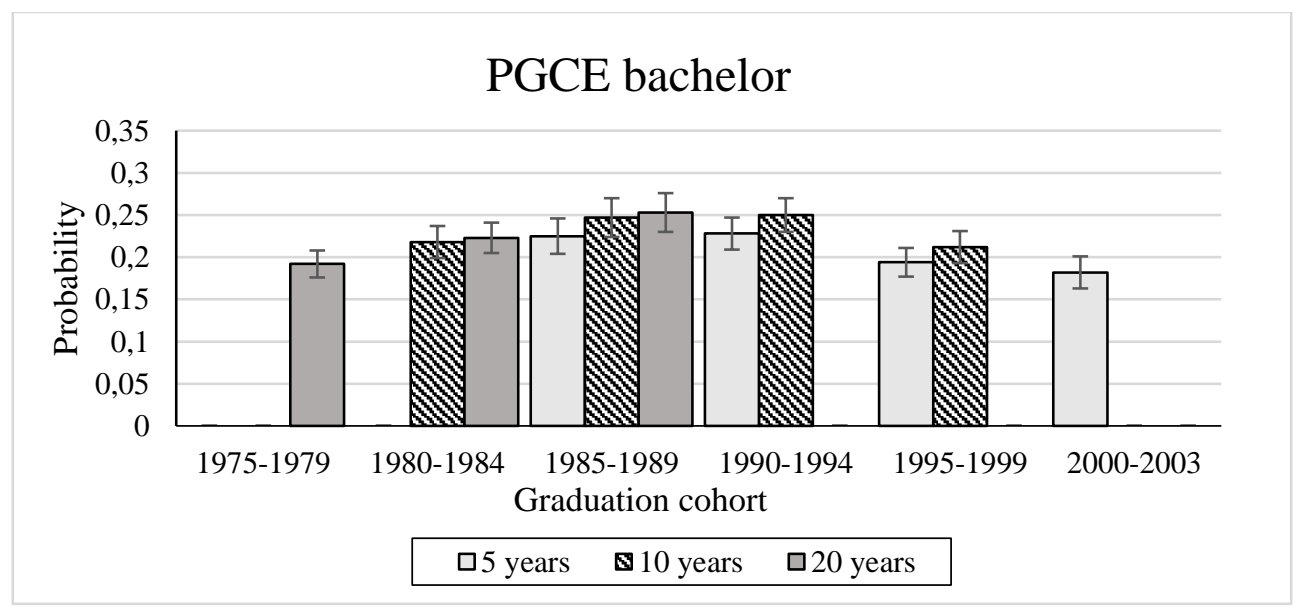

Figure 1. Predicted probability that bachelor's graduates with postgraduate teacher education (PGCE) are not employed in the school sector, by graduation cohort at 5, 10, and 20 years after graduation. 95\% CI error bars 


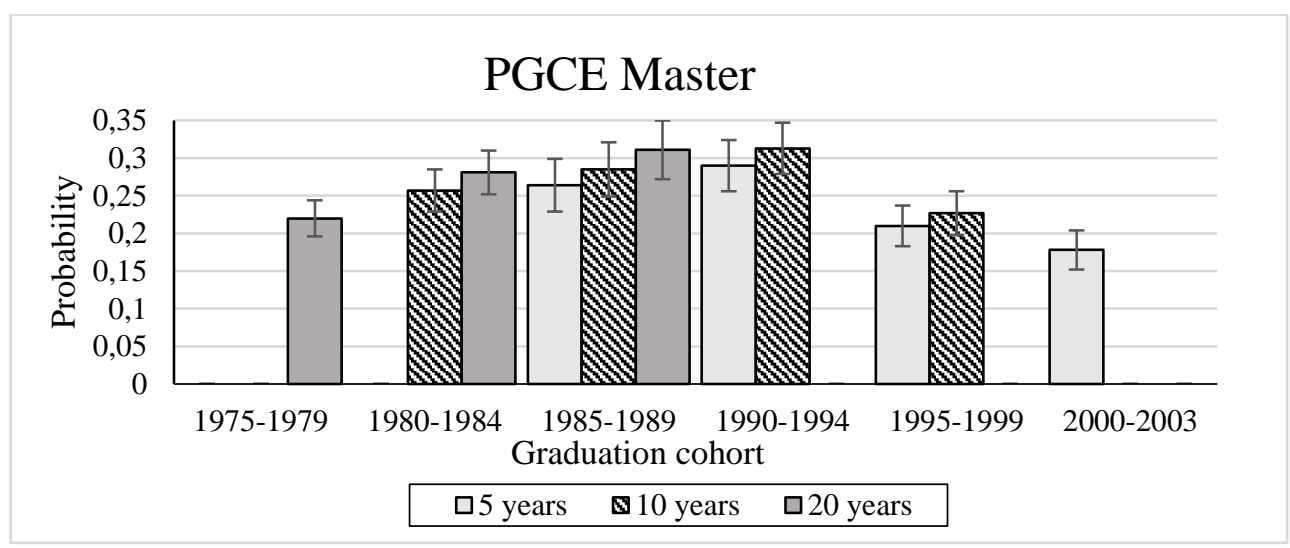

Figure 2. Predicted probability that master's graduates with postgraduate teacher education (PGCE) are not employed in the school sector, by graduation cohort, at 5, 10, and 20 years after graduation. 95\% CI error bars

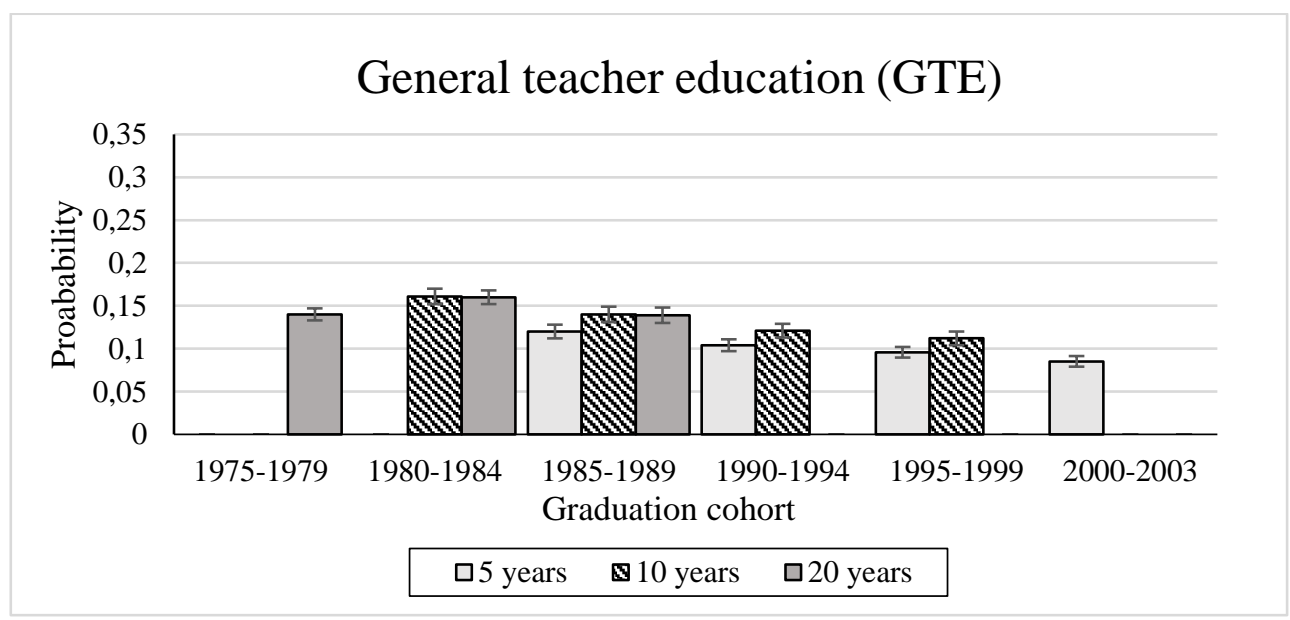

Figure 3. Predicted probability that General teacher education (GTE) graduates are not employed in the school sector, by graduation cohort, at 5, 10, and 20 years after graduation. $95 \%$ CI error bars

Between $18 \%$ and $25 \%$ of PGCE graduates with qualifications at the bachelor's level were not employed in the school sector (Figure 1). Of individuals who graduated between 1975 and 1979, 19\% were not employed in the school sector 20 years later. In the 1980's cohorts, the proportions outside teaching 20 years after graduation were somewhat higher (at $22 \%$ and $25 \%$ ), whereas attrition is somewhat lower among PGCE bachelor's degree-holders graduating between 1995 and 1999. In this cohort, $21 \%$ had left teaching within ten years, compared with $25 \%$ in the late 1980 s/early 1990s. These differences across cohorts are statistically significant, although not very large.

Figure 2 shows a similar trend among PGCE graduates with qualifications at the master's level: attrition increased significantly from the cohorts graduating in the late 1970 s to the late 1980 s and early 1990 s cohorts. From the early to late 1990 s, attrition levels declined (from $31 \%$ to $23 \%$, measured 10 years after graduation).

Figure 3 shows results for GTE graduates. Attrition in this group is lower, with levels varying between 9\% and 16\%. Attrition increased somewhat from the 1970s to early 1980 s cohorts, but subsequently, there was a steady trend toward lower attrition. Moreover, among GTE teachers, attrition appears to have been even lower in 
the 1990s than in the late 1970s, but some caution is necessary when comparing these cohorts, as they were not observed at the same career stages.

Generally, attrition was somewhat higher among master's graduates than among bachelor's graduates, and higher for teachers with a PGCE compared with teachers holding a GTE. This is in line with previous research and the predictions of human capital theories; teachers with credentials that are attractive in the labour market have a higher risk of leaving. However, in the most recent cohorts, there was no significant difference in attrition levels of bachelor and master's graduates. Differences within cohorts between five and 20 years after graduation were generally small, supporting findings in previous research that most attrition occurs in early and late career stages.

The effects of control variables were in line with findings in previous research (see Table A1). Being male, holding a social science, science or master's degree and residing in a central area are factors associated with a higher risk of leaving.

To examine how selection into teacher education affects attrition, the same analyses were conducted without control variables, and with a detailed subject of study variable and GPA (PGCE graduates only). These models yielded very similar results, suggesting that demographic variations or changes in selectivity of teacher education did not drive the results. The analyses with higher education GPA showed that the highest-performing PGCE graduates had a higher risk of leaving the teaching profession in all cohorts.

In summary, results from the cohort analyses showed no evidence of a trend toward higher teacher attrition. Although attrition was higher among graduates in the 1980 s than among teachers graduating in the late 1970s, attrition declined in subsequent cohorts. These patterns may reflect a decreased transferability of teacher credentials. For PGCE graduates, there was a decline in attrition from the mid-1990s. In 1994, the PGCE course was extended from one to two semesters. One possible explanation for the observed change is that the extension affected selection into PGCE training programs and that graduates in subsequent years differed from peers in previous cohorts in terms of motivation. For instance, the increased investment costs may have reduced the appeal of this program among graduates who see teaching as a fallback career.

\section{Attrition to other employment}

The subsequent analyses examine whether attrition to other types of employment has increased. In the cohort models, no distinction was made between this and attrition to non-employment. Moreover, the attrition levels included teachers who may never have worked as teachers. Because working conditions likely are more important for individuals with teaching experience, the following analyses compare annual attrition rates for different time periods, for teachers in different career stages, and for teachers employed at different school levels.

As reduced demand in the non-school labour market may have led to lower overall attrition, particular interest is directed toward differences between teachers employed in school levels that were unequally affected by the recent educational reform. Here, teacher education is included as a control variable, thus comparing teachers with similar training in different school levels. 


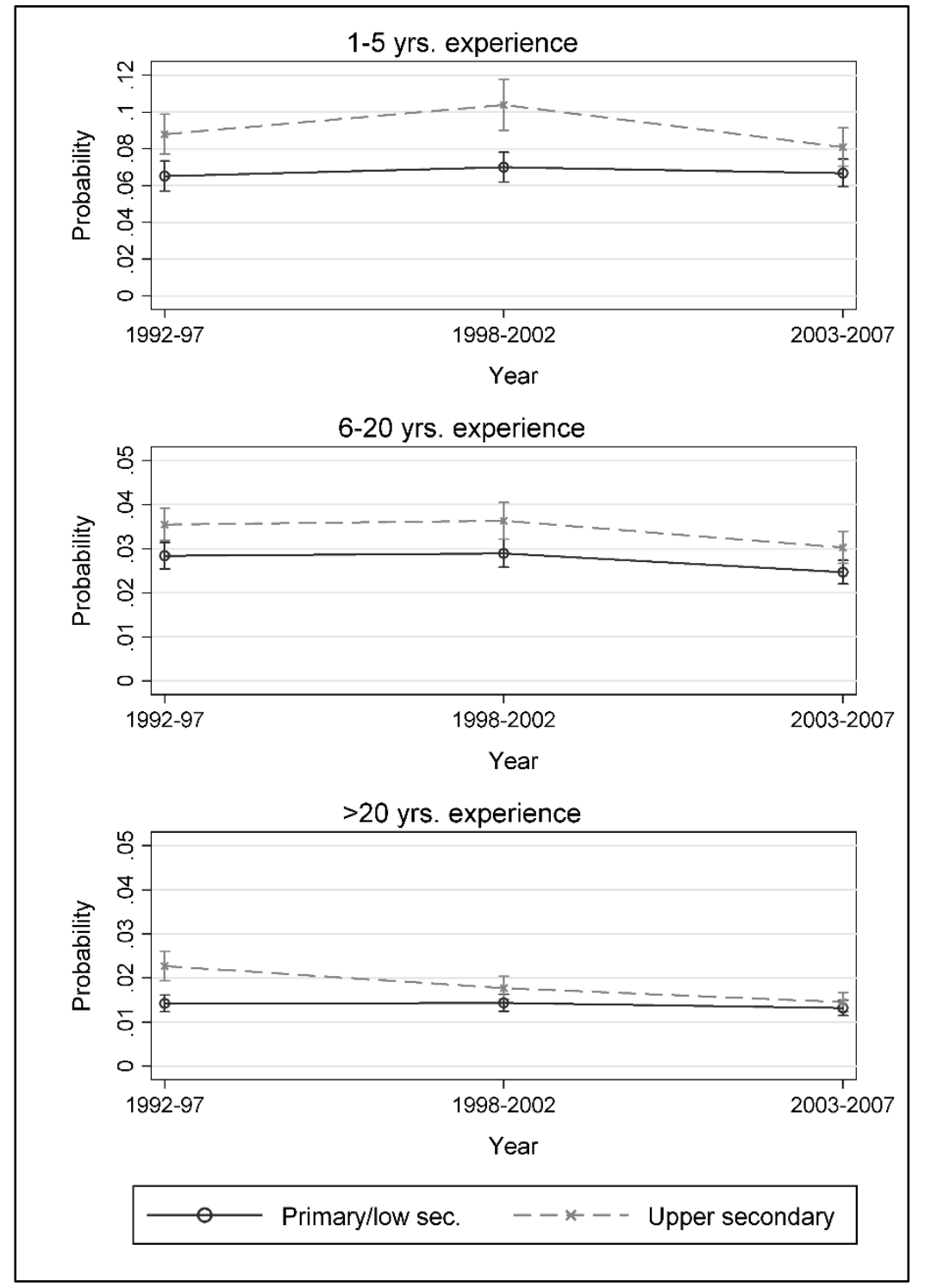

Figure 4. Annual attrition rates, exits to other employment (employment-exits), by school level in a previous year, time period, and career stage. 95\% CI error bars. Predicted for female, no children $<8$, bachelor's graduate in humanities with PGCE, no further education, residing in central municipality, aged 35 (1-5 years' experience), 45 (6-20 years' exp.) or 55 (>20 years' exp.)

Figure 4 shows exits to other employment among teachers in three time periods: 1992-1997, 1998-2002, and 2003-2007 (along the x-axes). ${ }^{8}$ Among early-career teachers, yearly attrition varied between $8 \%$ and $10 \%$ for upper secondary teachers and was approximately $7 \%$ for teachers in lower school levels. In the first two time periods, attrition levels were higher for upper secondary teachers, but in 2003-2007, the difference between school levels was smaller and not significant.

Among mid-career teachers (six to 20 years' experience), annual attrition was much lower, between $2 \%$ and $4 \%$. Attrition declined slightly in the last time period, and, although small, this difference is statistically significant (see Table A2). As

\footnotetext{
${ }^{8}$ Models with dummies for each year were also conducted; however, both graphs and regression tables are difficult to interpret making it more difficult to spot trends. Nevertheless, the main conclusions drawn from these analyses are the same as those presented in Figure 4.
} 
among early-career teachers, those employed in primary/lower secondary are less prone to leave than upper secondary teachers.

Among late-career teachers ( $>20$ years' experience), annual attrition to other employment was only $1 \%$ to $2.5 \%$. Whereas attrition levels were relatively stable over time for teachers employed in lower school levels, attrition decreased among experienced upper secondary teachers.

In line with previous research, attrition to other employment was highest among inexperienced teachers. Early-career attrition may represent a selection out of the profession of individuals who do not succeed as teachers. However, this finding also reflects the lower levels of job security facing recent graduates, not least because attrition here included teachers leaving to teach at a different school level. For latecareer teachers, exits to other employment were quite rare. This is not surprising, given that these teachers are a select group, who thus far have stayed in the profession. Moreover, seniors often face greater difficulties in the labour market, and the costs of changing careers are likely higher after teachers settle into their professional roles.

\section{Exits from the labour market}

If alternative employment opportunities are reduced, this could drive increasing numbers of teachers to leave the labour market altogether. In particular, experienced teachers may become more inclined toward entering early retirement. Figure 5 shows attrition to non-employment by age for teachers in each school level, with separate graphs referring to different time periods. For all three periods, annual exit rates were low for teachers aged 60 years or younger. Attrition to non-employment increases sharply as teachers enter their 60s. Moreover, it is clear that the reduction of the early-retirement age in 1997/1998 affected attrition levels. For the first period (1992-1997), exits from the labour market were rare among teachers younger than 65 years. At 65 years, attrition increased sharply; $20 \%$ to $25 \%$ of teachers exited the labour market at this age, and $40 \%$ of the remaining teachers left at the age of 66 years ${ }^{9}$. Exit rates were somewhat lower among upper secondary teachers than among teachers employed in primary/lower secondary schools.

For the two later time periods, the risk of leaving employment was similar to that of the first time period until teachers reached the age of 63 years. However, after opportunities for early retirement improved in the late 1990s, there was a marked increase in exits among teachers aged 62 to 64 years. In 1998-2002 and 2003-2007, $25 \%$ of teachers employed in lower school levels and approximately $15 \%$ of teachers employed in upper secondary schools exited the labour market at the age of 63 years, compared with $2 \%$ in 1992-1997. Furthermore, approximately $15 \%$ of the remaining primary/lower secondary teachers and $20 \%$ of upper secondary teachers retired at age 64 . The corresponding rates for the first period were $4 \%$ and $6 \%$.

${ }^{9}$ Note that these results refer to annual attrition and not to cumulative attrition. 


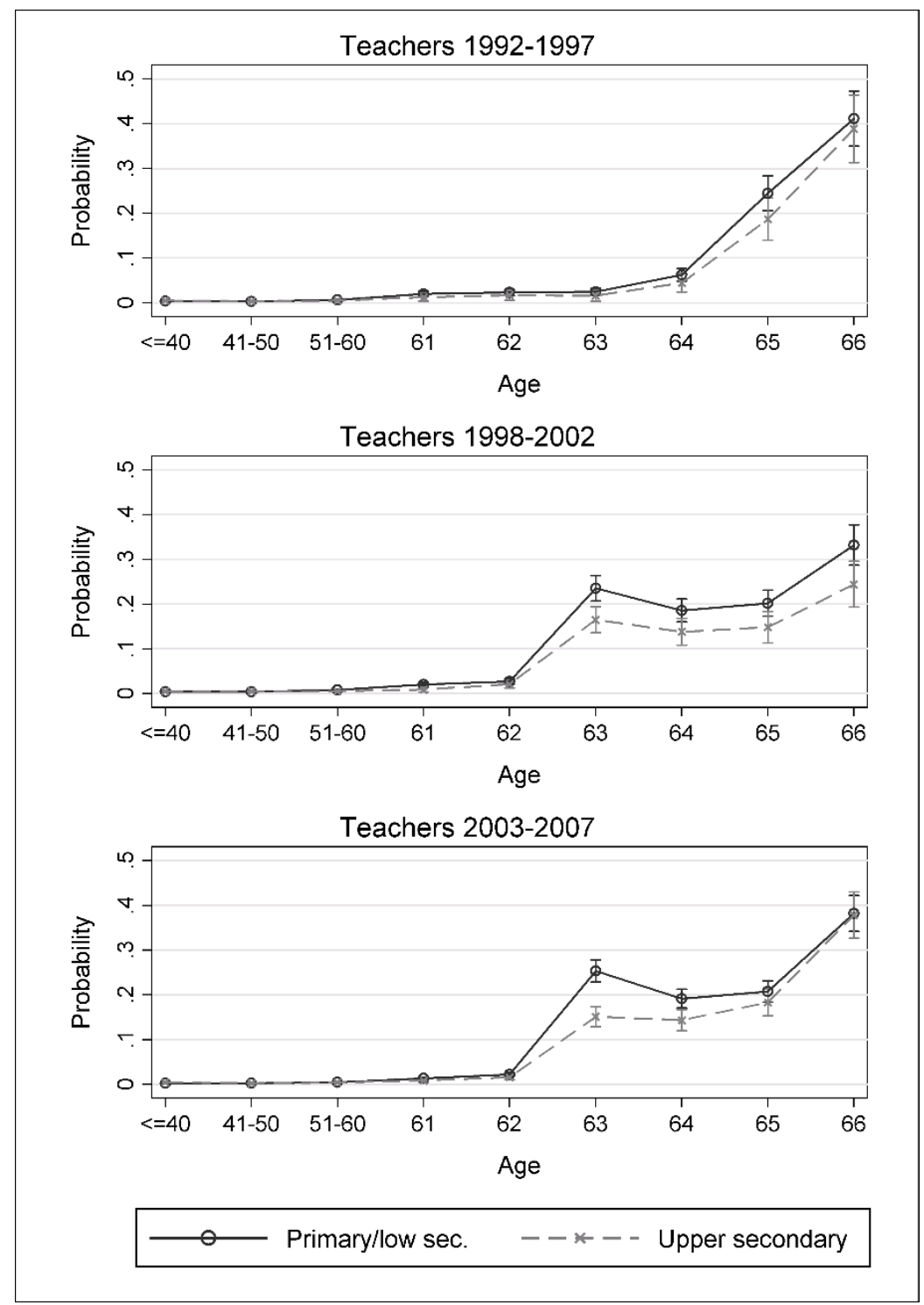

Figure 5. Annual attrition rates, exits to non-employment (retirement-exits), by school level in a previous year, time period, and age. 95\% CI error bars. Predicted for female, no children $<8$, bachelor's graduate in humanities with PGCE, no further education, residing in central municipality

In summary, in all time periods, early exits from the labour market were more common among primary/lower secondary teachers than among upper secondary teachers. This difference was more marked after the retirement age was reduced.

\section{Discussion and conclusion}

Despite widespread concerns for teacher attrition in relation to what has been termed the intensification thesis (Van Droogenbroeck \& Spruyt, 2014; Webb et al., 2004), there are few comprehensive studies on changes in attrition patterns of teachers over time. This paper, therefore, makes an important contribution in terms of examining broader attrition patterns over a relatively long time span. The first question raised was whether attrition is higher in recent cohorts graduating from teacher education compared with previous cohorts. 
The analyses showed that attrition from the teaching profession was somewhat higher in cohorts graduating in the 1980s compared with cohorts graduating in the late 1970s, but that attrition declined in later cohorts. The general pattern was similar across teachers with different types of teacher education. For GTE teachers, attrition was at the highest in the early 1980s. It is important to note that this was a period characterized by relatively low demand for teachers and high demand in other sectors. In the late 1980s, Norway experienced a recession and unemployment increased. As this limited the opportunities for leaving, it is not surprising that attrition levels among GTE teachers declined. For PGCE graduates, there was no similar decline in attrition patterns during the recession years. However, the short duration of the PGCE means that graduates in this period also entered this course during the recession. That is, the higher risk of unemployment may also have increased recruitment to PGCE courses among graduates with relatively low motivation for teaching.

In the mid-1990s, after the PGCE was extended from one to two semesters, there was a decline in attrition among PGCE graduates. This may be related to differences in selection, as motivation for teaching may be higher among those entering this course after the costs associated with PGCE increased. However, for both PGCE and GTE teachers, there was an indication of a further decline in attrition in recent cohorts. This supports the assumption of a decrease in the transferability of teachers' human capital to non-school employment. It is also possible that students' knowledge about labour market conditions affects recruitment to teacher education and that recent graduates less often view teaching as a fallback career. In summary, the results from the cohort analyses suggest that changes in labour market opportunities have a greater impact on teacher attrition levels than changes in intrinsic rewards do.

Whereas cohort attrition is sensitive to the conditions in the labour market at the time of graduation, differences in annual attrition rates can give a clearer picture of how changes in teachers' working conditions may have affected attrition for specific time periods. Because working conditions changed more in lower school levels, it was suggested that we would find evidence of increased attrition from primary/lower secondary schools compared with that from upper secondary schools. Based on previous research stating that late-career teachers are more negative toward educational change, it was expected that "intensification" would contribute to a particular increase in attrition in this group.

The analyses of annual attrition lend some support to these assumptions. Although overall attrition to other employment decreased between 1992 and 2007, attrition among teachers in lower school levels increased somewhat relative to upper secondary teachers. Attrition to other employment is generally higher for upper secondary teachers, but this difference declined over time, particularly among late-career teachers. Moreover, although early retirement increased markedly among teachers in both school levels after the retirement age was lowered in the late 1990s, this increase was largest in lower school levels. However, there is no evidence of a further increase in early retirement after the introduction of accountability policies around 2004. One explanation for this may be that these policies did not stand out in terms of contributing to increasing teachers' motivation for leaving the profession. Rather, it could be that earlier educational reforms have had a similar impact on (experienced) teachers' motivation to leave. It may also be that working in lower school levels is more physically and emotionally demanding, leading to more teachers at this level taking advantage of the opportunity for early retirement when available.

Overall, it is not clear that intensification has led to higher attrition. Several factors may contribute to this. First, it is possible that other factors such as economic incentives and the availability of attractive alternative employment opportunities play a larger role in teachers' decisions to remain in or leave the profession. Second, it may be that, although teaching is changing, not all change is for the worse. Although frequently understood as symptoms of deterioration and deprofessionalization 
of teacher work, increasing responsibilities and demands may also be understood as increasing professionalization, making teaching more complex and skilled (Hargreaves, 1994). A development toward more collaborative teaching cultures potentially promotes teacher retention, as teachers may receive more social support.

The attrition rates reported here are relatively low compared with attrition levels reported in countries such as the United Kingdom and the United States, from which much of the attrition literature originates. Although heightened demands, increasing accountability, more "social work," and growing amounts of paperwork seem to be fairly universal descriptions of how teachers' work has changed in recent decades, the timing and degree of change vary between countries (Hargreaves, 1994; Webb et al., 2004). In Norway, accountability policies were introduced later than in many other countries. Moreover, these policies have limited consequences for teachers compared with more "high-stakes" policies in some countries. An additional aspect characterizing school employment in Norway is a relatively high level of flexibility. Good opportunities for part-time work and partial retirement are likely to contribute to lower levels of exits from the labour market.

As there is a lack of systematic analyses of changes in teacher attrition, it is difficult to compare the findings in this paper with results from previous research. Similar studies from countries with more high-stakes accountability regimes, where data are available for more comprehensive examinations of attrition patterns over time, would improve the understanding of the relationship between intensification of teachers' work and teacher attrition. Furthermore, although increasing overeducation among higher education graduates is a tendency observed in several countries, differences in labour markets, economic conditions and relative pay may lead to different attrition patterns in different national contexts.

Although the observed trends indicate that intensification has not resulted in an increase in attrition, other parallel changes may have affected attrition in a reverse manner, preventing the detection of such patterns. The analytical design of this paper does not allow for firm causal interpretation. However, alternative explanations have been explored, by examining both attrition to non-employment and other employment, and by comparing teachers who were differently affected by educational reforms. Nevertheless, further research is needed to draw conclusions about the relationship between teachers' working conditions and attrition.

A further limitation of this paper is that labour market outcomes were observed only until 2008 when accountability policies were still quite recent. If the process leading from dissatisfaction with working conditions to attrition develops over longer time periods, it may be too soon to examine the full effects of such policies on attrition. It is also worth asking whether low attrition in the face of increasing demands is entirely good news. Because the demand for teachers is high and teacher turnover causes instability in schools, it is generally desirable that teachers stay in the profession. However, if teachers are increasingly discontent and motivated to leave, but do not see the opportunity to do so, their job engagement could decline, ultimately decreasing the quality of schooling.

\section{Acknowledgments}

The author wishes to thank Håvard Helland, Arne Mastekaasa, the research seminar participants at the Centre for the Study of Professions, and three anonymous referees for providing insightful comments on earlier drafts of this paper. 


\section{References}

Aanensen, T. (2010). Lønnsutvikling for ansatte i skoleverket 1959-2008 [Wage development for employees in the school system 1959-2008]. Samfunnsøkonomen, 64(1), 4-11.

Apple, M. W. (1986). Teachers and texts: A political economy of class and gender relations in education. London: Routledge.

Arnesen, C. Å. (2002). Flukt fra laerer og forskolelareryrket? [Flight from teaching?] (NIFUs skriftserie 8/02). Oslo: Nordic Institute for Studies of Innovation, Research and Education (NIFU).

Ballet, K., \& Kelchtermans, G. (2009). Struggling with workload: Primary teachers' experience of intensification. Teaching and Teacher Education, 25(8), 1150-1157. https://doi.org/10.1016/j.tate.2009.02.012

Barone, C., \& Ortiz, L. (2011). Overeducation among European University Graduates: A comparative analysis of its incidence and the importance of higher education differentiation. Higher Education, 61(3), 325-337. https://doi.org/10.1007/s10734-010-9380-0

Becker, G. S. (1993). Human capital: A theoretical and empirical analysis, with special reference to education (3rd ed.). Chicago, Ill.: NBER. https://doi.org/10.7208/chicago/9780226041223.001.0001

Borman, G. D., \& Dowling, N. M. (2008). Teacher attrition and retention: A metaanalytic and narrative review of the research. Review of Educational Research, 78(3), 367-409. https://doi.org/10.3102/0034654308321455

Caspersen, J., Aamodt, P. O., Vibe, N., \& Carlsten, T. C. (2014). Kompetanse og praksis blant norske larere: Resultater fra TALIS-unders $\phi$ kelsen $i 2013$ [Competence and practice among Norwegian teachers: Results from TALIS 2013]. Oslo: Nordic Institute for Studies of Innovation, Research and Education (NIFU).

Chevalier, A., Dolton, P., \& McIntosh, S. (2007). Recruiting and retaining teachers in the UK: an analysis of graduate occupation choice from the 1960s to the 1990s. Economica, 74(293), 69-96. https://doi.org/10.1111/j.14680335.2006.00528.x

Fladmoe, A., \& Leiulfsrud, H. (2013). How teachers experience the opinion climate on education in Norway and Finland. Nordic Studies in Education, 32(03-04), 159-176.

Gail, M. H., Wieand, S., \& Piantadosi, S. (1984). Biased estimates of treatment effect in randomized experiments with nonlinear regressions and omitted covariates. Biometrika, 71(3), 431-444. https://doi.org/10.1093/biomet/71.3.431

Grissmer, D. W., \& Kirby, S. N. (1992). Patterns of attrition among Indiana teachers, 1965-1987. Santa Monica, CA: Rand.

Guarino, C. M., Santibanez, L., \& Daley, G. A. (2006). Teacher recruitment and retention: a review of the recent empirical literature. Review of Educational Research, 76(2), 173-208. https://doi.org/10.3102/00346543076002173

Hargreaves, A. (1994). Changing teachers, changing times: Teachers' work and culture in the postmodern age. London: Cassell.

Hargreaves, A. (2005). Educational change takes ages: Life, career and generational factors in teachers' emotional responses to educational change. Teaching and Teacher Education, 21(8), 967-983. https://doi.org/10.1016/j.tate.2005.06.007

Harris, D. N., \& Adams, S. J. (2007). Understanding the level and causes of teacher turnover: A comparison with other professions. Economics of Education Review, 26(3), 325-337. https://doi.org/10.1016/j.econedurev.2005.09.007 
Hatch, T. (2013). Beneath the surface of accountability: Answerability, responsibility and capacity-building in recent education reforms in Norway. Journal of Educational Change, 14(2), 113-138. https://doi.org/10.1007/s10833-012-9206-1

Hedström, P. (2005). Dissecting the Social: Social Mechanisms and the Principles of Analytical Sociology. Cambridge: Cambridge University Press. https://doi.org/10.1017/CBO9780511488801

Høgsnes, G. (2000). Lønnsutvikling for ansatte i skoleverket [Wage development for employees in the school system]. Søkelys på arbeidsmarkedet, 17(1), 77-87.

Imsen, G., \& Volckmar, N. (2014). The Norwegian school for all: Historical emergence and neoliberal confrontation. In U. Blossing, G. Imsen \& L. Moos (Eds.), The Nordic Education Model (Vol. 1, pp. 35-55). The Netherlands: Springer Netherlands. https://doi.org/10.1007/978-94-007-7125-3_3

Ingersoll, R., Merrill, L., \& Stuckey, D. (2014). Seven trends: The transformation of the teaching force. CPRE Research Reports (4/2014). Retrieved from http://www.cpre.org/7trends

Kyriacou, C., \& Kunc, R. (2007). Beginning teachers' expectations of teaching. Teaching and Teacher Education, 23(8), 1246-1257. https://doi.org/10.1016/j.tate.2006.06.002

Lindqvist, P., Nordanger, U. K., \& Carlsson, R. (2014). Teacher attrition the first five years - A multifaceted image. Teaching and Teacher Education, 40, 94103. https://doi.org/10.1016/j.tate.2014.02.005

Luekens, M. T., Lyter, D. M., \& Fox, E. E. (2004). Teacher Attrition and Mobility: Results from the Teacher Follow-Up Survey, 2000-01. Washington, DC: Department of Education.

Maskit, D. (2011). Teachers' attitudes toward pedagogical changes during various stages of professional development. Teaching and Teacher Education, 27(5), 851-860. https://doi.org/10.1016/j.tate.2011.01.009

Mastekaasa, A. (2011). Brain drain? Recruitment and retention of high quality teachers in Norway. Oxford Review of Education, 37(1), 53-74.

https://doi.org/10.1080/03054985.2010.527730

Mausethagen, S. (2013a). Accountable for what and to whom? Changing representations and new legitimation discourses among teachers under increased external control. Journal of Educational Change, 14(4), 423-444. https://doi.org/10.1007/s10833-013-9212-y

Mausethagen, S. (2013b). A research review of the impact of accountability policies on teachers' workplace relations. Educational Research Review, 9, 1633. https://doi.org/10.1016/j.edurev.2012.12.001

Norwegian Ministry of Education. (1999). St.meld. nr 12 (1999-2000): ... og yrke skal båten bera... Handlingplan for rekruttering til laeraryrket [Action plan for recruitment to teaching]. Oslo: Norwegian Ministry of Education.

Norwegian Ministry of Education and Research. (2009). Rapport fra tidsbrukutvalget [Report from the time-use commission] Oslo: Norwegian Ministry of Education and Research.

OECD. (2005). Teachers matter: Attracting, developing and retaining effective teachers. Paris: OECD.

Opheim, V. (2004). Like muligheter, men ulikt utbytte? Betydning av sosial bakgrunn for overgang fra utdanning til arbeid blant nyutdannede kandidater $i$ perioden 1987-2001 [Equal opportunities, unequal outcomes? The impact of social background for the transition from education to work among recent graduates 1987-2001]. Oslo: Nordic Institute for Studies of Innovation, Research and Education (NIFU). 
Pomaki, G., DeLongis, A., Frey, D., Short, K., \& Woehrle, T. (2010). When the going gets tough: Direct, buffering and indirect effects of social support on turnover intention. Teaching and Teacher Education, 26(6), 1340-1346. https://doi.org/10.1016/j.tate.2010.03.007

Purcell, K., Wilton, N., Davies, R., \& Elias, P. (2005). Education as a graduate career: Entry and exit from teaching as a profession. London: Department for Education and Skills.

Roness, D., \& Smith, K. (2009). Postgraduate Certificate in Education (PGCE) and student motivation. European Journal of Teacher Education, 32(2), 111-134. https://doi.org/10.1080/02619760902778982

Rovde, O. (2004). Vegar til samling: Norsk laerarlags historie 1966-2001 [History of the Norwegian teachers' union 1966-2001]. Oslo: Samlaget.

Schøne, P. (1999). Rekruttering av nyutdannede til undervisningssektoren-hva betyr lønn? [Recruitment of recent graduates to the education sector - what is the importance of pay?]. Søkelys på arbeidsmarkedet, 99(16), 159-164.

Skaalvik, E. M., \& Skaalvik, S. (2010). Utfordringer i lærerrollen [Challenges to the teacher role]. In R.-A. Andreassen, E. J. Irgens \& E. M. Skaalvik (Eds.), Kompetent skoleledelse. Trondheim: Tapir akademisk forlag.

Skaalvik, E. M., \& Skaalvik, S. (2011). Teacher job satisfaction and motivation to leave the teaching profession: Relations with school context, feeling of belonging, and emotional exhaustion. Teaching and Teacher Education, 27(6), 1029-1038. https://doi.org/10.1016/j.tate.2011.04.001

Smethem, L. (2007). Retention and intention in teaching careers: will the new generation stay? Teachers and Teaching: theory and practice, 13(5), 465-480. https://doi.org/10.1080/13540600701561661

Smithers, A., \& Robinson, P. (2005). Teacher turnover, wastage and movements between schools. London: Department for Education and Skills.

Snartland, V., \& Øverbye, E. (2003). Skal jeg bli eller skal jeg gå? Pensjonsforventninger hos laerere og ingeniфrer [Should I stay or should I go? Retirement prospects among teachers and engineers]. Oslo: Norwegian Social Research (NOVA).

Stinebrickner, T. R. (1998). An empirical investigation of teacher attrition. Economics of Education Review, 17(2), 127-136. https://doi.org/10.1016/S0272-7757(97)00023-X

Stinebrickner, T. R. (2002). An analysis of occupational change and departure from the labor force - Evidence of the reasons that teachers leave. Journal of Human Resources, 37(1), 192-216. https://doi.org/10.2307/3069608

Struyven, K., \& Vanthournout, G. (2014). Teachers' exit decisions: An investigation into the reasons why newly qualified teachers fail to enter the teaching profession or why those who do enter do not continue teaching. Teaching and Teacher Education, 43, 37-45. https://doi.org/10.1016/j.tate.2014.06.002

Støren, L. A. (2014). Fører "mastersyke" til overutdanning? Om overgang fra studier til arbeidsliv [Does "master's inflation" lead to overeducation? On the transition from education to work]. In N. Frølich, E. Hovdhaugen \& L. I. Terum (Eds.), Kvalitet, kapasitet og relevans: Utviklingstrekk i norsk høyere utdanning (pp. 288-311). Oslo: Cappelen Damm akademisk.

Turmo, A., \& Aamodt, P. O. (2009). Forskjeller i lærerkompetanse i vidergående skole: Konsekvenser for elevenes læringsutbytte? [Differences in teachers' competences in upper secondary schools: Consequences for student outcomes?] Norsk pedagogisk tidsskrift, 93(2), 122-134. 
Tveit, S. (2014). Educational assessment in Norway. Assessment in Education: Principles, Policy \& Practice, 21(2), 221-237. https://doi.org/10.1080/0969594X.2013.830079

van Droogenbroeck, F., \& Spruyt, B. (2014). To stop or not to stop: An empirical assessment of the determinants of early retirement among active and retired senior teachers. Research on Aging, 36(6), 753-777. https://doi.org/10.1177/0164027513519449

Watt, H. M., Richardson, P. W., Klusmann, U., Kunter, M., Beyer, B., Trautwein, U., \& Baumert, J. (2012). Motivations for choosing teaching as a career: An international comparison using the FIT-Choice scale. Teaching and Teacher Education, 28(6), 791-805. https://doi.org/10.1016/j.tate.2012.03.003

Webb, R., Vulliamy, G., Hämäläinen, S., Sarja, A., Kimonen, E., \& Nevalainen, R. (2004). Pressures, rewards and teacher retention: A comparative study of primary teaching in England and Finland. Scandinavian Journal of Educational Research, 48(2), 169-188. https://doi.org/10.1080/0031383042000198530

Zou, G. (2004). A modified poisson regression approach to prospective studies with binary data. American Journal of Epidemiology, 159(7), 702-706. https://doi.org/10.1093/aje/kwh090 


\section{Appendix}

Table A1

Cohort attrition. Poisson regression with cluster robust SE, exponentiated coefficients. Dependent variable: Not employed in school-sector. Reference is 1975-1979 graduation cohort, male, no children under 8 , residing in low centrality region, not in further education, humanities graduate (PGCE), bachelor's degree (PGCE bachelor /GTE).

\begin{tabular}{|c|c|c|c|c|c|c|}
\hline & \multicolumn{2}{|c|}{ PGCE Bachelor } & \multicolumn{2}{|c|}{ PGCE Master } & \multicolumn{2}{|c|}{ GTE } \\
\hline 1980-1984 & $1.162^{* * *}$ & {$[1.070,1.263]$} & $1.278^{* * *}$ & {$[1.162,1.405]$} & $1.140 * * *$ & {$[1.080,1.204]$} \\
\hline 1985-1989 & $1.316^{* * *}$ & {$[1.204,1.440]$} & $1.416^{* * *}$ & {$[1.258,1.593]$} & 0.988 & {$[0.926,1.054]$} \\
\hline 1990-1994 & $1.335^{* * *}$ & {$[1.229,1.451]$} & $1.556^{* * *}$ & {$[1.404,1.724]$} & $0.856 * * *$ & {$[0.801,0.914]$} \\
\hline 1995-1999 & $1.134^{* *}$ & {$[1.031,1.247]$} & 1.125 & {$[0.994,1.274]$} & $0.790 * * *$ & {$[0.738,0.846]$} \\
\hline $2000-2005$ & 1.061 & {$[0.949,1.188]$} & 0.955 & {$[0.820,1.112]$} & $0.703^{* * *}$ & {$[0.647,0.763]$} \\
\hline Time ${ }^{1)}$ & $1.018^{* * *}$ & {$[1.010,1.026]$} & $1.016^{* *}$ & {$[1.006,1.025]$} & $1.031 * * *$ & {$[1.023,1.039]$} \\
\hline Time 2) & $0.985^{* *}$ & {$[0.975,0.994]$} & 0.993 & {$[0.982,1.005]$} & $0.969 * * *$ & {$[0.960,0.979]$} \\
\hline Female & $0.898 * * *$ & {$[0.846,0.954]$} & $0.871^{* * *}$ & {$[0.805,0.942]$} & $0.628 * * *$ & {$[0.598,0.659]$} \\
\hline Child<1 & 1.019 & {$[0.944,1.100]$} & $1.175^{* * *}$ & {$[1.077,1.283]$} & $0.865^{* * *}$ & {$[0.814,0.921]$} \\
\hline Child 1-3 & 1.059 & {$[0.990,1.134]$} & $1.139 * *$ & {$[1.053,1.232]$} & $0.882^{* * *}$ & {$[0.834,0.932]$} \\
\hline Child 4-7 & 0.992 & {$[0.933,1.055]$} & $1.082^{*}$ & {$[1.013,1.155]$} & $0.924 * *$ & {$[0.880,0.971]$} \\
\hline Female $X$ Child $<1$ & 0.965 & {$[0.867,1.073]$} & 0.914 & {$[0.796,1.049]$} & $1.188^{* * *}$ & {$[1.096,1.287]$} \\
\hline Female X Child 1-3 & $0.909 *$ & {$[0.827,0.998]$} & 0.986 & {$[0.878,1.108]$} & $1.382^{* * *}$ & {$[1.288,1.482]$} \\
\hline Female X Child 4-7 & 0.919 & {$[0.841,1.004]$} & 0.91 & {$[0.819,1.010]$} & 0.998 & {$[0.934,1.066]$} \\
\hline Age graduation & $0.991^{* * *}$ & {$[0.986,0.995]$} & $0.989 * *$ & {$[0.982,0.997]$} & $0.985^{* * *}$ & {$[0.981,0.990]$} \\
\hline In furth. educ. & $1.212^{* * *}$ & {$[1.162,1.265]$} & $1.296 * * *$ & {$[1.218,1.378]$} & $1.172^{* * *}$ & {$[1.132,1.215]$} \\
\hline Centrality lev. 2 & 1.129 & {$[0.963,1.322]$} & $1.335^{*}$ & {$[1.017,1.752]$} & 1.053 & {$[0.963,1.152]$} \\
\hline Centrality lev. 3 & $1.155^{*}$ & {$[1.011,1.318]$} & $1.364^{* *}$ & {$[1.094,1.700]$} & 1.053 & {$[0.977,1.135]$} \\
\hline Centrality lev. 4 & $1.372^{* * *}$ & {$[1.224,1.537]$} & $1.634^{* * *}$ & {$[1.341,1.992]$} & $1.245^{* * *}$ & {$[1.166,1.330]$} \\
\hline Centrality lev. 5 & $1.898 * * *$ & {$[1.702,2.117]$} & $2.325^{* * *}$ & {$[1.918,2.820]$} & $1.797^{* * *}$ & {$[1.682,1.919]$} \\
\hline Social science & $1.293 * * *$ & {$[1.217,1.374]$} & $1.727^{* * *}$ & {$[1.571,1.900]$} & & \\
\hline Science & $1.242^{* * *}$ & {$[1.161,1.328]$} & $1.486^{* * *}$ & {$[1.384,1.596]$} & & \\
\hline Master degree & $1.467 * * *$ & {$[1.393,1.544]$} & & & $2.289 * * *$ & {$[2.170,2.414]$} \\
\hline Observations & 93009 & & 38027 & & 316378 & \\
\hline $\mathrm{N}$ Individuals & 11637 & & 4948 & & 40440 & \\
\hline Log lik. & -61704 & & -28487 & & -147166 & \\
\hline Chi2 & 1146.861 & & 826.104 & & 3546.528 & \\
\hline$p$ & 0 & & 0 & & 0 & \\
\hline
\end{tabular}

$95 \%$ confidence intervals in brackets

$* \mathrm{p}<0.05, * * \mathrm{p}<0.01, * * * \mathrm{p}<0.001$

1) Linear time spline 5-10 years since graduation

2) Linear time spline 11-20 years since graduation 
Table A2

Employment-exit. Poisson regression with cluster robust SE, exponentiated coefficients. Dependent variable: Not employed in same school level. Reference is first time-period (1992-1997), GTE graduate, employed in primary/lower secondary, male, no children $<8$, low centrality municipality, not in further education, no master's degree. Separate models for teachers in different career-stages.

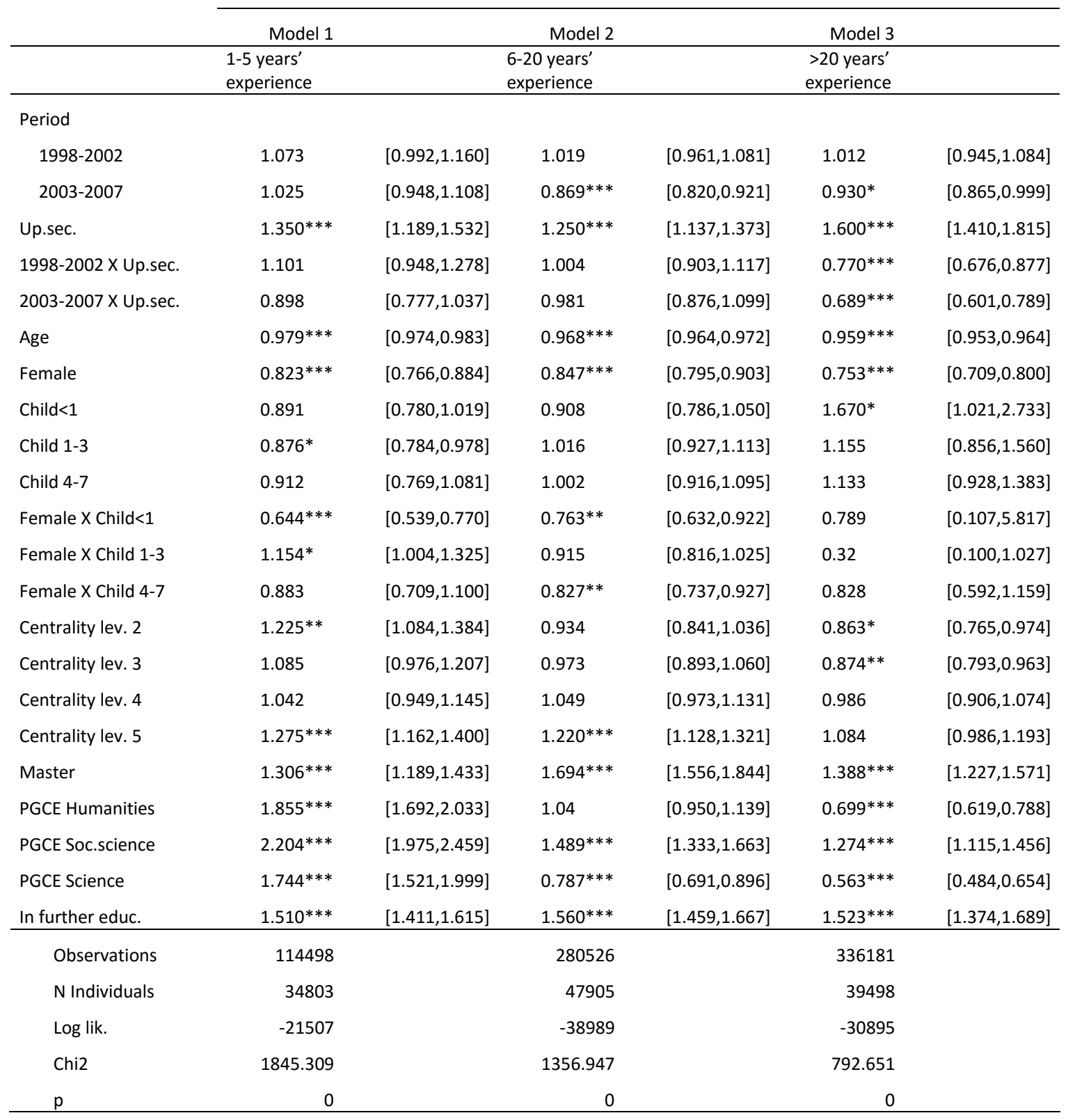

$95 \%$ confidence intervals in brackets

$* \mathrm{p}<0.05, * * \mathrm{p}<0.01, * * * \mathrm{p}<0.001$ 
Table A3

Retirement-exits. Poisson regression with cluster robust SE, exponentiated coefficients. Dependent variable: Not employed. Reference is GTE graduate, age 40 or younger, employed in primary/lower secondary, male, no children $<8$, low centrality municipality, not in further education, no master's degree. Separate models for different time-periods.

\begin{tabular}{|c|c|c|c|c|c|c|}
\hline & \multicolumn{2}{|l|}{ Model 1} & \multicolumn{2}{|l|}{ Model 2} & \multicolumn{2}{|l|}{ Model 3} \\
\hline & 1992- 97 & & 1998-02 & & 2003-2007 & \\
\hline \multicolumn{7}{|l|}{ Age } \\
\hline $41-50$ & $0.810^{* *}$ & {$[0.698,0.940]$} & 1.069 & {$[0.908,1.259]$} & 1.025 & {$[0.814,1.291]$} \\
\hline $51-60$ & $1.584^{* * *}$ & {$[1.352,1.855]$} & $2.118^{* * *}$ & {$[1.814,2.472]$} & $1.631^{* * *}$ & {$[1.332,1.997]$} \\
\hline 61 & $4.896^{* * *}$ & {$[3.642,6.583]$} & $5.014^{* * *}$ & {$[3.920,6.414]$} & $4.770^{* * *}$ & {$[3.655,6.224]$} \\
\hline 62 & $5.605^{* * *}$ & {$[4.159,7.555]$} & $6.783^{* * *}$ & {$[5.370,8.566]$} & $8.062^{* * *}$ & {$[6.377,10.192]$} \\
\hline 63 & $6.005^{* * *}$ & {$[4.433,8.134]$} & $58.263^{* * *}$ & {$[50.263,67.535]$} & $91.199^{* * *}$ & {$[76.576,108.613]$} \\
\hline 64 & $15.114^{* * *}$ & {$[12.114,18.857]$} & $45.991^{* * *}$ & [39.150,54.026] & $68.880^{* * *}$ & {$[57.434,82.606]$} \\
\hline 65 & $59.173^{* * *}$ & {$[50.747,68.998]$} & $49.949^{* * *}$ & {$[42.256,59.044]$} & $74.583^{* * *}$ & {$[61.945,89.798]$} \\
\hline 66 & $99.508^{* * *}$ & {$[86.105,114.998]$} & $82.160^{* * *}$ & {$[70.060,96.349]$} & $137.425^{* * *}$ & {$[114.826,164.472]$} \\
\hline Up.sec. & $1.237^{*}$ & {$[1.012,1.511]$} & $1.427^{* *}$ & {$[1.127,1.806]$} & $1.643^{* * *}$ & {$[1.228,2.199]$} \\
\hline 41-50X Up.sec. & 0.904 & {$[0.678,1.206]$} & 0.827 & {$[0.589,1.159]$} & $0.596^{*}$ & {$[0.363,0.977]$} \\
\hline 51-60X Up.sec. & $0.628^{* *}$ & {$[0.461,0.854]$} & $0.470^{* * *}$ & {$[0.347,0.638]$} & $0.602^{* *}$ & {$[0.415,0.875]$} \\
\hline 61 X Up.sec. & 0.505 & {$[0.235,1.085]$} & $0.314^{* * *}$ & {$[0.162,0.611]$} & $0.402^{* *}$ & {$[0.221,0.734]$} \\
\hline 62 X Up.sec. & 0.594 & {$[0.286,1.234]$} & $0.543^{*}$ & {$[0.329,0.898]$} & $0.436^{* *}$ & {$[0.265,0.718]$} \\
\hline 63 X Up.sec. & 0.52 & {$[0.232,1.168]$} & $0.492^{* * *}$ & {$[0.373,0.648]$} & $0.363^{* * *}$ & {$[0.266,0.497]$} \\
\hline 64 X Up.sec. & $0.578^{*}$ & {$[0.343,0.975]$} & $0.521^{* * *}$ & {$[0.382,0.710]$} & $0.456^{* * *}$ & {$[0.330,0.632]$} \\
\hline 65 X Up.sec. & $0.617^{* *}$ & {$[0.458,0.832]$} & $0.515^{* * *}$ & {$[0.371,0.714]$} & $0.538^{* * *}$ & {$[0.388,0.746]$} \\
\hline 66 X Up.sec. & $0.764^{*}$ & {$[0.595,0.981]$} & $0.515^{* * *}$ & {$[0.380,0.699]$} & $0.603^{* *}$ & {$[0.443,0.821]$} \\
\hline Female & $1.201^{* * *}$ & {$[1.106,1.305]$} & $1.214^{* * *}$ & {$[1.135,1.298]$} & 1.05 & {$[0.994,1.109]$} \\
\hline Child $<1$ & 0.657 & {$[0.350,1.233]$} & $0.194^{* *}$ & {$[0.062,0.606]$} & $0.148^{* *}$ & {$[0.036,0.597]$} \\
\hline Child 1-3 & 0.855 & {$[0.603,1.213]$} & $0.503^{* *}$ & {$[0.318,0.797]$} & $0.566^{*}$ & {$[0.353,0.907]$} \\
\hline Child 4-7 & $0.682^{*}$ & {$[0.473,0.982]$} & $0.522^{* *}$ & {$[0.332,0.821]$} & $0.576^{*}$ & {$[0.352,0.944]$} \\
\hline Female $X$ Child $<1$ & $3.462^{* * *}$ & {$[1.797,6.672]$} & $9.217^{* * *}$ & {$[2.901,29.286]$} & $9.768^{* *}$ & {$[2.373,40.212]$} \\
\hline Female $X$ Child 1-3 & $5.986^{* * *}$ & {$[4.228,8.475]$} & $8.831^{* * *}$ & {$[5.564,14.018]$} & $4.286^{* * *}$ & {$[2.673,6.872]$} \\
\hline Female X Child 4-7 & $2.627^{* * *}$ & {$[1.774,3.891]$} & $2.543^{* * *}$ & {$[1.557,4.155]$} & $1.811^{*}$ & {$[1.044,3.142]$} \\
\hline Centrality lev. 2 & 0.993 & {$[0.855,1.153]$} & 0.951 & {$[0.835,1.084]$} & 0.916 & {$[0.823,1.019]$} \\
\hline Centrality lev. 3 & 0.994 & {$[0.875,1.130]$} & 1.07 & {$[0.966,1.185]$} & 1.004 & {$[0.923,1.091]$} \\
\hline Centrality lev. 4 & $1.134^{*}$ & {$[1.011,1.272]$} & 1.005 & {$[0.915,1.103]$} & 0.937 & {$[0.869,1.010]$} \\
\hline Centrality lev. 5 & $1.235^{* * *}$ & {$[1.092,1.396]$} & 1.011 & {$[0.911,1.121]$} & 0.952 & {$[0.873,1.039]$} \\
\hline Master & $0.765^{* * *}$ & {$[0.659,0.888]$} & $0.854^{*}$ & {$[0.756,0.963]$} & $0.788^{* * *}$ & {$[0.716,0.868]$} \\
\hline PGCE Humanities & 1.018 & {$[0.899,1.153]$} & 0.958 & {$[0.865,1.061]$} & 0.988 & {$[0.908,1.076]$} \\
\hline PGCE Soc.science & 1.056 & {$[0.914,1.220]$} & 0.911 & {$[0.784,1.058]$} & 0.975 & {$[0.856,1.110]$} \\
\hline PGCE Science & 0.984 & {$[0.826,1.173]$} & 0.996 & {$[0.879,1.128]$} & 0.92 & {$[0.829,1.021]$} \\
\hline In further educ. & $4.326^{* * *}$ & {$[3.870,4.834]$} & $2.739^{* * *}$ & {$[2.436,3.080]$} & $2.304^{* * *}$ & {$[1.980,2.681]$} \\
\hline Observations & 257538 & & 226399 & & 259851 & \\
\hline $\mathrm{N}$ Individuals & 54409 & & 58215 & & 63819 & \\
\hline Log lik. & -13361 & & -16242 & & -17056 & \\
\hline Chi2 & 12635.791 & & 13094.502 & & 15100.74 & \\
\hline $\mathrm{p}$ & 0 & & 0 & & 0 & \\
\hline
\end{tabular}


With: Are Teachers Increasingly Leaving the Profession?

95\% confidence intervals in brackets

$* \mathrm{p}<0.05, * * \mathrm{p}<0.01, * * * \mathrm{p}<0.001$ 


\section{\& PROFESSIONS \\ PROFESSIONALISM}

ISSN: 1893-1049

\section{Karolina Parding, Anna Berg-Jansson, Therese Sehlstedt, Susan McGrath-Champ and Scott Fitzgerald \\ Differentiation as a Consequence of Choice and Decentralization Reforms-Conditions for Teachers' Competence Development}

Karolina Parding, Luleå University of Technology,

Sweden

Anna Berg-Jansson, Luleå University of Technology,

Sweden

Therese Sehlstedt, Luleå University of Technology,

Sweden

Susan McGrathChamp,

Sydney University,

Australia

Scott Fitzgerald, Curtin University, Australia

\section{Contact:}

Karolina Parding, Luleå University of Technology,

Sweden karolina.parding@ltu. se

\begin{abstract}
This paper examines the conditions for teacher competence development as they relate to the current restructured governance of the education sector in Sweden. In reviewing the literature, contextual factors in the workplace are often pointed out as central to conditions for competence development. However, we argue that a sector-level approach is useful in examining and explaining competence development conditions, especially in times of governance change. We describe how a workplace's geographical location and budgetary situation, along with its size and age, relate to how teachers experience their working conditions. The findings indicate that the organization of work at a local workplace level impacts the conditions for competence development. Moreover, various regional and local characteristics seem to affect the conditions for competence development in that the organization and governance of the education sector create different conditions for competence development.
\end{abstract}

Keywords: Welfare sector professionals, teachers, competence development, governance change, differentiation

Welfare-sector professionals find themselves in a time of significant change. For example, teachers in Sweden are working in an environment characterized by reform agendas such as choice, privatization, marketization, competition as well as decentralization (Parding \& Berg-Jansson, 2016; Lundström \& Parding, 2011; Parding \& Lundström; 2011). Similar trends can be found in the Nordic context and elsewhere, such as Taiwan and Australia (e.g., Kamp, 2016; Huang, 2016; Parding, McGrath-Champ, \& Stacey, 2017). Indeed, competence development ${ }^{1}$ is an essential aspect of professional work. Prior to the current school choice reform and the decentralization reforms (municipalization) at the beginning of the 1990s, when the Swedish education sector was the state's responsibility, and non-public schools hardly existed, the state was responsible for organizing and catering for formal

\footnotetext{
${ }^{1}$ By conditions for competence development, we mean conditions for formal competence development (e.g., courses) and informal competence development (e.g., daily exchange of ideas; Jansson \& Parding, 2011). While we discuss conditions for competence development, which is an umbrella term for various forms of learning and development, both formal and non-formal, we also use the terms "professional development" and "professional learning," as these terms are used in some of the research referenced in this paper.
}

Received: 7 Dec 2016

Accepted: 6 May 2017 
competence development for all teachers. Informal competence development, on the other hand, has always been more local in nature. We argue that the labour market in the education sector can be described in terms of a differentiation of teachers' working conditions, including those relating to competence development. For example, between 2015 and 2016 there were 1303 school units at the upper secondary level, 860 public schools (842 municipal and 18 county council) and 443 non-public schools (Swedish National Agency for Education [SNAE], 2015a). These figures can be compared to between 1992 and 1993 when there were 599 schools, including 542 public (387 municipal and 155 county council) and 57 non-public schools (SNAE, $\mathrm{n} / \mathrm{a}$ ). Before the municipalization reform of 1990, there were only a handful of non-public schools and all other teachers were employed by the state. While the figures for 2015 to 2016 refer to school units, where one school can consist of several units, and the figures for 1992 to 1993 refer to entire schools, the trend is clear: the number of employers has increased significantly. As both municipal and non-public employers today themselves decide on what formal and informal competence development to organize for, it can be assumed that teachers' current restructured labour market means that competence development conditions differ depending on workplace context. This paper examines and discusses teachers' competence development conditions as they relate to the Swedish education sector's current restructured governance system. This paper is guided by the following research questions: How do teachers describe their conditions for competence development, focusing on content and organization of work? How can these experiences be understood as they relate to municipalization and school choice reforms?

There are both theoretical and practical motives for analysing and discussing competence development conditions. For instance, competence development can be seen as an essential aspect of professional knowledge development. In fact, professional occupations are based on theoretical knowledge, which is then applied by professionals who put their theoretical knowledge into practice (Brante, 2011). Moreover, according to Freidson (2001), professionals should prioritize interpretation over developing specific theoretical knowledge. As the teaching profession has been subject to governance changes, one can assume that the conditions for competence development are also affected. At the same time, changes in professionals' demands amplify the need for continuous competence development (Billett, Harteis, \& Gruber, 2014). Therefore, it is important to take a closer look at these conditions. However, studies have shown a lack of focus on competence development, even though interest has been growing in this area (Dellgran, 2015). There has also been a relative lack of focus on the workplace contexts in which professionals are situated, and the point has been raised that there is a need to consider the specific work organizations and the organization of work within them (e.g., Svensson, 2008; Muzio, Brock, \& Suddaby, 2013).

In addition to the theoretical relevance of examining professionals and their competence development conditions in times of changing governance, practical motives must be addressed as well. It is widely known that the work environment of welfaresector professionals, such as teachers, is highly strenuous. Their problems can be summarized as an increase in work demands and high levels of stress (NUT, 2011; NUT, 2013a; TCO, 2013; Sveriges företagshälsor, 2014). In their seminal study on working conditions and health, Karasek and Theorell (1990) found that one way to combat problematic work environments, such as high-stress levels, was for staff to be given good learning conditions. Therefore, the conditions for competence development can be considered crucial for the work environment. For example, Lancaster and Di Milia (2015, p. 442) state, "organizations that develop their learning capability reportedly benefit from increased job performance, employee self-efficacy, customer satisfaction and profitability." In fact, ample research on the relationship between the organizational context and turnover supports the importance of competence development. For instance, Smith and Rowley (2005) found that increased participation in professional development was related to lower teacher turnover and that 
teachers who reported less control over classroom practices and less influence over school policy were more likely to change schools or leave the profession altogether.

The remainder of this paper is structured as follows: we present previous research on competence development conditions as it relates to the organization of work. Thereafter, we describe the Swedish case in order to contextualize and provide a base for generalizations in similar contexts. Subsequently, we describe the qualitative interviews that form this paper's empirical base. Next, we present our findings and identify three factors that influence how competence development conditions are experienced, namely, the geographical location, budgetary conditions, and size and age of the workplace. Finally, a discussion and conclusion are presented where we argue that the competence development conditions in school choice and the decentralization reform context can be described in terms of local and regional differentiation.

\section{Previous research on the organization of work and competence development}

This section presents previous research on the conditions for competence development. The first relevant field is the sociology of professions (SoP), which focuses on professional groups and their conditions for work, but with less emphasis on competence development and local organizational contexts. The second field of relevance is a workplace-learning theory, which focuses on the importance of the organization of work in relation to learning, although it does not specifically examine professional work. The third and final field of relevance is education research, which focuses specifically on competence development for teachers. Each of these three fields contributes different aspects that help us understand the conditions for competence development for teachers. In fact, all three fields are interconnected. For instance, a recent handbook on professional and practice-based learning (Billett et al., 2014) has gathered researchers from both the SoP and workplace-learning fields, as well as from the education field. It should be noted that the presentation below is not intended to be a comprehensive overview of all previous research, but is intended to present different strands of thoughts that are relevant to this paper.

Research on competence development has been rather scarce within the SoP, although more studies have started to appear in recent years (Dellgran, 2015). In their overview of the research on professional development among professional groups, Havnes and Smeby (2014, p. 932) claim that research has shifted from a transmission-oriented approach (meaning there is a transmitter and a receiver of certain transmitted content) to learning as "situated in social practice, institutional cultures and structures in which learning revolves around work." This also includes a shift from decontextualized to situated learning, from the individual to the organizational and from content to the design of the learning processes (Havnes \& Smeby, 2014). However, Havnes and Smeby claim that practice is still primarily based on the transmission-oriented model in work organizations. Moreover, in the SoP, the governance of the professions, including professionalism and the relationship between the profession and the state is a recurrent theme, not the least manifesting itself in studies on state reform in relation to professions (e.g., Dent, Bourgeault, Denis, \& Kuhlmann, 2016; Molander \& Terum, 2008; Evetts, 2009). Indeed, the state is an actor that influences the conditions of professions. Therefore, it is necessary to consider state reform in studies that examine the conditions for competence development.

Research on workplace learning widely emphasizes that learning is indeed situated. As Eraut, Alderton, Cole, and Senker (2000, p. 254) explain, "the organization of work, social relations in the workplace, the effect of challenge and support on individual competence, self-efficacy and risk taking were key factors affecting the 
level and the decision of the learning which occurred." In fact, Ellström (2010) describes how the last two decades have seen increased research on learning at work, as well as on the workplace as a site for learning. At the same time, the research emphasizes that workplace design, or the organization of work, as it were, either enables or constrains learning possibilities (Ellström \& Kock, 2008; Ellström, Ekholm, \& Ellström, 2008). These ideas are still emphasized today with researchers claiming that "during both initial and ongoing professional development, individual learning processes are influenced and shaped through their professional environment and practices" (Billett et al., 2014, p. xviii), which indicates that workplace circumstances are essential for understanding how competence development conditions can be experienced. Fenwick emphasizes the importance of seeing schools as workplaces that are continuously changing and where "space is open, relational and multiple, socially produced and productive of social relations: unfinished and always becoming" (Fenwick, 2013, p. 361). This view implies considering the specific features of a workplace when discussing when discussing professional work and learning.

The education literature tends to focus on the usefulness of competence development, and to some extent, looks into what conditions enable or constrain its usefulness. Timperley (2011) describes going from professional development to professional learning, which means going from teachers partaking in learning activities somewhat passively to teachers being engaged in their own learning. For this to happen, the principal must lead the staff and organize work in a manner that allows for this kind of learning. Much of the current research claims that competence development needs to be job-embedded, instructionally focused, collaborative, ongoing and frequent in order to be considered useful among teachers (Hunzicker, 2011; Field, 2011; Bryan, 2011). This perspective aligns well with ideas on workplace learning. Furthermore, researchers in the education literature mention specific contexts as essential for understanding the conditions of competence development, as emphasized in the field of SoP and workplace learning theory. In line with Timperley, Webster-Wright (2009) argues that when professional development is organized into external courses that are outside of the everyday workplace, they become decontextualized and, thus, difficult to apply. Another voice on this theme is Kelchtermans (2006, p. 221) who claims "collaboration and collegiality [which is assumed to be a prerequisite for professional development] do not happen in a vacuum, but—on the contrary - always appear in the particular context of the school, at a particular moment in time." Regarding the organizational context, Kelchtermans (2006) claims that cultural, as well as structural working conditions, determine the conditions for professional development.

The examples from the three fields mentioned above acknowledge context as central to examining and understanding competence development conditions. In the education and workplace learning literature, context refers to specific local workplace contexts, whilst in the SoP we can see how the relationship between professions, state reform and professionalism is discussed, indicating that it is also of relevance to include context in terms of organization of and governance of the sector in which the professionals are situated, when examining conditions for competence development. The number of employers in the education sector-each with its own way of organizing work, including competence development-has increased substantially; therefore, the changed governance and organization of the education sector can also be seen as amplifying differentiated conditions. Put another way, conditions for competence development are shaped not only by specific workplace contexts but also by local and regional characteristics where the workplace happens to be located. While it can be presumed that local and regional differences have always been present, one can also assume that the decentralization of responsibility and the marketization of education would amplify these differences. 


\section{Organization and governance of competence development: The case of the Swedish education sector}

Before 1990, the national government was responsible for formal competence development; therefore, the conditions were the same for all teachers (SOU, 2014, p. 5). As mentioned initially, two reforms have profoundly changed this. First, municipalization reform at the beginning of the 1990s (Proposition, 1990/91:18) meant that the Swedish parliament and government would determine the overall national goals for the Education Act, the curricula and the syllabuses for subjects that were common to all upper secondary school programmes. However, each local municipality (approximately 290) became responsible for their schools' budgets and, therefore, took over responsibility for employment. This meant that working conditions, including competence development conditions, devolved to the local and municipal level, which created condition differentiation. Second, around the same time, the socalled "school choice" reform was introduced, opening up for non-public school providers and owners (SOU, 1991/92:95; SOU, 1992/93:230). This allowed for further differentiation of conditions for competence development, as even more employers were established and each employer was allowed to decide how, when and what to offer their employees competence development.

Today, apart from each school being able to organize and set aside funding for their own competence development, there is the possibility for employers and public schools to apply for government grants related to competence development. ${ }^{2}$ The Swedish National Agency for Education (SNAE) allocates funds based on regional and local factors, such as population and county size (SNAE, 2015b). For example, metropolitan municipalities and large cities have the highest allocation of funds, while commuter, suburban and sparsely populated municipalities lie at the other end of the spectrum and do not participate in national competence development programmes to any large extent. There is also a significant variance between Sweden's 21 counties. Therefore, differentiation in formal competence development conditions depends on what region and local workplace context a teacher is situated in.

Furthermore, it seems that professionals are highly dissatisfied with the current conditions for competence development. The National Union of Teachers (NUT) found that $50 \%$ of their teachers thought they lacked the competence development they needed (NUT, 2011). The same results reappear with approximately $50 \%$ of teachers in physical education, modern languages, and mathematics reporting that they do not get what they identify needing (NUT, 2013b; NUT, 2016). In fact, in the modern languages, $50 \%$ claim not receiving subject related competence development in the last five years (NUT, 2016). The latest Teaching and Learning Survey (TALIS) (SNAE, 2014) shows that the share of teachers who claimed to partake in competence development activities was lower in Sweden than the TALIS mean. Moreover, an evaluation of larger national programmes and efforts shows that learning obstacles exist when work is organized in such a way that it becomes practically difficult to partake in the programmes or efforts. In line with this finding, the latest TALIS report (SNAE, 2014) shows that schedule clashes and high costs prevent Swedish teachers from participating in the competence development programmes they wish to attend. Another obstacle is that programmes and efforts are often based on the individual's rather than the organization's need for competence, which makes it difficult to spread new competencies to other teachers (SOU, 2013:30).

In a recent Swedish government official report (SOU, 2014:5) it is emphasized that teachers, and the teaching profession more broadly, have lost some of their ability to influence their competence development as a result of the municipalization reform. This is because the responsibility for competence development has shifted

${ }^{2}$ The government grant contributes to competence development programmes but does not cover all the costs, which means that the applying school needs to find additional funding. 
from the state to the local municipalities. This is considered problematic, as "teachers competence development fills an important function in that teachers should be able to keep their knowledge base and in the long run have the power over what it means to be teachers" (SOU, 2014:5).

The description of local school organizations owning the formal competence development of teachers reflects Fenwick's (2013) discussion on transitions in professionals' working conditions. One transition involves regulation, governance, and accountability, where an organization gaining control over the regulation of an occupation. This paper will apply this argument to Swedish teachers and draw upon Fenwick's (2013) claim that professional identity and learning are affected by this transition. First, we will describe how this study was designed.

\section{Methods}

\section{Qualitative interviews in three market contexts}

This article builds on qualitative interviews with Swedish upper-secondary school teachers, which is based on a large research project funded by the Swedish research council for health, working life and welfare (FORTE, 2013-0177). The project focuses on teachers' working conditions as they relate to the education sector's recent reforms. This paper examines teachers' experiences with competence development within their specific local employment contexts. We have analysed approximately 30 interviews with teachers from eight schools. The SNAE $(2011 ; 2012)$ identified six markets types: ${ }^{3}$ city areas, large regional centres, small regional centres, large local centres, small local centres and municipal centres. We chose to situate our study in a region where the most common market types (small regional centre, large local centre and small local centre) were represented. This was a strategic choice, as previous research has focused largely on the areas with the heaviest competition. The interviewees were situated in both public and non-public workplaces. There was only one school in the small regional centre, and it was a public school. There were public and non-public schools in the large local centre, so we selected two public schools and two non-public schools. We aimed for the same quota in the small local centre; however, we were only able to find two public schools and one non-public school that were willing to participate in this study.

The interviews were semi-structured. The interviewees were asked to describe their specific workplaces, how their work was organized, how they experienced the local governance, the conditions for competence development, the ethical considerations and market logic. Finally, they were asked to describe how they viewed the competition, along with the positive and negative aspects of the school choice reform. We also asked the interviewees to reflect upon changes related to each of these themes over time. The interviews lasted approximately one hour with some conducted individually and others carried out in pairs, based on the preference of the interviewees. All of the interviews were taped and transcribed verbatim.

While our study initially aimed to examine if and how experiences of working conditions (and ultimately the organization of work) differed between public and non-public workplaces, a much more complex picture emerged. We found that the interviewees explained their views primarily in relation to their workplace's local and regional conditions. The interviewees described how the competence development programmes were organized, and how they would have wanted it to be. Our analysis showed that the answers could be linked to one of the following contextual

${ }^{3}$ These groupings are based on the size of the local market, in terms of number of pupils and other regional characteristics (SNAE, 2011; 2012). 
factors: the geographical location, budgetary conditions, and size and age of the workplace. It should be noted that while these are three separate analytical themes, they seem to interact and even overlap with each other and in practice. This analysis followed the steps described by Gibbs' (2007), moving from descriptive codes to the thematic level, and finally, to the analytical level.

The generalizations derived from this qualitative study are analytical rather than statistical. The interviewees work in organizations that can be described as relatively horizontal. Moreover, teaching has been described as an autonomous profession, i.e., teachers work mainly for themselves or with professional peers (Abbott, 1988). In addition, the teaching profession involves direct contact with citizens where basic services (defined as rights in the welfare state) are provided (Blomqvist \& Rothstein, 2000; Caspersen, 2007). Lastly, the school choice reform and decentralization drive are central to this study. Therefore, our findings may be valuable for other professional groups in similar circumstances and for teachers in similar governance contexts.

We will now present the empirical findings, which reveal three factors that explain why the interviewees describe their conditions differently.

\section{Results}

\section{Local and regional conditions and their impacts}

A point of entry for this paper is that the school choice reform and decentralization at the beginning of the 1990s paved the way for further differentiation in teachers' working conditions, including conditions for competence development. The state is no longer responsible for competence development. Instead, each employing organization is responsible for formal competence development conditions, as well as informal competence development conditions.

One of the main findings of this study is that differences cannot be explained simply through the lens of public and non-public employers. Rather, regional and local characteristics seem to be of primary importance. For example, geographical differences exist throughout the country in terms of urbanization levels, including proximity to bigger towns or cities where there are more formal courses to choose from. Geographical differences in terms of high and low urbanization levels also exist, which result in different levels of competition. For example, the level of competition is generally lower in remote places. We can also see a differentiation in terms of the development of distinct regional and local conditions. In fact, a rather complex combination of factors influences how interviewees describe the conditions for competence development. The interviewees' answers can be linked to their school's geographic location and related budgetary conditions, as well as workplace size and age. The workplace's geographic location, together with its budgetary conditions, seem to be more strongly related to formal competence development, while the workplace's size and age appear to be more closely related to informal competence development. However, of course, any statistical correlations would need to be tested using quantitative measures.

\section{Geographical conditions}

Geographical proximity to larger towns is an enabling factor for good formal competence development conditions. However, proximity itself is not enough because it does not make competence development happen. Interviewees working in so-called "peripheral" schools far from university towns or bigger cities seem to find formal competence development problematic. The geographic distance makes it difficult to attend courses, and the interviewees say they experience this as a constraint. One 
example is a teacher who works in a relatively large public school in a large local centre with no university who stated, "We live where we live. Sometimes it would be good if it were a bit cheaper to get a flight to Arlanda [Stockholm]. There is a totally different supply there." It is not only the price associated with travelling for competence development but also finding enough time to do so; being able to hand over ones teaching to someone else is a problem for teachers who want to attend formal competence development in a different city. It seems that the organization of work does not easily adapt to this type of need, which is about more than the geographic location of the workplace.

On the other hand, interviewees in workplaces close to or even in university towns (small regional centres and large local centres) have quite different opportunities to attend formal competence development programmes, although this depends on the subject one teaches. One interviewee who works at a large public school in a small regional centre described the problem as follows:

Since we are situated in a university town, they have so many useful courses to offer, but it differs from subject to subject. The teachers in natural sciences, they have the Tuesday and Wednesday [during the yearly competence development week] at the university, and they get super good things, and every year there is like a smorgasbord with lots of researchers presenting their stuff.

This quote illustrates the different conditions for formal competence development, even within the very same workplace. To sum up, the geographical factor seems to play a primary role in conditions for formal competence development. Where the workplace is situated (e.g., the distance from a good supply of courses) affects the opportunities available to teachers. Generally, when the workplace is located far away from a range of options for formal competence development, it constrains possibilities. This can be linked to how work is organized, such as whether teachers are given free time to pursue competence development opportunities. However, the next section will show that such opportunities are also linked to the employer's budgetary situation.

\section{Budgetary conditions}

We also found that the problems related to competence development in geographically peripheral workplaces tended to be linked to budgetary conditions, as this corresponded with precarious municipal economy, much in terms of out-migration. Thus, in more remote workplace contexts, not only did geographical distance constrain the conditions for competence development in the form of distance from external courses, but the strained economy also made competence development less of a priority. One interviewee employed at a public school in a small local centre said, "There are restrictions in terms of what budgetary resources there are. A lot of good competence development is arranged at different places and in the best of worlds we could go." This quote illustrates how the employer's budget constrained the opportunities to participate in formal competence development in other towns. In workplaces with bigger budgets, interviewees described the conditions for competence development as abundant. One interviewee working in a public school with good resources in a small local centre said he had the opportunity to travel to Stockholm for a yearly subject-related conference, which he considered "the most beneficial competence development factor." Interestingly, the interviewee showed awareness that this was not a reality for teachers at other schools in the same town or in other towns. "I know that at other schools they can't go," as the interviewee put it.

In sum, the budgets of public organizations largely depend on municipal budgets. This means that teachers in wealthy municipalities have better resources than those that are struggling financially. In addition, the municipality's public servants decide how to allocate funds to the municipality's operations, including schools. The non- 
public employing organizations, on the other hand, often work more like enterprises in that they dispose of their own, while at the same time they may have partly different aims and goals. Therefore, the type of competence development that is offered and how it is organized seem to be linked to budgetary circumstances that vary between employers, as well as between and within sectors.

\section{Workplace size and age}

The analysis of the interviews indicated that the size of the schools affected how teachers experienced the competence development conditions. In larger, usually older public schools, colleagues had the ability to able to share and discuss their ideas with peers. Work was often organized in such a way that colleagues teaching the same subjects shared offices and belonged to the same team, thus creating an opportunity for daily sharing. When asked about collaboration and learning with colleagues (i.e., informal competence development) one interviewee in a relatively large public school that was situated in a large local centre said, "Us, history teachers, we are building up that [a collegial learning platform]. We have talked about even building a little database with tips and tricks that one can do, a little local learning platform." This indicated that the subject was the most important factor for the competence development of upper secondary level teachers, which was not a new finding (e.g., Parding, 2007; Parding \& Abrahamsson, 2010). However, such opportunities for competence development relied on having several teachers in the same subject, preferably sharing offices or corridors, which was only the case for schools of a certain size. Smaller workplaces, on the other hand, presented their own opportunities, as described in more detail below.

However, there were certain drawbacks related to working in a larger workplace. For example, they way larger schools organized competence development programmes was often described as uniform and standardized, with "one size fits all" solutions and slow and bureaucratic processes. This was highlighted by an interviewee working in a larger public school in a small regional centre:

Well, they [the competence development days organized by the school or the local municipality] suck, excuse me, but they really do.... It is the usual, the cheapest model possible where we are gathered in a lecture hall somewhere, during [the competence development week], and listening to someone standing there lecturing all of us [from different subjects] at the same time.

Competence development programmes of this type were not described as useful. However, in smaller workplaces, which often meant non-public schools, interviewees were sometimes the only teacher in their subject, meaning competence development in the form of subject-specific sharing between colleagues was very limited. One example was an interviewee who worked at a small non-public school located in a small regional centre who held a shared position. In order to work full time, the interviewee taught at two (non-public) schools. This interviewee did not have any colleagues in her subject; therefore, it was not possible to organize the teachers' workspaces or teams even, based on subject. Not having any colleagues in the same subject was experienced as a constraint for competence development and was even described as an incentive to change workplaces. As the interviewee explained, "That thing of exchanging and sharing ideas can become a concern when working in a small school. Therefore, I think one strives for that collegial collaboration with colleagues who do similar things." At the same time, small schools, which were often newer and non-public, allowed for the fast and easy organization of competence development programmes when needed. Furthermore, interviewees working in small non-public schools in small regional centres knew exactly how much yearly funding was available for each of them for competence development, and it their responsibility to ask the principal about accessing it. As one interviewee said, "My view is 
that if one is curious and has a conversation, a performance review conversation, with the principal, then one can get the competence development possibilities one wants here. That is my opinion." Another aspect that seems to relate to working in a newer and smaller school is that when one teacher learns something new, it spreads to the rest of the collegium. One interviewee said that it hardly mattered who attended a course or learned something new because it was shared widely. As that interviewee described, "Lily is dealing with X [a specific issue]. Well, all that she has done rubs off on to the rest of us, so that we learn from what she has acquired by taking part in a formal course." This might have been because this was a relatively small and new school, and perhaps a sign of how it was physically organized. Such situations indicated that there was a flexible system in place for competence development, both in regards to formal and less formal competence development.

In sum, we did not aspire to present what the conditions were at each of the eight schools the interviewees worked in, but rather how the conditions were experienced in various workplace contexts. Neither did we aspire to establish any statistical correlations in terms of experiencing the conditions for competence development and whether the interviewees worked in public or non-public, small or large, new or older, more or less prosperous, or in high or low competition. Nonetheless, what we did show was that specific workplaces, along with the local and regional characteristics associated with workplaces, did seem to imply different competence development conditions. This differentiation was obvious in our findings. School characteristics, as well as the local and regional characteristics within which the teacher was situated, affected the conditions for competence development. The common denominator was the variety of contexts the interviewees described.

\section{Discussion and conclusions}

\section{Differentiated conditions}

The main finding of this paper was that the conditions for competence development, in the context of school choice reform and municipalization, could be described as differentiated. It became clear that the intended - and perhaps unintended-consequences of state reform(s) were complex (see also Jansson \& Parding, 2011). The analysis of the interviews revealed that the geographic location, budgetary resources, and size and age of a workplace were central to understanding how different interviewees described and experienced their working conditions. These findings can be said to reflect a mesolevel analysis. While we acknowledged that there were differences in the conditions for competence development before the reforms, mainly for informal competence development, our study was not comparative. However, while we did not seek to map out "how much had changed," both the works referenced in the context section and our empirical data indicated that the conditions can certainly be described as differentiated today.

In line with Samuelsson and Lindblad (2015, p. 174), we argued that teachers, as an example of welfare-sector professionals, were situated in specific political and social contexts and that these circumstances affected working conditions. The findings in this paper showed that the organization of work at a school and at a local level affected the competence development conditions for teachers. For instance, in terms of how the workplace opens up for, or constrains, informal competence development, which is whether or not teachers can easily share with subject colleagues. These findings were neither new nor surprising; rather they were consistent with our previous studies (Jansson \& Parding, 2011; Parding \& Abrahamsson, 2010). Moreover, it could be argued that the local differences mirrored regional differentiation. In other words, in relation to our previous research (Jansson \& Parding, 2011; Parding \& Abrahamsson, 2010), as well as to the empirical data presented in this 
paper, it can be argued that the issue of context must be seen in a broader sense. The local and regional circumstances of a workplace must be considered when examining the conditions for competence development among welfare-sector professionals, as school choice and municipalization reforms seem to have complex consequences on various levels.

Indeed, the education literature, as well as the workplace learning literature presented earlier, acknowledged that local workplace contexts were central to the examination and understanding of competence development conditions (e.g., Eraut et al., 2000; Ellström et al., 2008; Webster-Wright, 2009; Kelchtermans, 2006). In the SoP, there has been a macro and to some extent micro focus. However, this paper pointed to the relevance of applying a mesolevel approach, which was demonstrated through the themes of the geographic location, budgetary conditions, and size and age of the workplace. It demonstrated how teachers experienced their working conditions and more specifically their conditions for competence development in relation to current reform agendas. Therefore, this paper argues for the relevance of taking a sector-level approach, which means examining competence development by looking at the governance and organization of the sector itself. Applying theories on the temporal and spatial dimensions of work (Herod, McGrath-Champ, \& Rainnie, 2010) could be useful in this endeavour. Using a geographically informed approach, we can potentially understand the conditions that professionals experience in their workplaces in relation to the surrounding milieu. We argue that this is highly relevant for a study on the competence development conditions experienced by teachers during times of changing governance, such as decentralization and privatization reforms.

From the perspective of the SoP, our findings also reveal a (perhaps unintended) shift in the actor(s) that are responsible for professional development in the welfare sector. Responsibility previously lay with the state, which was solely responsible for competence development. However, today the responsibility is dispersed across the various municipalities and non-public employers. In practice, a large number of actors are now responsible for both formal and informal competence development. As described above, influence over what competence development and how it is organized and catered for is necessary for a profession to own the profession-specific knowledge development (SOU, 2014:5). As there is no single counterpart (the state), rather there are many, it is questionable whether the teaching profession can be said to have interpretation priority in terms of deciding competence development's content or form. Perhaps there is even less influence than before.

Our findings can also be linked to Kirsten and Wemke (2017) who discuss the formal national competence development programmes offered by the SNAE, which they see as an expression of the governance of the teaching profession, as well as an instrument for controlling the profession. Analysing six competence development programmes over the last 20 years, they argue that power has moved from schools to the state in terms of who gets to determine their goals and plans. This indicates a shift in governance where the state has taken over the role of setting educational priorities. While Wermke and Kirsten see a greater tendency for "top-down" national standardization, this study reveals highly localized and regionalized conditions. However, these localized and regionalized conditions stem from state reforms, thus top-down initiatives. For further research, it would also be relevant to examine workplace micro-political constructions in more detail, as well as who determines the priorities of schools in terms of competence development and how work is organized to enable formal and informal competence development. In fact, profession-specific theoretical knowledge, which can be linked to the issue of competence development, is seen as essential to professions (Freidson, 2001); therefore, a relevant empirical question would be how this process is shaped in different workplace contexts.

Overall, it is important to advance the knowledge about competence development conditions in the current context of differentiated conditions, as good conditions for competence development, or learning, as Theorell (2015) labels it, are pivotal in 
professions where there is high-stress, high demands and low control. Providing good learning conditions for individuals and organizations is one way to improve the work environment. Therefore, this is an HRM issue of high importance (Evers, van der Heijden, Kreijns, \& Gerrichhauzen, 2011), especially considering the problematic working conditions faced by the teaching profession today.

\section{Acknowledgements}

This research was supported by FORTE, The Swedish Research Council for Health, Working Life and Welfare, dnr 2013-0177. We are also immensely grateful Dr. Ola Fransson for the comments on the earlier versions of the manuscript. Moreover, we would like to thank the anonymous reviewers for the valuable comments, which have helped improve the manuscript.

\section{References}

Abbott, A. (1988). The system of professions: An essay on the division of expert labor. Chicago, IL: University of Chicago Press.

Billett, S., Harteis, C., \& Gruber, H. (2014). Introduction. In S. Billett, C. Harteis $\&$ H. Gruber, (Eds.), International handbook in professional and practice-based learning (pp. xvii-xxi). Springer: Dordrecht.

Blomqvist, L., \& Rothstein, B. (2000). Välfärdstatens nya ansikte: Demokrati och marknadsreformer inom den offentliga sektorn [The welfare state's new face: Democracy and market forms in the public sector]. Agora: Stockholm.

Brante, T. (2011). Professions as science based occupations. Professions \& Professionalism, 1, 4-20. https://doi.org/10.7577/pp.v1i1.147

Bryan, C. (2011). Professional development during a period of change: A smallscale case study exploring the effect of context on practice in a South African rural school. Professional Development in Education, 37(1), 131-141. https://doi.org/10.1080/19415257.2010.499302

Caspersen, J. (2007). Aspects of professionalism: Collective nursing-personalised teaching? In C. Aili, L-E. Nilsson, L.G. Svensson \& P. Denicolo (Eds), Tension between organisation and profession: Professionals in nordic public service (pp. 115-131). Lund: Nordic Academic Press.

Dellgran, P. (2015). Människobehandlande professioner [Human service professions]. In S. Johansson, P. Dellgran \& S. Höjer (Eds.), Människobehandlande organisationer: Villkor för ledning, styrning och professionellt välfärdsarbete [Conditions for management, governance and welfare professional work] (pp. 166-193). Stockholm: Natur \& Kultur.

Dent, M., Bourgeault, Y. L., Denis, J-L., \& Kuhlmann, E. (2016). The Routledge companion to the professions and professionalism. Padstow, Cornwall: Routledge.

Ellström, P. E., \& Kock, H. (2008). Competence development in the workplace: Concepts, strategies and effects. Asia Pacific Education Review, 9(1), 5-20. https://doi.org/10.1007/BF03025821

Ellström, P. E. (2010). Informal learning at work: Conditions, processes and logics. In M. Malloch, L. Cairns, K. Evans \& D. B. O'Connor (Eds.), The Sage handbook of workplace learning (pp.105-119). London: Sage publications.

Ellström, E., Ekholm, B., \& Ellström, P-E. (2008). Two types of learning environment: Enabling and constraining. Journal of Workplace Learning, 20(2), 84-97. https://doi.org/10.1108/13665620810852250 
Eraut, M., Alderton, J., Cole, G., \& Senker, P. (2000). Development of knowledge and skills at work. In F. Coffield (Ed.), Differing visions of a learning society (pp. 231-262). Bristol: Policy Press.

Evers, A. T., van der Heijden, B. I. J. M., Kreijns, K, \& Gerrichhauzen, J. T. G. (2011). Organisational factors and teachers' professional development in Dutch secondary schools. Journal of European Industrial Training, 36(1), 24-44. https://doi.org/10.1108/03090591111095727

Evetts, J. (2009). The management of professionalism: A contemporary paradox. In S. Gewirtz, P. Mahony, I. Hextall \& A. Cribb (Eds.), Changing teacher Professionalism: International trends, challenges and ways forward. (pp. 1930). Abingdon, Oxon: Routledge.

Fenwick, T. (2013). Understanding transitions in professional practice and learning: Towards new questions for research. Journal of Workplace Learning, 25(6), 352-367. https://doi.org/10.1108/JWL-06-2012-0047

Field, K. (2011). Reflection at the heart of effective continuing professional development. Professional Development in Education, 37(2), 171-175. https://doi.org/10.1080/19415257.2011.559700

Freidson, E. (2001). Professionalism: The third logic. Cambridge: Policy Press.

Gibbs, G. (2007). Analysing qualitative data. London: Sage. https://doi.org/10.4135/9781849208574

Havnes, A., \& Smeby, J-C. (2014). Professional development and the professions. In S. Billett, C. Harteis \& H. Gruber (Eds.), International handbook of research in professional and practice-based learning (pp. 915-954). Dordrecht, NL: Springer. https://doi.org/10.1007/978-94-017-8902-8_34

Herod, A., McGrath-Champ, S., \& Rainnie, A. (2010). Foundations. In A. Herod, S. McGrath-Champ \& A. Rainnie (Eds.), Handbook of employment and society: Working space (pp. 1-16). Edward Elgar: UK.

https://doi.org/10.4337/9781849806305.00007

Huang, B. R. (2016). Transformation and framework of teacher professional development in Taiwan. Policy Futures in Education, 4(7), 926-942. https://doi.org/10.1177/1478210316666428

Hunzicker, J. (2011). Effective professional development for teachers: A checklist. Professional Development in Education, 37(2), 177-179. https://doi.org/10.1080/19415257.2010.523955

Jansson, A., \& Parding, K. (2011). Changed governance of public sector organizations $=$ challenged conditions for intra-professional relations? International Journal of Public Sector Management, 24 (3), 177-186. https://doi.org/10.1108/09513551111121329

Kamp, A. (2016). Welfare professions in transition. Nordic Journal of Working Life Studies, 6(S1), 1-6. https://doi.org/10.19154/njwls.v6i1.4882

Karasek, R., \& Theorell, T. (1990). Healthy work: Stress, productivity, and the reconstruction of working life. New York: Basic Books.

Kirsten, N., \& Wemke, W. (2017). Governing teachers by professional development: State programmes for continuing professional development in Sweden since 1991. Journal of Curriculum Studies, 49(3), 391-411. https://doi.org/10.1080/00220272.2016.1151082

Kelchtermans, G. (2006). Teacher collaboration and collegiality as workplace conditions: A review. Zeitschrift fur Pädagigik, 52(2), 220-237.

Lancaster, S., \& Di Milia, L. (2015). Developing a supportive learning environment in a newly formed organisation. Journal of Workplace Learning, 27(6), 442-456. https://doi.org/10.1108/JWL-08-2014-0061 
Lundström, U., \& Parding, K. (2011). Teachers' experiences with school choiceclashing logics in the Swedish education system. Education Research International, ID 869852, 1-10. https://doi.org/10.1155/2011/869852

Molander, A., \& Terum, L. I. (2008). Profesjonsstudier [Studies on the professions]. Oslo: Universitetsförlaget.

Muzio, D., Brock, D. M., \& Suddaby, R. (2013). Professions and institutional change: Towards institutionalist sociology of the professions. Journal of Management Studies, 50, 699-721. https://doi.org/10.1111/joms.12030

NUT (National Union of Teachers/Lärarnas Riksförbund). (2011). Arbetsmiljöundersökning 2011 [2011 Work environment report]. Stockholm: NUT.

NUT (National Union of Teachers/Lärarnas Riksförbund). (2013a). Lärarnas riksförbunds arbetsmiljörapport [The National Union of Teachers' work environment report]. Stockholm: NUT.

NUT (National Union of Teachers/Lärarnas Riksförbund). (2013b). Det räcker inte att rulla en boll: En rapport om idrottslärarnas arbetsvillkor [Rolling a ball is not enough: A report on physical education teachers and their working conditions]. Stockholm: NUT.

NUT (National Union of Teachers/Lärarnas Riksförbund). (2016). Språk-så mycket mer än engelska: En rapport om moderna språk [Languages—so much more than English: A report on modern languages]. Stockholm: NUT.

Parding, K. (2007). Upper secondary teachers' creation of discretionary powerThe tension between profession and organisation. (Doctoral dissertation). Luleå universitetstryckeri, Luleå.

Parding, K., \& Abrahamsson, L. (2010). Learning gaps in a learning organization-Professionals' values versus management values. Journal of Workplace Learning, 22(5), 292-305. Https://Doi.Org/10.1108/13665621011053208

Parding, K., \& Lundström, U. (2011). Lärares upplevelser av friskolereformeneffekter av marknadiseringen av den svenska gymnasieskolan. Tidskriften Arbetsmarknad och Arbetsliv, 17(4), 59-79.

Parding, K., \& Berg-Jansson, A. (2016). Teachers' working conditions amid Swedish school choice reform: Avenues for further research. Professions \& professionalism, 6(1), 1-16.

Parding, K., McGrath-Champ, S., \& Stacey, M. (2017). Teachers, school choice and competition: Lock-in effects within and between sectors. Policy Futures in Education, 15(1), 113-128. https://doi.org/10.1177/1478210316688355

Proposition. (1990/91:18). Om ansvaret för skolan [On the responsibility for the education sector]. Stockholm: The Swedish Government.

Samuelsson, K., \& Lindblad, S. (2015). School management, cultures of teaching and student outcomes: Comparing the cases of Finland and Sweden. Teachers and Teaching, 49, 168-177. https://doi.org/10.1016/j.tate.2015.02.014

Smith, T. M., \& Rowley, K. J. (2005). Enhancing commitment or tightening control: The function of teacher professional development in an era of accountability. Educational Policy, 19(1), 126-154. https://doi.org/10.1177/0895904804270773

SNAE (Swedish National Agency for Education). (n/a). Skolor och elever, läsåren 1992/93-1994/95 [Schools and pupils, 1992/93-1994-95]. Stockholm: Swedish National Agency for Education. Retrieved from www.skolverket.se/statistikoch-utvardering/statistik-i-tabeller/gymnasieskola/skolor-och-elever/skolor-ochelever-i-gymnasieskolan-lasar-1994-95-1.29631 
SNAE (Swedish National Agency for Education). (2011). Skolmarknadens geografi: Om gymnasieelevers pendling på lokala och regionala skolmarknader [The geography of the school market: On upper secondary students' commenting on local and regional school markets]. Stockholm: Swedish National Agency for Education.

SNAE (Swedish National Agency for Education). (2012). Mapping the school market: Synthesis of the Swedish National Agency for Education's school market projects. Stockholm: Swedish National Agency for Education.

SNAE (Swedish National Agency for Education). (2014). TALIS 2013: En studie av undervisnings- och lärmiljöer i årskurs 7-9, Rapport 408 [A study of teaching and learning environments in year 7-9, Report 408]. Stockholm: Swedish National Agency for Education.

SNAE (Swedish National Agency for Education). (2015a). Skolenheter och elever, läsåren 2006/07-2015/16 [School units and pupils 2006/07-2015/16]. Stockholm: Swedish National Agency for Education. Retrieved from https://www.skolverket.se/statistik-och-utvardering/statistik-itabeller/gymnasieskola/skolor-och-elever/skolor-och-elever-i-gymnasieskolanlasar-2015-16-1.241625

SNAE (Swedish National Agency for Education). (2015b). Bidrag till skolans utveckling: Fokus på Hur kommuner tar del av statsbidrag 2011-2014 [Contributions to the development of schools: Focus on how municipalities take part of the statsbidrag 2011-2014]. Stockholm: Swedish National Agency for Education.

SOU (Swedish government's recent official report/Statens offentliga utredningar). (1991/92:95). Om valfrihet och fristående skolor [On choice and independent schools]. Stockholm: Ministry of Education and Research.

SOU (Swedish government's recent official report/Statens offentliga utredningar). (1992/93:230). Valfrihet skolan [Choice in education]. Stockholm: Ministry of Education and Research.

SOU (Swedish government's recent official report/Statens offentliga utredningar). (2013:30). Det tar tid: Om effekter av skolpolitiska reformer [It takes time: On effects of school political reforms]. Stockholm: Ministry of Education and Research.

SOU (Swedish government's recent official report/Statens offentliga utredningar). (2014:5). Staten fär inte abdikera —om kommunalisertingen [The State must not abdicate-About municipalisation]. Stockholm: Ministry of Education and Research.

Svensson, L. G. (2008). Profesjon og organisasjon [Profession and organisation]. In A. Molander \& L. I. Terum (Eds.), Profesjonsstudier [Studies on the professions] (pp. 130-143). Oslo: Universitetsförlaget.

TCO (Swedish Confederation of Professional Employees). (2013). TCO granskar: Stressbarometer 2013\#05/13 [TCO's review: Stress barometer 2013\#05/13]. Stockholm: Swedish Confederation of Professional Employees.

Sveriges företagshälsor. (2014). Jobbhälsobarometern 2014:1 [Work health barometer 2014:1]. Sveriges företagshälsor: Stockholm.

Theorell, K. (2015). Användbart: En kvartalstidskrift om arbetsmiljöforskning, $\mathrm{Nr}$ 3 [Useful: A quarterly journal on workenvironment research, No 3]. Stockholm: Arbetslivsjournalisterna.

Timperley, H. (2011). Realizing the power of professional learning. UK: Open University Press.

Webster-Wright, A. (2009). Reframing professional development through understanding authentic professional development. Review of Educational Research, 79(2), 702-739. https://doi.org/10.3102/0034654308330970 


\title{
${ }_{8}$ PROFESSIONS \\ PROFESSIONALISM
}

ISSN: 1893-1049

Volume 7, No 2 (2017), e1806

http://doi.org/10.7577/pp.1806

Kari Tove Elvbakken

\section{Veterinarians and Public Health: Food Control in the Professionalization of Veterinarians}

\begin{abstract}
This article explores the role of food control in the professionalization of veterinarians in Norway. Veterinarians became engaged in public health through food control and market inspection, which were the responsibility of Norway's city boards of health from the 1860s. Food inspection served a double purpose: to ensure honest trade and to maintain the safety of food. I argue that food control, which was associated with cities' efforts to secure public health and order, was important to the legitimacy of the veterinarian profession. This activity is not what one today sees as a core practice of veterinarians, which is the prevention and curing of animal sickness. Exploring boundary activities at the fringes of a profession, and especially activity connected to the city and the state, may shed light on the more general sources of professional influence and legitimacy in the Norwegian profession state.
\end{abstract}

Keywords: Professionalism, veterinarians, professionalization, public health, food control

Studies of professionalisation often focus on the processes connected to education, research, professional associations, journals, and professional practice, especially practices over which a profession gains a monopoly. Some rather remarkable aspects of Norwegian veterinarians' situation inspired this article. Norwegian veterinarians had no educational institution and no monopoly over the curing of animals until 1935, but they did gain a monopoly over a specific public health and food control activity, namely, meat control. From the early 1890 s, a veterinary research institution and an independent veterinary directorate were established. How could it be that the Norwegian veterinary research institution and an independent agency appeared so early and an educational institution and a monopoly over curing so late? I will discuss the crucial role of food control and public health engagement in the professionalization

Kari Tove

Elvbakken, University of Bergen, Norway

\section{Contact:}

Kari Tove

Elvbakken,

University of

Bergen,

Norway

karitove.elvbakken @uib.no of Norwegian veterinarians.

\section{On the veterinary profession}

The veterinary practice has its roots in tending to the health of army horses. The first academic college for veterinarians opened in Lyon, France, in 1762. Carr-Saunders and Wilson (1933) see the veterinary profession as one of the classic professions, and they point to differences between veterinary education in Britain and that on the continent. In Britain, the roots of veterinary education were more practical, with a weak academic basis. Veterinary education on the continent was academic, and the position of veterinarians was different with respect to positions of prestige in practice, government, and science. A Danish veterinary college opened in Copenhagen in

Received: 12 Sept 2016

Accepted: 20 March 2017

Page 1 
1773, inspired by the Lyon College, while Norway's veterinary college did not open until 1935.

In her study of the sociology of professions in Sweden, Hellberg (1978) discusses veterinarians as an example of the role of shifting groups of clients in the professionalization process. She argues that the increased strength of the European veterinary profession during the latter decades of the 19th century has to be related to their role in the process of the modernization of agriculture. Hellberg identified three periods of professionalization: the first, the "horse doctor" period, continued into latter decades of the 1800s. The army - and therefore the state-was the most important employer of veterinarians. During the "animal doctor" period, contributions to agriculture and the treating of animal diseases were predominant. Hellberg frames the final stage, which continues to the present day, as the "pet doctor" period.

A recent volume on the history of Norwegian professions includes veterinarians as one of 34 professions (Asdal \& Druglitrø, 2014). The authors explore the process of gaining jurisdiction for the profession, inspired by Andrew Abbot's work (1988), and they include institutional factors in their history. The authors emphasize efforts by the veterinary organization (established in 1888) to gain jurisdiction over the health of animals, to fight quackery and to promote animal welfare, all around the turn of the 19th century. A monopoly over the provision of health care for animals was formalised in 1935. The influence of animal health issues on import restrictions is seen as part of a nation-building strategy and of the tensions between Sweden and Norway in the years before the dissolution of the union in 1905. Aspects of the role played by the relations between the two countries are also explored in works on the history of the veterinary administration (Asdal, 2005, 2006). However, the studies by Hellberg and Asdal do not explore the role played by food and meat control or public health, and the present article aims to contribute to the literature by doing so.

In the European context, Hardy's (2003) study of veterinarians and public health is of interest. Hardy discusses the practice of British veterinarians in public health and the veterinarians' struggle to build a state veterinary agency, starting in the 1860s. When the state introduced a veterinary administration in the Ministry of Agriculture in 1939, veterinary public health activities disappeared from the field of public health at the local, city level. With reference to Schwabe (1969), Hardy underlines that the veterinarians in Europe had achieved a stronger position in public health during the late 1800 s and early 1900s than had veterinarians in the UK and US. Koolmees (2000) addresses the same issue in relation to the Netherlands, where veterinarians entered the food control units in the cities from the late 1800s.

The veterinarian and medical professions are often seen as separate, "by virtue of their easily segregated functions and their capacity to practice as entrepreneurs to maintain themselves separately" (Freidson, 1970/1988, p. 52). In the professionalization literature, the number of studies of the professionalization of physicians is high. By contrast, research on the veterinary profession in general, as well as comparative studies between countries and professions, are few. In a review of 207 comparative studies of professional groups, Bourgeault, Benoit, and Hirschkorn (2009) find only a very few that include veterinarians, the majority concerning physicians and jurists.

\section{Theoretical framework}

The present study is inspired by a number of contributions to profession literature. Historical-sociological perspectives have inspired studies of the relationship between professionalization and state-building processes (Burrage, Jarausch, \& Siegrist, 1990). Relations with the state and the roles and tasks of a profession in the state apparatus may vary over time and between situations. This calls for exploring the specific services in specific contexts that particular professions offer to the authorities, which for veterinarians were the various practices that they performed 
within the field — or ecology (Abbott, 2005) — of medicine. Professionalization studies often refer to the very different roles of the state in Europe and the US. Stateoriented professions tend to be typical of the continent, and perhaps to an even stronger degree in the Nordic countries. In a comparative study of the health professions in Norway and Sweden, Vibeke Erichsen (1995) finds the concept of "the profession state" to be useful. This concept refers to the importance of actor groups within a profession, acting within or in alliance with the central health administration. Their contributions to institution building may, in turn, contribute to the profession's authority and legitimacy. Erichsen underlines that Scandinavian professions connected to the health sector have largely developed through the state (Erichsen, 1993, p. 395).

The decision to study professions as entities composed of different segments has been inspired by Bucher and Strauss (1961), who emphasise that professions are usually composed of segments that together form an amalgam - the profession - and discuss the possibly different roles of these segments, asserting that some segments may have common features with social movements. The authority and trust achieved by one segment may also be important to other segments.

Freidson (2001, p. 144) argues that the concept of segments does not necessarily refer to specialization into new professions, but it may underline that segments can be characterized by different fields of practice or use of knowledge or different reference groups, while nonetheless having a common community within the profession. In this context, the relationship with the authorities, whether at local or state level, can be said to represent a reference group clearly different from groups related to different specialities within medicine, or veterinary medicine, such as groups of patients or farmers. However, state or local authorities as reference groups may be very wide and complex.

The analysis of professions as an amalgam of groups of actors may originate in Brante's (1988) call for studies of different professional groups of actors, such as for physicians; practitioners, university teachers or civil servants. However, different segments of a profession may have divergent positions and roles with respect to the state and research communities, and their practices may address different fields of knowledge and relations to the authorities. In line with this, a profession may be understood and analysed as being composed of different actor groups, based on different activities and with different connections of knowledge, clients and organizations. A study of physicians by Phillip Elliott (1972) has motivated investigation into the kinds of knowledge and skills that different segments of a profession offer to the authorities - or to different groups of clients.

Many studies of professionalization refer to the concept of "jurisdiction" and the work of Andrew Abbott on professions (1988). His analytical concept of "profession formation" is connected to the division of labour between professions. Different fields of practice can have different jurisdictions - with different dynamics in relation to the state. DiMaggio (1989) points to another concept used by Abbott: "the niche." DiMaggio finds a profession's ability — or good fortune - to find, develop or inhabit a niche to be a very important analytical tool in the study of professionalism. A profession can find new niches of work and practice, with new opportunities to gain jurisdiction and influence. Activities on the fringes of a profession's core activity may reveal a niche practice with new responsibilities, roles, and jurisdiction. Furthermore, professional entrepreneurs may play important roles within a niche. Whether a niche is seen as the core or at the fringe of a professional field is likely to change over time. Jurisdiction may be connected to a fringe or a core activity, possibly with different results.

A recent study explores the role of hygiene and psychiatry in the professionalizing of medicine in Norway in the 1800s and early 1900s (Elvbakken \& Ludvigsen, 2016). Hygiene and psychiatry were disciplines addressing issues of social order. With their specific knowledge and expertise they contributed to the standing of physicians generally. The concept of hygiene, or public health, was synonymous with 
state medicine or politica medica and the practice of hygiene had close ties to the state. This argument is in line with Larson (1977), who notes that physicians, in general, earn respect from the efforts of physicians in public health.

The main question in this study is related to veterinary engagement in public health, which is discussed as a niche aspect of the veterinary profession and from a historical perspective. What was the contribution of public health activity to the veterinary profession? The discussion is based on an examination first of local public health activity involving veterinarians, and second of what happened at the governmental level in connection to these issues. In each section, the characteristics of legitimacy and value from this niche activity are explored. Since the assumption is that segments outside the core professional activity can bring value and legitimacy to the profession as such, important aspects of legitimacy will be discussed. This includes legitimacy from practice, knowledge and scientific activity, as well as the importance connected to that activity. It is assumed that the values from this field of practice are important for the legitimacy of veterinarians more generally.

\section{Material and study design}

The author's 1997 study of the institutionalization of food control in Norway up to the 1990s included an analysis of the role of veterinarians (Elvbakken, 1997). That project provided a collection of material that is re-examined in the present study. This material includes documents from ministries and directorates, such as proposals and preparatory work for legislation, but also journals and publications from key actors. This material has been supplemented by new material, such as reports from the Norwegian Veterinary College, official veterinary statistics and other official documents. In addition, historical contributions on the formation of the veterinarian profession, such as Horne (1925) and Frøslie and Ødegaard (1991), are used as sources and as guides to other documents.

In the following, veterinarians' involvement in public health and food control at a local level is explored first. Then, the central veterinary administration is investigated. These sections outline the central characteristics of veterinary public health activity and the legitimacy of this activity. The discussion that follows focuses on what this activity meant for the professionalization of veterinarians in Norway and, more generally, the role of niches within professions.

\section{Public health and food control}

Public health legislation in Norway was first implemented with the Public Health Act of 1860, which required local authorities to organize boards of health. These local boards were headed by the city physician, a chief medical officer, employed by and answerable to the state. Although Norwegian cities were rather small, some saw enormous growth in the second half of the 19th century and experienced public health problems similar to those of other European cities (Rosen, 1958/1993).

The cholera epidemics of the 1830 s and 1850 s, when temporary city health commissions were set up to combat them, provided an important background for Norwegian public health legislation (Benum, 1979). This legislation was inspired by an international awareness of public health problems but especially by the British Public Health Act of 1848 and what followed (Berg, 1986). Problems with housing, poverty, alcoholism, food supply, food adulteration and the flow of infectious diseases were considered to be of vital importance. The hygiene situation in the cities during industrialization was of serious concern in across Europe (Porter, 1994). Illnesses and unrest threatened order, as well as life and health. Such problems were also addressed in Norway, where the boards of health and many city physicians played an active role following the introduction of numerous public health initiatives, such as supplying water, opening public baths and regulating sewage. 


\section{Food market and food control}

Across Europe, urbanization and new challenges related to the supply of food to cities all presented problems for the food market. This included problems of food adulteration and fraud, as occurred in Britain from the early 1800s (Burnett, 1989). The emerging food industry was using chemicals and additives, often as camouflage for less fresh food. In Stockholm, the old system of marketplace slaughtering collapsed in the late 1800s (Hirdman, 1983). These and other problems connected to food were on the public health agenda in most cities. Simultaneously, the consumption of meat was increasing, even among poor families. The export and import of meat were also contributory factors (Koolmees, 2000); sanitary problems were particularly connected to milk and meat, both of which were considered to pose health risks. Meat was inspected for tuberculosis, trichinae and "spleen fire" (anthrax). In the late 1870s, such inspections were extended to the regular control of slaughterhouses. Regulations to inspect meat for export were drawn up in many countries, especially to secure export interests.

Milk could become infected and spread disease and illness. Milk control activities were conducted in milk shops, dairies and farms in cities like Oslo, Bergen, and Trondheim. The adulteration of milk by dilution with water was of special concern; dilution was a crime and posed a threat to honest trade, as the water might be contaminated, thereby rendering the milk unhealthy. When intentional dilution was proven (which, of course, was difficult), the guilty party would have to pay a fine, and get the name printed in the newspapers. Milk, meat and hygiene standards in shops and restaurants were inspected, and chemical and bacteriological laboratory analyses were conducted to determine whether the food had been adulterated or contaminated. Several reports on investigations of places where milk was sold were published in journals for physicians and for veterinarians. In addition, in other food control units in Oslo, Bergen and Trondheim, research was initiated by the city administration. The Norwegian Veterinary Journal was published from 1888 but the first volumes do not include many articles on food control, and the editors were not very eager to receive food control reports (Elvbakken, 1997).

Organizing the food market was on the agenda, and in the city of Bergen, for example, city authorities built a market hall in 1877 to encourage an honest and hygienic food trade. This was a common international strategy; cities built market halls to secure hygienic and honest trade in food. In England, more than 700 market halls were built during the late 1800s and first decades of the 1900s (Schmichen \& Carls, 1999).

\section{City veterinarian}

In 1878, Bergen appointed its first city veterinarian, Ivar Nielsen. He was appointed to the Board of Health to control the food markets, especially those for meat and milk. The government would later support Nielsen with scholarships to study certain livestock diseases, but he served the city during his long lasting engagement, for about 40 years (Elvbakken, 1997). A city laboratory for bacteriological and chemical analyses of the food that sanitary inspectors collected from the market and butcheries was built soon after Nielsen arrived in Bergen. The chemical analyses included determinations of whether milk was diluted by water (Norges officielle statistik [NOS], 1893). The state later supported this first Norwegian veterinary laboratory.

Ivar Nielsen was educated at the Danish veterinary college, which was modelled on the first academic veterinary college in Lyon (Carr-Saunders \& Wilson, 1933). Nielsen was scientifically oriented and the first Norwegian veterinarian to publish internationally. He was involved in research at the Bergen Museum, which had a strong scientific milieu and included medical scientists such as Armauer Hansen (Forland \& Haaland, 1996). The list of his publications shows that Nielsen did not publish on food control, but rather on veterinary medical science. Nielsen published 
in European veterinary journals and the Norwegian Veterinary Journal. From 1909 to 1918 , his writing primarily concerned veterinary medicine and microbiology (Elvbakken, 1997, pp. 158-79). Nielsen was interested in medical science and the natural sciences, then emerging in Bergen. In the 1880s his studies (financed by the government) of the sheep plague produced knowledge for the state, as well as scientific publications. Nielsen received a state scholarship for several years from the late 1880 s to study different diseases among Norwegian livestock. Reports from his studies and comments from the Medical Director on these reports are included in the state budget proposals (e.g., Sth. Prp. 49, 1890).

\section{Meat Control}

Food control was conducted under the Public Health Act, but specific legislation was implemented in 1892 for meat control, aiming at a legal framework for public slaughtering. The initiative for specific meat inspection legislation came from the health authorities in the capital, Oslo, in 1891.The Board of Health issued a detailed report on the bad conditions and operation of abattoirs in the city and underlined that hygiene was very poor (Flateby, 1979). The board wanted a public slaughterhouse to be built to replace slaughtering by unhygienic private enterprises. The City Magistrate requested that the Ministry of Justice develop a legal framework to charge fees for slaughtering in order to offset the costs. The ministry agreed and proposed legislation that required meat inspection in towns with more than 4,000 inhabitants, where meat inspection was to be carried out by veterinarians (Horne, 1925). The Ministry of the Interior, which at the time was responsible for agriculture and veterinary issues, agreed to the proposal. Gaining public control over slaughtering and meat inspection was regarded as urgent. A government proposition was passed by Parliament in June 1892. The new legislation was to be administered by the Directorate of Health, within the Ministry of Justice, as it was a public health issue.

At the turn of the 20th century, many European countries regulated the inspection of meat by implementing specific regulations (Koolmees, 2000). Many European cities took responsibility for slaughtering, as it was considered to pose significant safety risks and therefore was the responsibility of the government. Meat inspection occurred at two points: during the slaughtering process and when the meat was on sale. The meat control legislation addressed the first aspect, whereas public health legislation regulated the inspection of meat for sale. Despite the rapid passing of legislation in Norway, it took time before new public slaughterhouses could be built. Oslo opened its slaughterhouse in 1913, followed by a German-inspired slaughterhouse in Bergen in 1919. In both cities, the city veterinarian became the slaughterhouse director. From 1896, Norway's annual official veterinary statistics included information on meat control. In 1920, for example, 30 meat control units in cities and three in municipalities reported on the controls of livestock, like horses, cattle, sheep, and pigs, and the numbers and reasons for rejecting access to the market. Among the reasons, undernutrition prior to slaughter was a common issue.

\section{Hygiene and legitimacy}

The Public Health Act of 1860 provided a comprehensive legal framework within which city authorities could set regulations and establish units for food control, and several cities appointed veterinarians for this purpose. The control and regulation of marketplaces were a common issue in European cities at the time. Scholliers (2014) notes, for example, the importance of local laboratory initiatives in the development of food control in Brussels.

Beginning in the 1850s, international congresses of hygiene were held in Europe (Roemer, 1994), and among the topics were milk and meat inspection. The import and export of animals and meat, as well as the sufficiency and safety of the food supply, were urgent problems. Norwegian scholars and board of health members 
participated, and some went abroad to study public health initiatives (Elvbakken \& Ludvigsen, 2016). Through contact with the European scientific community, Norwegian hygienists and city veterinarians gained inspiration for their activities at home. The relations between the city boards of health and the country's sole university at the time were close, and most of the professors in the university's Department of Hygiene had served on the board of health in the capital, Oslo. At the university, this discipline often involved the boards of health in research during the 1800s and early 1900s.

Through the meat inspection legislation, veterinarians gained a monopoly over a public activity linked to their clientele, the farmers. Veterinarians were given the power to reject meat coming onto the market. City food control and meat inspections were the responsibility of the boards of health, which were headed by state-employed medical officers. Alliances between public health physicians and public health veterinarians were important. This situation has similarities to the situation in Britain, as noted by Hardy (2003).

Involvement in public health included involvement in the scientific activity, and some city veterinarians participated and gained respect as researchers. City public health activity encouraged legislation on meat control to secure the hygienic status of the meat and to make public slaughtering possible. From this, veterinarians gained influence and a monopoly over an important activity, connected to the maintenance of public order, based on legitimacy derived from science in partnership with medicine.

\section{Veterinary administration}

Norwegian public administration dates back to 1814 when Norway was separated from Denmark and forced into a union with Sweden that lasted until 1905. However, during the union with Sweden, Norway was allowed to keep the main provisions of its 1814 constitution and its parliament, the Stortinget, which required the building of a state apparatus. However, the state bureaucracy was small, and resources were few (Svalestuen, 1988).

Within the field of health administration, beginning in 1858, accounts of veterinary matters were included in the government's Annual Health Report. In 1865, the government allocated money to the fight against imported or endemic contagious livestock diseases (Horne, 1925), and in 1867, a military veterinarian was engaged to serve as a consultant to the administration responsible for health. The first Director of Health was employed in 1875, and the administration of health was moved from the Ministry of Interior to the Ministry of Justice in 1878; veterinary issues were included in health administration. The number of veterinarians was low, however, and according to Horne, recruiting veterinarians was difficult due to poor working conditions and a lack of interest in sending students abroad. From 1886, veterinary reports were published separately under their own titles (Norwegian Official Statistics), but the responsibility for them remained with the administration of health.

From the 1870 s, ministries started to employ specialists in order to serve and support the development of important fields. For example, an agricultural expert was hired as a consultant and later became a Director of Agriculture. Government counselling agencies were established from the 1870 s to promote new technologies in agriculture. This was a dual strategy: reforming agriculture was important in itself but also for the Norwegian nation-building process (Jacobsen, 1964). In the field of health, as well as that of agriculture, expertise was included in the central administration, even if the resources were few.

Until 1890, the veterinary and human health administrations were placed under the purview of the Ministry of Justice, where the Director of Health licensed veterinarians and compiled veterinary statistics (Svalestuen, 1988). Licensing depended on education from an approved institution and citizenship. The state only licensed 
veterinarians educated abroad, most often from Copenhagen, but also from Stockholm. On October 1, 1890, the Ministry of the Interior took over veterinary issues from the Ministry of Justice (Horne, 1925). Later, from 1900, veterinary issues moved to the new Ministry of Agriculture.

Health administration was also undergoing changes in the years around 1890 . These changes are interesting and must be understood as elements of larger, more comprehensive changes in Norway's state and nation building, in relation to policy and administration. Such changes will not be discussed further in this article, however.

\section{Veterinary issues and scholarship 1}

Veterinary issues emerged onto the agenda in the Norwegian parliament for the first time in 1815, during its third session (Horne, 1925). Veterinarians were seen as essential for the state, first and foremost for the army. The establishment of an educational institution for veterinarians and a veterinary administration was also discussed. The previous practice, in place since the $1790 \mathrm{~s}$, in which counties were obliged to send students to Copenhagen each year, was less relevant in the new situation. In the 1820 s, it was decided to buy land for a future education institution and to send one candidate abroad to study veterinary administration and education to inspire the building of similar Norwegian institutions (Elvbakken, 1997).

The physician Christian Peter Bianco Boeck (1798-1877) was granted funds to study veterinary education and veterinary administration abroad, in France, Germany and Denmark. When he returned, he presented plans for veterinary education at the university. The plans were ambitious and far too expensive, however, and were not implemented. From 1828 to 1840 , Boeck lectured on veterinary medicine but without an institution in which to serve. He did, however, act as a consultant to the health administration on animal and veterinary issues until being appointed a professor of physiology, comparative anatomy and veterinary medicine in 1840 at the university, which had opened in 1813. These plans met with resistance at the university, especially in the medical faculty (Elvbakken, 1997). This was also the situation in Sweden, where the inclusion of veterinary science and education in the medical faculties was fought (Hellberg, 1978). In Sweden, veterinary education became practical, with a weak scientific basis. That did not happen in Norway.

\section{Veterinary issues and scholarship 2}

The relationship between animal and human health was put firmly on the agenda in Europe in the latter half of the 19th century, especially in response to tuberculosis and other contagious diseases. By the late 1870s, the connections between animal health and human health were increasingly recognized (Waddington, 2004). The agricultural revolution also drew more attention to animal health in Norway, as it did in other countries. At a time when Norwegian agriculture was undergoing a wave of modernization, fear of importing animal diseases through cattle from Europe prompted the rising prominence of the veterinarians (Asdal, 2006).

After having proposed on many occasions that Parliament should grant a second (after Boeck) scholarship for veterinary education and administration abroad, the first Director of Health succeeded in 1888. The scholarship was awarded to medical doctor Ole Olsen Malm (1854-1917), who received his veterinary degree in 1889 and embarked on a study tour of France, England and Germany. Upon returning to Norway, he was hired as the Chief Medical Officer for Veterinary Matters in the Ministry of Justice, within the health administration. Malm had proposed that he be given the title of director, to lead a directorate within the Ministry of Interior, where the Directorate of Agriculture, led by a director, was located. Both the Ministry of Interior and the Ministry of Justice, including the Medical Director, disagreed (St. prp. No. 49, 1890; St. prp. No. 1, VI, 3, 1891). Soon after, however, responsibility 
for veterinary issues was moved to the Ministry of the Interior.

Malm's proposal in 1890 included a wide range of issues. He saw the question of a veterinary administration, a directorate, as the most important, although it was also very important to be able to build a research laboratory, as will be discussed below. In addition, he argued for money to support the journal for veterinarians, which had been established in 1888. A laboratory was important in order to have research supporting the administration. The state, as well as the cities, needed laboratories to support these activities. In line with earlier proposals put forward by a professor of hygiene, Ernst Lochmann, in the 1870s and 1880s, Malm argued for a veterinary professorship at the university. Whereas the first travelling veterinarian, Boeck, had concentrated on the building of a veterinary college, Malm gave priority to veterinarian administration and a research laboratory.

Malm (1899) saw the importance of ensuring the inspection of animals slated for export to avoid the spread of disease. Moreover, as Asdal and Druglitrø (2014) note, by forbidding the importation of Swedish live animals when infectious animal diseases threatened, Malm acted on behalf of the state authorities by protecting the borders during the process of nation building. Securing the health of the livestock was underlined as being of great interest to farmers. As Asdal points out, Malm underlined his hygiene-oriented values and efforts, in contrast to the Director of Agriculture, who concentrated on economic issues (Asdal, 2006).

\section{State laboratory and research}

Malm argued for the need of a state laboratory, like those in the cities. The establishment of The Veterinary Laboratory by the government in 1891 was early compared with Sweden, where a similar laboratory did not open until 1911. Veterinary Director Malm was responsible for the laboratory and had a dual position, combining the roles of scientific researcher and administrator. In 1892, veterinarian Halvor Horne (1866-1952) was appointed as laboratory assistant and secretary in the directorate. Later, he wrote an extensive volume on the veterinary administration and veterinary history (Horne, 1925). For a quarter of a century, Malm and Horne divided their days between the laboratory and the directorate office. They were scientists and heads of veterinary administration. From 1892 to 1911, Malm and Horne published 92 articles (Elvbakken, 1997, 218ff). The Norwegian Journal for Veterinarians commenced publication in 1889. It depended upon research activity at the Veterinary Laboratory, as well as research conducted by city veterinarians, such as those in Bergen. The topics of the scientific work, reflected in the publications by Malm and Horne, covered a broad range of diseases, such as tuberculosis, glanders, brucellosis and anthrax, and dealt with various animals, such as cattle, horses, cats, pigs, and sheep. A restricted number of articles addressed food control issues, mostly by Malm on meat and milk inspection and abattoirs.

The Veterinary Laboratory was, in Malm's words, "the seed from which, after a while, let us hope it is soon, must spring forth a Norwegian veterinary school" (Malm, 1899). The strategy was to build a research milieu that would in time develop into something else; the "big future plan" was to have a veterinary university. Malm offered veterinarians the opportunity to work under his supervision at the laboratory and argued for travel stipends. He begged colleagues to send anatomical and pathological specimens to the laboratory.

The connection between animal health and human health was important with regard to research, especially concerning tuberculosis, a point that Malm underscored. The relationship between animal and human medicine was the topic of his doctoral lecture in 1894 and his thesis, On Tuberculin. His dissertation in human medicine was printed as an addendum to the Report on the Veterinary Administration in Norway for the year 1894. In 1892, Malm produced a tuberculosis vaccine using the Koch method, and he was the first in Scandinavia to produce tuberculin, which was intended for both human and veterinary use. 


\section{Legitimacy from physicians to veterinarians}

A new situation arose in 1894 when the Director of Health, Holmboe, suggested that the activities specified by meat inspection legislation be taken over by the Ministry of the Interior and the Chief Medical Officer for Veterinary Administration, Ole Malm. Holmboe and Malm were both physicians and colleagues and had been members of the Medical Association in the 1880s, where Malm was influential (Berg, 1986). Malm was willing to take over the administration of the legislation, but only if his position as a chief medical officer was elevated to that of the director. As a director, he would have a directorate to lead that would be independent of the Agricultural Directorate. Malm was thus appointed Director of the Veterinary Directorate in 1895, and meat control legislation came under his jurisdiction. Responsibility for a specific piece of legislation provided an argument for an independent directorate. In this respect, it is reasonable to state that the administration of meat inspection became a lever to securing an independent veterinary administration. With the meat control legislation of 1892, meat control became a niche over which vets were granted legal jurisdiction. The Veterinary Director attained his independent position within the ministry by taking responsibility for meat inspection.

Malm argued for an academic and scientific education, strongly resisting the establishment of a craft-like education (Malm, 1899). The Directorate of Agriculture was responsible for the Norwegian College of Agriculture, which opened in 1859 outside the capital and was given the status of a college in 1899. It was proposed more than once that veterinary education is offered there, as the college had a veterinarian, but Malm opposed the move. Veterinary education was to be medical and scientific, if not at the university, at least at a veterinary college, like in Copenhagen. He was also strongly opposed to having a veterinary education within an institution subjugated to the agricultural directorate. It was considered better to depend on foreign institutions than to compromise the quality of research and education. As mentioned earlier, the veterinary administration in Sweden was separated from the health administration in 1947 (Hellberg, 1978). The independence of the Norwegian veterinary administration was not inevitable. Rather, it came about through cooperation with physicians and as a result of taking responsibility for meat control legislation. It can be said that Malm, as an entrepreneur, exploited the opportunities that arose in this niche field of public health. The veterinarians took over and gained a new field of practice from the physicians.

\section{Discussion}

The field of food control in the Norwegian context was open to the veterinarians, in collaboration with physicians, in public health activity in the cities. Milk and meat inspection were fields that veterinarians had the competence to cover. Their knowledge of animals and their laboratory skills in a time of growing interest in bacteriology and microbiology was useful.

In the interplay of food control, administration, and research, the Norwegian veterinary profession was formed. The profession's entrepreneurs leaned towards food control, especially meat inspection. Meat control was an essential part of food control in the cities, and veterinarians gained a monopoly in this field. It is reasonable to claim that veterinarians acquired legitimacy from their work in public health in the cities and that this strengthened their overall position. Using meat inspection as the lever, the veterinary administration was separated from the health administration at the central level. This allowed veterinarians to obtain positions in the ministry with a Veterinary Director equal (rather than subordinate) to the Director of Agriculture.

Co-operation with physicians was important. Even though food inspection was 
not considered to be important by representatives of veterinary medicine, city veterinarians were included in local public health partnerships. Veterinarians concerned with hygiene may be seen as belonging on the fringe of the profession, but veterinarians served in local health administrations and had public positions. Some cities also had partnerships in research.

The legitimacy that city veterinarians and meat inspectors acquired seems to have strengthened the position of veterinarians in general. Norwegian physicians transferred responsibility for food control to veterinarians; food control was available to veterinarians, and physicians were willing to allow them to manage this area. We see a segment of the profession with a monopoly on the overseeing of slaughterhouses, a practice important to public health. Veterinarians thus earned a specific role in the new Norwegian state, even if the numbers were small; a majority of the licensed veterinarians were employed by the state or city, in $1895(58 \%)$ and 1920 $(63 \%)$ (NOS, 1895, 1920). This was a state-financed and state-built profession, and the veterinary profession can be seen as a statist profession, educated abroad, often on public scholarships.

From the beginning, there were strong connections between veterinary public practice, veterinary administration and veterinary science in the cities. Veterinary education had a scientific orientation as early as the 1820 s, and in Malm's time, nearly a century later, this principle was maintained; the norm of science seems to be strong. When the Norwegian Veterinary College opened in 1935, it offered a veterinary medical education. Its first rector, Halvdan Holth (1880-1959), combined his position as rector with that of director of the Veterinary Laboratory (Frøslie \& Ødegaard, 1991). Veterinary research was performed in a dual institutional context, in the Veterinary Laboratory from its opening in 1891, but also within the Boards of Health in cities such as Oslo and Bergen.

Public health activity may be a field that, in general, contributed to legitimacy. Magali Sarfatti Larson (1977, p. 39) underlines that physicians, in general, benefited from the respect that physicians earned in public health during the years of epidemics in the 1850 s - respect that gave physicians "capital" that could be used in other situations and contexts. This is in line with the view that public health or hygiene activity and psychiatry contributed legitimacy to the medical profession, as both activities concerned order and were linked to basic functions of the authorities (Elvbakken \& Ludvigsen, 2016). Similarly, for veterinarians, city public health activities generated valuable respect for the authorities responsible for securing health and order. Malm took possession of the field handed over by the director of health. One may ask why. Many reasons can be found. For one thing, this may be understood as the result of a situation in which the field of hygiene was wide, and where other forms of expertise were needed. For another, Norwegian public administration was in its formative years and was relatively open to efforts made by entrepreneurs. If the Director of Health Holmboe was less interested in food and meat control than the former director - who had proposed the meat control legislation - perhaps this helps to explain how the field was ceded.

In addition to public health activity, the veterinary administration was important in the prevention of animal disease. As Asdal and Druglitrø (2014) underline, the veterinary authorities banned the importation of live cattle from Sweden in a period of threatening infectious cattle disease, which was important for the nation-state as it was seen to be connected to Norwegian efforts to gain independence from Sweden in the years up to 1905 . The fact that veterinarians were working to prevent animal diseases by hygienic efforts would have supported the economic interests in the agenda of the agricultural Directorate, to use the concepts discussed by Asdal (2006).

This professionalization process demonstrates the close relationship between the vets and the city authorities, as well as the significance of the combination of scientific work with hygiene inspections in promoting the profession. This finding supports the view that we should examine not only the core practices of professions but 
also what might be regarded as fringe practices that may have been viewed differently in other situations. Different practices can provide access to groups of clients (such as city authorities) and reference groups (such as scientific networks) that are important to the strength of a profession. Insights from Bucher and Strauss (1961) have motivated the present discussion of the role of veterinarians in public health. In line with Abbott (1988), this is studied as a possible niche activity. I argue that practices at the fringes of veterinary jurisdiction contribute to the profession as a whole and that niches may be as important as core areas.

\section{Conclusion}

Food control veterinarians provided valuable knowledge to the state. They cooperated with the physicians of the cities and central government. This case may provide a nuanced picture of the professionalization of veterinary medicine. Microbiological and bacteriological research in veterinary medicine provided useful knowledge for food inspection, and the Boards of Health were partners in hygiene research. The interplay between research and administration illuminates the formation of the Norwegian veterinary profession in a significant way. Veterinarians earned respect and authority through their practices in the field of public health.

In Norway, with a new and rather small state administration, an independent veterinary administration came early. In the laboratory, veterinary entrepreneurs combined research and administration. The contributions of veterinarians to public health, research and the directorate paved the way for the professionalization of veterinarians.

This case study may illustrate the importance of studying professions not as united entities but as groups of professionals or segments with some common characteristics and varying practices, knowledge bases and orientations. The important features of one field of practice may promote the process of professionalization. Scholars represented in the contemporary profession literature call for studies with comparative perspectives, across countries and professions over time (Brante, 2011). I argue that the case of the Norwegian veterinary profession can contribute to a more general discussion about the understanding of professions and professionalization, focusing on the roles that one segment - veterinarians in public health and their field of practice - had in the process of professionalization. Public health engagement offered co-operation with the vital interests of the city and nation in the late $1800 \mathrm{~s}$ when industrialization and urbanization were connected to a rise in epidemics and threats to the good order of cities. Public health dealt with important societal problems, which in turn gave public health and veterinarians' status and authority in the cities. This cooperation contributed to a scientific legitimacy that, in turn, was important to providing a scientific basis for education, even if it came very late.

\section{References}

Abbott, A. (1988). The system of professions: An essay on the division of expert labor. Chicago: The University of Chicago Press.

Abbott, A. (2005). Linked ecologies: States and universities as environments for professions. Sociological Theory, 23(3), 245-274. https://doi.org/10.1111/j.0735-2751.2005.00253.x

Asdal, K. (2005). Grensetrafikk, nedslag i matpolitikkens og veterinærvesenets historie [Border trafic — on the history of food policy and veterinary administration]. Oslo: Unipub

Asdal, K. (2006). Making space with medicine. Scandinavian Journal of History, 31(3-4), 255-269. https://doi.org/10.1080/03468750601010365 
Asdal, K., \& Druglitrø, T. (2014). Veterinærer [Veterinarians]. In R. Slagstad \& J. Messel (Eds.), Profesjonshistorier (pp. 298-330). Oslo: Pax.

Benum, E. (1979). Sentraladministrasjonens historie, Bind 2 1845-1884 [The history of the Norwegian central administration 1845-1884]. Oslo: Universitetsforlaget.

Berg, O. (1986). Verdier og interesser-den norske lægeforenings fremvekst og utvikling [Values and interests - the growth and development of the Norwegian association of physicans]. In Ø. Larsen, O. Berg \& F. Hodne (Eds.), Legene og samfunnet [Doctors and society] (pp.151-333).Oslo: Den norske lægeforening.

Bourgeault, I. L., Benoit, C., \& Hirschkorn, K. (2009). Introduction: Comparative perspectives on professional groups, current issues and critical debates. Current Sociology, 57(4), 475-485. https://doi.org/10.1177/0011392109104350

Brante, T. (1988). Sociological approaches to the professions. Acta Sociologica, 31(2), 119-142. https://doi.org/10.1177/000169938803100202

Brante, T. (2011). Professions as science-based occupations. Professions \& Professionalism, 1(1), 4-20. https://doi.org/10.7577/pp.vli1.147

Bucher, R., \& Strauss, A. (1961). Professions in process. American Journal of Sociology, 66(4), 325-334. https://doi.org/10.1086/222898

Burnett, J. (1989). Plenty \& want: A social history of diet in England from 1815 to the present day. London: Methuen.

Burrage, M., Jarausch, K., \& Siegrist, H. (1990). An actor-based framework for the study of the professions. In M. Burrage \& R. Torstendahl (Eds.), Professions in theory and history: Rethinking the study of the professions. London:Sage.

Carr-Saunders, A. M., \& Wilson, P. A. (1933). The professions. Oxford: Clarendon Press.

DiMaggio, P. (1989). Review of the book "The system of professions": An essay on the division of expert labour, by Andrew Abbott. American Journal of Sociology, 95(2), 534-535. https://doi.org/10.1086/229319

Elliott, P. (1972). The sociology of the professions. Exeter: Macmillan.

Elvbakken, K. T. (1997). Offentlig kontroll av noeringsmidler, institusjonalisering, apparat og tjenestemenn [Food control, the institutionalization, the organization and the officials]. (Doctorial thesis), Department of organization and administration theory, University of Bergen, Bergen.

Elvbakken, K. T., \& Ludvigsen, K. (2016). Medical professional practices, university disciplines and the state: A case study from Norwegian hygiene and psychiatry 1800-1940. Hygiea Internationalis, 12(2), 7-28. https://doi.org/10.3384/hygiea.1403-8668.161227

Erichsen, V. (1993). States and health care. Scandinavian welfare state research. European Journal of Political Research, 23, 387-405. https://doi.org/10.1111/j.1475-6765.1993.tb00366.x

Erichsen, V. (1995). State traditions and medical professionalization in Scandinavia. In T. Johnson, G. Larkin \& M. Saks (Eds.), Health professions and the state in Europe. London and New York: Routledge.

Flateby, A. M. (1979). Opptakten til en norsk næringsmiddellovgivning, ca. 18801910 [The prelude to a Norwegian food control legislation, ca 1880-1910]. (Master's thesis), University of Oslo, Oslo.

Forland, A., \& Haaland, A. (1996). Universitetet i Bergen 50 år, Bind 1. Bergen: Universitetet i Bergen.

Freidson, E. (1970/1988). Profession of medicine. A study of the sociology of applied knowledge. Chicago: University of Chicago Press.

Freidson, E. (2001). Professionalism: The third logic. Chicago: The University of Chicago Press. 
Frøslie, A., \& Ødegaard, Ø. (1991). Historikk.Veterincerlaboratoriet som forutsetning for et effektivt veterincervesen-Et 100-års-perspektiv In Veterincerinstituttet 1891-1991 [The history-The veterinary laboratory as a precondition for an effective veterinary service 1891-1991]. Oslo: Statens veterinære laboratorietjeneste.

Hardy, A. (2003). Professional advantage and public health: British veterinarians and state veterinary services, 1865-1939. Twentieth Century British History, 14(1), 1-23. https://doi.org/10.1093/tcbh/14.1.1

Hellberg, I. (1978). Studier i profesjonell organisation. En profesjonsteori med tillämpning på veterinäryrket [Studies in professional organization. A theory of professions aplied to the veterinary profession]. (Doctorial dissertation), Department of sociology, Uppsala Universitet, Uppsala.

Hirdman, Y. (1983). Magfrågan [The Food Question]. Stockholm: Bonnier.

Horne, H. (1925). Veterincervesenets historie [The history of the veterinary administration]. Oslo: Cappelen.

Jacobsen, K. D. (1964). Teknisk hjelp og politisk struktur [Technical support and political structure]. Oslo: Universitetsforlaget.

Koolmees, P. A. (2000). Veterinary inspection and food hygiene in the twentieth century. In D. F. Smith \& J. Phillips (Eds), Food, science, policy and regulation in the twentieth century (pp. 53-68). London: Routledge.

Larson, M. S. (1977). The rise of professionalism: A sociological analysis. Berkeley: University of California Press.

Malm, O. (1899). Bidrag til veterinærvesenets historie i Norge [Contributions to the histry of the Veterinary Adminstration in Norway]. Norsk Veterincertidsskrift, 1, 1-39.

NOS (Norges officielle statistik). (1893). Beretning om sundhetstilstanden og medicinalforholdene $i$ Norge 1891 [On the sanitary situation and the medical conditions in Norway 1891]. Tredje rekke no 185, Kristiania. Retrieved from http://www.ssb.no/a/histstat/nos/nos_iii_185.pdf

NOS (Norges officielle statistik). (1895). Beretning om veterincerveesenet og kjødkontrollen i Norge for aaret 1893 [On veterinary administration and meat control]. Tredje rekke no 270, Kristiania 1887. Retrieved from http://www.ssb.no/a/histstat/nos/nos iii 270.pdf

NOS (Norges officielle statistik). (1922). Veterincervesenet og kjøttkontrollen 1920 [On veterinary administration and meat control]. Rekke VII, 43, Kristiania Retrieved from http://www.ssb.no/a/histstat/nos/nos_vii_043.pdf

Porter, D. (Ed.) (1994). The history of public health and the modern state. Amsterdam: Clio Medica 26.

Roemer, M. I. (1994). Internationalism in medicine and public health. In D. Porter (Ed.), The history of public health and the modern state (pp 403-423). Amsterdam: Clio Medica 26.

Rosen, G. (1958/1993). A history of public health. New York: Johns Hopkins University Press. https://doi.org/10.1037/11322-000

Scholliers, P. (2014). Constructing new expertise: Private and public initiatives for safe food (Brussels in the first half of the nineteenth century). Medical History, 58(4), 546-563. https://doi.org/10.1017/mdh.2014.52

Schmichen, J., \& Carls, K. (1999). The British market hall: A social and architectural history. New Haven and London: Yale University Press.

Schwabe, C.W. (1969). Veterinary medicine and human health. Baltimore: Williams\&Wilkins. 
St. prp. no. 49, 22th of February 1890. (1890). [Budget proposal from the government to the Parliament]. Retrieved from

https://www.stortinget.no/no/Saker-og-

publikasjoner/Stortingsforhandlinger/Lesevisning/?p=1890\&paid=2\&wid=b\&p $\underline{\text { sid=DIVL1562 }}$

St. prp. no. 1, VI, 3. (1891). [Budget proposal to the Parliament]. Retrieved from https://www.stortinget.no/no/Saker-og-

publikasjoner/Stortingsforhandlinger/Lesevisning/?p=1891\&paid=1\&wid=a\&p $\underline{\text { sid=DIVL811\&pgid }=\mathrm{a} \_0927 \& \mathrm{~s}=\text { False } \& \mathrm{vt}=\mathrm{a} \& \mathrm{did}=\mathrm{DIVL} 875}$

Svalestuen, A. (1988). Helsevesenet 1814-1940; En admininstrasjonshistorisk oversikt [The history of the Health Administration 1814-1940, an overview of the history of the administration]. Norsk Arkivforum, 6.

Waddington, K. (2004). To stamp out "so terrible a malady": Bovine tuberculosis and tuberculin testing in Britain, 1890-1939. Medical History, 48(1), 29-48. https://doi.org/10.1017/S0025727300007043 